\title{
A review of recent advances in water-gas shift catalysis for hydrogen production
}

\author{
Parisa Ebrahimi ${ }^{1} \cdot$ Anand Kumar $^{1}$ (1) $\cdot$ Majeda Khraisheh $^{1}$
}

Received: 16 May 2020 / Accepted: 15 July 2020 / Published online: 3 August 2020

(C) The Author(s) 2020

\begin{abstract}
The water-gas shift reaction (WGSR) is an intermediate reaction in hydrocarbon reforming processes, considered one of the most important reactions for hydrogen production. Here, water and carbon monoxide molecules react to generate hydrogen and carbon dioxide. From the thermodynamics aspect, pressure does not have an impact, whereas low-temperature conditions are suitable for high hydrogen selectivity because of the exothermic nature of the WGSR reaction. The performance of this reaction can be greatly enhanced in the presence of suitable catalysts. The WGSR has been widely studied due do the industrial significance resulting in a good volume of open literature on reactor design and catalyst development. A number of review articles are also available on the fundamental aspects of the reaction, including thermodynamic analysis, reaction condition optimization, catalyst design, and deactivation studies. Over the past few decades, there has been an exceptional development of the catalyst characterization techniques such as near-ambient $\mathrm{x}$-ray photoelectron spectroscopy (NA-XPS) and in situ transmission electron microscopy (in situ TEM), providing atomic level information in presence of gases at elevated temperatures. These tools have been crucial in providing nanoscale structural details and the dynamic changes during reaction conditions, which were not available before. The present review is an attempt to gather the recent progress, particularly in the past decade, on the catalysts for lowtemperature WGSR and their structural properties, leading to new insights that can be used in the future for effective catalyst design. For the ease of reading, the article is divided into subsections based on metals (noble and transition metal), oxide supports, and carbon-based supports. It also aims at providing a brief overview of the reaction conditions by including a table of catalysts with synthesis methods, reaction conditions, and key observations for a quick reference. Based on our study of literature on noble metal catalysts, atomic Pt substituted $\mathrm{Mn}_{3} \mathrm{O}_{4}$ shows almost full $\mathrm{CO}$ conversion at $260{ }^{\circ} \mathrm{C}$ itself with zero methane formation. In the case of transition metals group, the inclusion of $\mathrm{Cu}$ in catalytic system seems to influence the $\mathrm{CO}$ conversion significantly, and in some cases, with $\mathrm{CO}$ conversion improvement by $65 \%$ at $280^{\circ} \mathrm{C}$. Moreover, mesoporous ceria as a catalyst support shows great potential with reports of full $\mathrm{CO}$ conversion at a low temperature of $175^{\circ} \mathrm{C}$.
\end{abstract}

Keywords Low-temperature water-gas shift $\cdot$ Catalyst nanostructure $\cdot$ Hydrogen production $\cdot \mathrm{CO}$ conversion

\section{Introduction}

Fossil fuels have been continuously used as the primary source of energy for a long time. These resources are not renewable and pollute the atmosphere through greenhouse gases emission, which is linked to global warming. The depletion in fossil fuel reservoirs as well as the knowledge of

Anand Kumar

akumar@qu.edu.qa

1 Department of Chemical Engineering, Qatar University, PO Box 2713, Doha, Qatar their adverse environmental impacts has gained researchers attention to think about alternative and clean sources of energy [1]. Hydrogen is considered as a promising renewable alternative that minimizes $\mathrm{CO}_{2}$ emissions and produces only water as a byproduct upon combustion [2]. Traditionally, among the non-fossil fuel-based methods, hydrogen has been produced by mixing iron (in the metal state) with strong acids, or using the well-established water electrolysis process. However, both techniques have some drawbacks, such as being costly to operate and not adequate to meet the growing market demands, which resulted in methane steam reforming being the most popular method for industrial-scale hydrogen production [3]. Recent research and development in the direction of alternative and sustainable energy production, such as wind energy, 
solar energy, and geothermal energy, indicates that future energy demands will be met by a mixture of sources to decrease our dependence on fossil fuels. As the renewable energy becomes cheaper with time and starts to gradually dominate the energy market, diverse applications of existing hydrocarbons are being sought by converting them into more valuable chemicals and products rather than combusting them for energy production, which is not environmentally friendly and expected to be more expensive in the future.

The abundance of water and sunlight as affordable sources offers a good alternative for hydrogen generation. Hence, photocatalytic water splitting is considered to have a potential for sustainable production of hydrogen that can be employed in different scales of hydrogen generators [4]. For achieving high conversion efficiency in solar water splitting, photocatalysts should have some critical features such as high absorption of visible light, low charge recombination, and high surface reaction [5]. It is assumed that photocatalytic hydrogen is conceivable as a commercial fuel in the future, yet a considerable research is required in this area, addressing the aforementioned key points for manufacturing. The enhancement in photocatalytic performance is attributed to the presence of oxygen vacancies, which act as trapping sites via taking photogenerated holes or electrons that could be beneficial in the carrier's separation [6]. Furthermore, during the synthesis of photocatalysts, nanostructures and morphologies can be controlled to facilitate the generation of oxygen vacancies that efficiently raise the adsorption capacity and consequently make gas molecules (including $\mathrm{O}_{2}, \mathrm{~N}_{2}, \mathrm{H}_{2} \mathrm{O}$, and $\mathrm{CO}_{2}$ ) active [7]. Oxygen vacancies help promote hydrogen evolution reaction performance, due to their beneficial role in charge transfer and water molecule dissociation [8].

Hydrocarbons are converted to other chemicals, including hydrogen, by means of reforming processes in the presence of suitable catalysts. The WGSR, ubiquitous in reforming processes, is known to play a central role in adjusting hydrogen and carbon monoxide amount. In the WGSR, water reacts with $\mathrm{CO}$ to form hydrogen and carbon dioxide $\left(\mathrm{CO}+\mathrm{H}_{2} \mathrm{O}\right.$ $\left.\leftrightarrow \mathrm{CO}_{2}+\mathrm{H}_{2}\right)$, where the $\mathrm{CO}_{2}$ can be separated from the stream to get pure hydrogen [9]. The WGSR is relevant to various industrial sectors, directly or indirectly, such as the fertilizer industry for the production of ammonia, petroleum refineries, and fuel cell for generating power as well as transportation applications [10]. This reaction is exothermic, which makes it thermodynamically suitable at lower temperatures [11]. Being exothermic in nature may lead the system to a thermally runaway condition at higher temperature if appropriate cooling arrangements are not made. The heat released will increase the temperature further accelerating the reaction and generating more heat. Hence, control and monitoring the temperature is mandatory in order to prevent such instability. Since the WGSR is an equilibrium-limited exothermic reaction, lower temperatures will favor more hydrogen production, however with slower kinetics [12]. Higher temperatures are more desirable for reforming reactions. Therefore, if a high ratio of $\mathrm{H}_{2}$ to $\mathrm{CO}$ is needed and $\mathrm{CO}_{2}$ in the reaction amount is larger than the stoichiometric value, higher temperatures are not favorable [13]. With the objective of enhancing the reaction performance, the WGS reaction has been studied by many groups using different catalysts, resulting in a substantial literature elucidating the catalysis and reactor design aspects. Some review articles are also available summarizing the effect of various parameters, such as reactants flow rate, temperature, and pressure on WGSR in the presence of catalysts [14-16]. Catalyst composition, metal-support interactions, porosity, and surface area effects have been widely reported; however, in our knowledge, a study relating the catalyst nanostructures with WGSR performance is still lacking. The microscopic imaging techniques have seen a remarkable improvement in the past few decades, enabling us to image and monitor the changes at nanoscale structures while performing catalytic reactions, with structural details leading to single-atom precision. This enhancement resulted in revealing valuable nanoscale insights that tend to affect the catalytic reactions significantly, leading to the emergence of novel research areas such as single-atom catalysts, tandem catalysts, and shape-size selective catalysts. We believe that a study is needed to collect and correlate the key developments relating the nanostructure information with catalytic performance, specifically for a ubiquitous reaction like WGSR with a high industrial significance. Herein, our aim is to provide a review of the recent progress in catalysts for lowtemperature water-gas shift reaction over the last decade, with a primary focus on catalyst nanostructure analysis. In addition, we also aim to provide an overview of the recent development in catalyst preparation techniques, reaction conditions, supported catalysts design for WGSR.

\section{Mechanism}

Despite the simplicity of the reaction and extensive studies over the years, the WGS reaction mechanism is still controversial and complicated due to the sensitivity of the catalysts to minor changes in operational conditions. There are two prominent mechanisms for the WGS reaction: the regenerative (redox) mechanism and the associative (LangmuirHinshelwood) mechanism. Generally, at high temperatures, the WGS reaction is accepted to follow the redox mechanism, where $\mathrm{CO}$ molecule adorbs on the catalyst surface and abstracts one oxygen from the metal-oxide support to form carbon dioxide. Loss of oxygen from metal-oxide creates an oxygen vacancy that is fulfilled by dissociating a water molecule to generate hydrogen and oxygen atoms. Hydrogen atoms combine and desorb as hydrogen gas whereas oxygen atom is captured by the oxygen deficient metal-oxide [17]. The 
associative mechanism, on the other hand, has been reported at low as well as high temperatures, usually proceeds by the adsorption of $\mathrm{CO}$ and $\mathrm{H}_{2} \mathrm{O}$ on the catalysts surface leading to a reactive intermediate that subsequently decomposes to produce $\mathrm{CO}_{2}$ and $\mathrm{H}_{2}$ [18]. Nonetheless, the redox mechanism is still the most widely accepted mechanism for WGSR. Theoretically, Sun et al. combined DFT calculations with micro-kinetic analysis on $\mathrm{Au} / \mathrm{TiO}_{2}$ catalysts to conclude that the redox mechanism was the most plausible route for WGS [19]. Ammal and Heyden also reached the same outcome from their investigation on $\mathrm{Pt} / \mathrm{TiO}_{2}(110)$ catalysts, that both $\mathrm{Pt}$ clusters and single cationic Pt follow the redox mechanism [20]. This mechanism involves $\mathrm{CO}$ oxidation through obtaining atomic $\mathrm{O}$ from $\mathrm{H}_{2} \mathrm{O}$, via either two consecutive steps of $\mathrm{H}$ abstraction, or one $\mathrm{H}$ abstraction followed by two OH species disproportionation [21, 22]:

$$
\left\{\begin{array}{l}
\mathrm{H}_{2} \mathrm{O}+\mathrm{Red} \rightarrow \mathrm{H}_{2}+\mathrm{Ox} \\
\mathrm{CO}+\mathrm{Ox} \rightarrow \mathrm{CO}_{2}+\mathrm{Red}
\end{array}\right.
$$

In this mechanism, the surface of the catalyst is successively oxidized by $\mathrm{H}_{2} \mathrm{O}$ and then reduced by $\mathrm{CO}$. Low temperatures are reported to be more favorable for hydrogen production, which is the primary objective and focus of this review article.

\subsection{Catalysts in low-temperature water-gas shift catalysts}

In order to facilitate the WGS reaction for a large scale of hydrogen production, choosing a suitable catalyst is important, which plays a central role in accelerating the reaction. A good catalyst would facilitate the adsorption of reactants on the surface of catalyst, their reaction, and desorption of the products to regenerate the active sites for the cyclic process of adsorption-reaction-desorption with new reactant molecules. An optimum interaction between gaseous molecules and catalyst surface is required as a weak interaction would result in low conversion due to quick desorption of the reactants, whereas a strong interaction could also result in low conversion and catalyst deactivation as the adsorbed molecules are too strongly bound to the surface leading to catalyst poisoning. These interactions are best understood in terms of volcano plots highlighting the optimum interactions leading to highest conversion of reactants. Figure 1 shows a 3D volcano plot for WGSR rate over the surfaces of transition metals as a function of the binding energies of atomic oxygen and carbon monoxide, formed on chemisorption-energy amounts on step sites. The presented model offers a good qualitative estimate of the relative order of activity of selected transition metal catalysts compared to the experiments. The figure reveals $\mathrm{Cu}$ to be the most active among the investigated catalysts, by being at the center with optimum adsorption energies for $\mathrm{O}$ and $\mathrm{CO}$ interactions [23].

Availability of oxygen vacancies, optimum strength for $\mathrm{CO}$ adsorption, and activity for water dissociation are some common characteristic roles of WGS catalysts [24]. In general, an ideal catalyst used for driving low-temperature WGS reactions should be cost-effective and CO-tolerant for large-scale uninterrupted operations as $\mathrm{CO}$ is known to have a poisoning effect on catalysts, even at an insignificantly low concentrations [25]. Besides, in terms of energy efficiency, the appropriate catalysts must be thermally stable and active at temperatures below $250^{\circ} \mathrm{C}$ to provide reasonably high reaction rates. According to the literature, a wide variety of catalysts have been employed to reduce the overall cost of hydrogen production and enhance the low-temperature WGS reaction catalytic activity and stability. In the following sections, a comprehensive summary of the recent development on different types of catalysts used in low-temperature WGS reaction is presented. It includes the catalyst preparation method, the operation conditions, nature of catalyst support, along with the efficiency for hydrogen production. Our particular focus is on the nanostructure of the catalyst, which has not been extensively covered in previously reported reviews. The catalysts are classified based on the metals used as well as the type of support.

\subsection{Type of active metal}

\subsubsection{Noble metal based}

For commercial applications, any WGS catalysts should be free from some inherent disadvantages such as low stability and activity, along with the need for specific pretreatment and regeneration [26]. Chemically speaking, noble metals are well-known to be most resistant against corrosion and oxidation. Platinum $(\mathrm{Pt})$, rhodium $(\mathrm{Rh})$, gold $(\mathrm{Au})$, palladium $(\mathrm{Pd})$, and silver (Ag) are the commonly known noble metals, which have been extensively studied in recent years for WGS applications. The catalyst activity of the noble metals depend on many variables such as the method for catalyst preparation, noble metal amount, the support used, the amount, and characteristics of the prompter in case a promoter is used [27]. In multicomponent catalysts, the complex interactions between the metals and support also have a significant impact on the catalytic activity. Moreover, in the operation phase, the experimental variables like the space time, the reaction temperature, and the feed composition are influential [28]. The WGS catalysts activity of this group is known to depend on crystal size, dispersion, metal loading, metal oxide support, and the nature of the dopant used [27]; however, some contrary reports also exist indicating the activity of $\mathrm{Pt} / \mathrm{TiO}_{2}$ and $\mathrm{Ru} / \mathrm{TiO}_{2}$ not dependent on the metal loading or the crystallite size $[29,30]$.

Reducible oxides are reported to significantly improve the catalyst activity at low temperatures. Vecchietti et al. 
Fig. 13 D volcano plot of the turnover frequency for the lowtemperature WGSR vs $\mathrm{O}$ and $\mathrm{CO}$ adsorption energies [23]

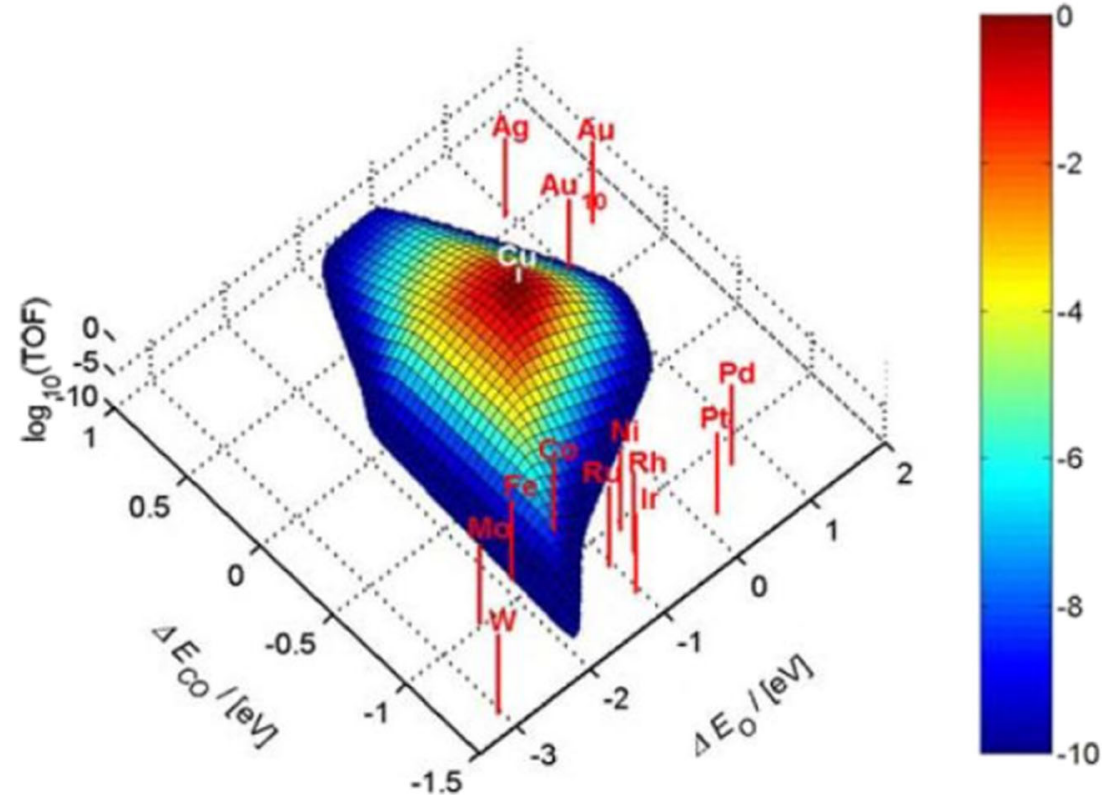

discussed that water dissociation seems to be a critical step for reaction to move forward [31]. They studied the activation of water on oxygen vacancies on both pure as well as galliumdoped ceria supported platinum catalysts. The results showed a reverse correlation between the activity of the WGS catalyst and oxygen vacancies number [31]. In another study conducted by Tiwari et al., Pt nanoparticles with nanocrystalline $\mathrm{CeO}_{2}$ support were investigated for low-temperature WGS reaction [32]. The $0.9 \mathrm{Pt}-\mathrm{CeO}_{2}$ (with $0.9 \mathrm{wt} \% \mathrm{Pt}$ ) catalyst showed the best activity $(85.1 \%)$ with $1.66 \times 10^{10} \mathrm{~mol} \mathrm{~cm}^{-1} \mathrm{~s}^{-1} \mathrm{CO}_{2}$ formation rate at $140{ }^{\circ} \mathrm{C}$ and 20,000 GHSV [32]. The nanostructure of the catalyst is shown in Fig. 2a-d, with HRTEM in Fig. 2c showing Pt crystallite size of $0.8 \mathrm{~nm}$ on spherical $\mathrm{CeO}_{2}$ support of size between 40 and $50 \mathrm{~nm}$ [32]. Increasing the wt\% of Pt resulted in an increase in Pt crystallite size as well as a lower surface dispersion of $\mathrm{Pt}$ of $\mathrm{CeO}_{2}$, negatively affecting the overall catalytic performance, providing conclusive evidence of higher interaction between $\mathrm{Pt}$ and $\mathrm{CeO}_{2}$ resulting in improved WGS activity [32].

Nguyen-Phan et al. investigated the performance of both $\mathrm{Au}$ - and Pt-based metal catalysts on hydrogen production through various conversion processes like WGS reaction [37]. The activity of Pt was concluded to be much higher compared to $\mathrm{Au}$ catalysts, where $\mathrm{Pt}$ was also susceptible to quick deactivation, possibly by $\mathrm{CO}$ poisoning or oxidation by water molecules [37]. Palma et al. presented a strategy to alleviate the challenges of $\mathrm{Pt}$ supported on $\mathrm{Ce} / \mathrm{Zr}$, suffering from deactivation caused by sintering and coking as well as high selectivity of methane [38]. They used wet impregnation method to synthesize supported bimetallic catalysts $(\mathrm{Pt} / \mathrm{M} /$ $\left.\mathrm{CeZrO}_{4}(\mathrm{M}=\mathrm{Na}, \mathrm{Mo}, \mathrm{Sn}, \mathrm{Cu}, \mathrm{Zn})\right)$ and compared their performance with monometallic ones. According to the result, in 473-675 $\mathrm{K}$ temperature range, $1 \mathrm{Pt} / 1 \mathrm{Sn} / \mathrm{CeZrO}_{4}$ and $1 \mathrm{Pt} / 1 \mathrm{Na} /$
$\mathrm{CeZrO}_{4}$ showed similar $\mathrm{CO}$ conversion as Pt-based monometallic catalysts, however, with higher hydrogen production and reduced methane formation than the bimetallic systems. In general, the $1 \mathrm{Pt} / 1 \mathrm{Sn} / \mathrm{CeZrO}$ catalyst had the best conversion and hydrogen selectivity at 480-673 K. At lower temperatures, however, the monometallic $1 \mathrm{Pt} / \mathrm{CeZrO}_{4}$ catalyst exhibited the best performance [38].

The use of supercritical fluid deposition (SCFD) is considered a promising catalyst preparation method, which has been recently highlighted in some studies. Deal et al. synthesized platinum catalysts on alumina support, both in the presence and absence of ceria by this method and tested them for WGS reaction [39]. The result of the analysis showed $\mathrm{Pt}$ to be in a highly dispersed form on the support. The $\mathrm{CeO}_{\mathrm{x}} / \mathrm{Al}_{2} \mathrm{O}_{3}$ pretreatment in $\mathrm{H}_{2}$ before $\mathrm{Pt}$ deposition resulted in more $\mathrm{Pt}$ nucleation on $\mathrm{Ce}$ than in the non-pretreated support. However, the non-pretreated Ce-containing catalyst showed a more uniform particle size with the Pt nanoparticles enclosed in the crystallites of ceria. No methanation or deposition of carbon was witnessed in any of the experiments. Measuring the reaction rate confirmed that the catalyst was more active for WGS, with the rates per Pt mass exceeding the values reported in most literature for WGS reaction on the $\mathrm{Pt}-\mathrm{CeO}_{\mathrm{x}}$ catalysts. The high catalytic activity was attributed to the considerable amount of interfacial platinum/ceria contacts due to unique nanoscale interactions [39]. Kaftan et al. investigated $\mathrm{KOH}-$ coating Pt/alumina catalytic performance on WGS reaction [40]. They found that both activity and selectivity of the catalyst improved compared to the uncoated catalyst. Besides, the selectivity of $\mathrm{CO}_{2}$ increased in the coated sample because of hydroxides and carbonates film formation on the catalyst surface [40]. González-Castaño et al. introduced a precatalytic buffer layer of $\mathrm{CeO}_{2} / \mathrm{Al}_{2} \mathrm{O}_{3}$ oxides in $\mathrm{Pt} / \mathrm{CeO}_{2} /$ 


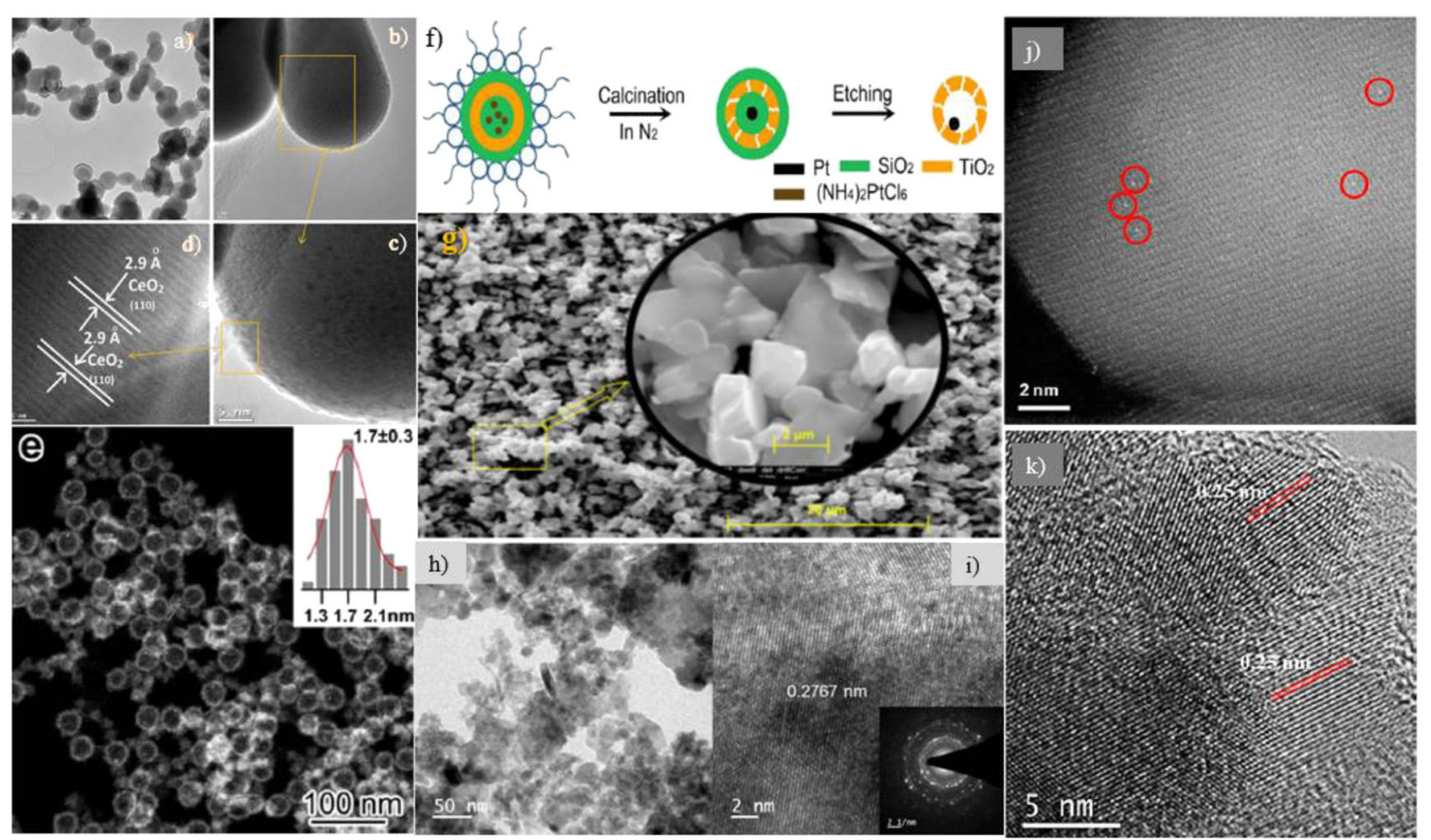

Fig. 2 a-d TEM images of the $0.9 \mathrm{Pt}-\mathrm{CeO}_{2}$ catalyst [32]. e, f HAADFSTEM images of the Pt@ $\mathrm{TiO}_{2}$ yolk/shell nanospheres and the Pt nanoparticles size distribution in the hollow $\mathrm{TiO}_{2}$ nanospheres. Along with synthesis of the $\mathrm{Pt} @ \mathrm{TiO}_{2}$ yolk/shell nanospheres [33]. g SEM image of

$\mathrm{Al}_{2} \mathrm{O}_{3}$ catalytic system for WGS reaction [41]. The inclusion of the buffer layer did not affect the $\mathrm{CO}$ oxidation; however, it increased the number of engaging sites during the reaction in the water dissociation phase leading to a catalytic activity enhancement in real conditions [41].

Recently, Pt-Re bimetallic clusters on $\mathrm{TiO}_{2}$ support were reported to be a superior catalyst than Pt cluster alone for the low-temperature WGSR [42]. In order to understand the impact of both the Pt-Re clusters composition as well as Re oxidation, Duke et al. investigated a model system with bimetallic clusters grown on the surface of a rutile $\mathrm{TiO}_{2}(110)$. The results showed that pre-oxidized clusters had lower activity in comparison to both unoxidized Pt-Re and pure Pt, which indicated that $\mathrm{ReO}_{\mathrm{x}}$ sites are not active in the WGS reaction. Reduced CO poisoning in Pt-Re clusters demonstrated a higher WGS activity of the bimetallic clusters [42]. Synergistic effects at the interface of the metal-carbide are reported to cause a chemical activity enhancement for pure $\mathrm{Pt}, \mathrm{TiC}$, and MoC [43]. Rodriguez et al. found a correlation between $\mathrm{Pt} / \mathrm{MoC}$ and $\mathrm{Pt} / \mathrm{TiC}$ (001) water dissociation capability and their activity in the low-temperature WGS reaction. They found that both of these catalysts are highly active, stable, and selective with excellent catalytic performance. Moreover, small Pt coverage on the carbide substrates had the highest activity among the tested catalysts [43]. the pure $\mathrm{Mo}_{2} \mathrm{C}$ catalyst [34]. $\mathbf{h}$, i Bright-field and HRTEM images of $\mathrm{Mn}_{2.94} \mathrm{Pt}_{0.06} \mathrm{O}_{4-\delta}$ [35]. j, k AC-HAADF-STEM images of Pt/Fe-0.05 and HRTEM image of $\mathrm{Pt} / \mathrm{Fe}-0.05$ [36]

Pt nanoparticles with $\mathrm{TiO}_{2}$ support have also been considered as an appropriate catalyst for the low-temperature WGS reaction, which exhibited the potential to be employed in a fuel cell system [33]. Zhao et al. published a synthesis strategy that affords uniform particles of $\mathrm{Pt} / \mathrm{TiO}_{2}$ with $\mathrm{Pt}$ nanostructures tunable size of around 1.0 to $2.6 \mathrm{~nm}$ incorporated in $\mathrm{TiO}_{2}$ nanoshells of a thickness of $\sim 3-5 \mathrm{~nm}$ and diameter of $~$ $32 \mathrm{~nm}$ (Fig. 2e, f). These yolk/shell nanostructured catalysts were found to have remarkable stability, and their activity monotonically increased with the Pt nanoparticles size for the low-temperature WGS [33]. Rivero-Crespo et al. used water clusters to isolate and stabilize single atom $\mathrm{Pt}_{1}{ }^{1+}$ that showed activity for WGSR at a low temperature of $50^{\circ} \mathrm{C}$ [44]. They suggested that the water cluster could help in regulating the metal charge that facilitates the adsorption of reactants resulting in efficient low-temperature WGS catalysis, where a double water attack mechanism generates $\mathrm{CO}_{2}$ with both oxygen coming from water [44].

The performance of $\mathrm{Pt}$ catalysts loaded on different supports, $\mathrm{Mo}_{2} \mathrm{C} / \eta-\mathrm{Al}_{2} \mathrm{O}_{3}, \mathrm{Mo}_{2} \mathrm{C} / \gamma-\mathrm{Al}_{2} \mathrm{O}_{3}$, or $\mathrm{Mo}_{2} \mathrm{C}$, were tested by Osman et al. for low-temperature WGS reaction [34], where $\mathrm{Pt} / \mathrm{Mo}_{2} \mathrm{C} / \eta-\mathrm{Al}_{2} \mathrm{O}_{3}$ was found to be a promising catalyst with $44 \% \mathrm{CO}$ conversion at $180{ }^{\circ} \mathrm{C}$. However, $4 \mathrm{wt} \% \mathrm{Pt}$ $\mathrm{Mo}_{2} \mathrm{C}$ (Fig. $2 \mathrm{~g}$ ) presented the highest catalytic activity and stable performance with $50 \%$ conversion at $180{ }^{\circ} \mathrm{C}$ and no

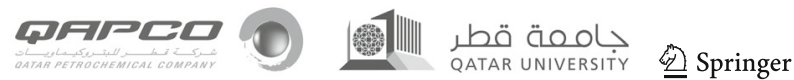


deactivation over $85 \mathrm{~h}$ of time on stream (TOS) at $250{ }^{\circ} \mathrm{C}$ temperature, maintaining over $70 \% \mathrm{CO}$ conversion [34]. This improved performance was attributed to a uniform distribution of smaller Pt nanoparticles on $\mathrm{Mo}_{2} \mathrm{C}$ structure compared to other supports. Recently, sonochemical synthesis has emerged as one of the useful methods for synthesizing metal oxides [45]. Anil et al. synthesized a series of noble metal substituted $\mathrm{Mn}_{3} \mathrm{O}_{4}$ catalysts via this method. All of the noble metal-supported $\mathrm{Mn}_{3} \mathrm{O}_{4}$ catalysts exhibited good activity for both low-temperature WGS and $\mathrm{CO}$ oxidation reactions. Atomic Pt substituted $\mathrm{Mn}_{3} \mathrm{O}_{4}\left(\mathrm{Mn}_{2.94} \mathrm{Pt}_{0.06} \mathrm{O}_{4-\delta}\right)$, with the possibility of single-atom active sites (Fig. $2 \mathrm{~h}, \mathrm{i}$ ), revealed excellent activity, with $99.9 \%$ conversion at $260^{\circ} \mathrm{C}$ and no methane formation, owing to a strong interaction existing between $\mathrm{Pt}$ and $\mathrm{Mn}_{3} \mathrm{O}_{4}$ [35].

In order to design a metal-based catalyst with a high performance, identifying the effect of size at the atomic level is important. A comparative study on a series of $\mathrm{Pt} / \mathrm{FeO}_{\mathrm{x}}$ catalysts with two types of $\mathrm{Pt}$, one as nanoparticles and the other as single atoms, was conducted by Chen et al. to evaluate the catalytic performance for low-temperature WGS reaction [36]. The results exhibited lower activation energy by $\mathrm{Pt}$ downsizing, and Pt single atom with $0.05 \mathrm{wt} \%$ loading (Fig. $2 \mathrm{j}, \mathrm{k}$ ) was found to be the most active catalyst with a $\mathrm{CO}$ conversion of $\sim 65 \%$ at $300{ }^{\circ} \mathrm{C}[36]$. In a theoretical study conducted by Fajín et al., the platinum nanotube performance was analyzed for the WGS reaction [46]. The authors suggested that Pt nanotube showed improved performance compared to the extended platinum surfaces or Pt nanoparticles deposited on metal oxides. Pt nanotubes were identified to be structurally more stable and avoided catalysts sintering in WGS reaction [46].

$\mathrm{Pd}$ is another well-known noble metal widely investigated for WGS reaction, as a single metal or in alloyed forms with other metals. Pd with different $\mathrm{Co}_{3} \mathrm{O}_{4}$ catalysts was investigated by Kono et al. for water-gas shift (WGS) reaction to produce hydrogen [48]. Palladium alone on cobalt oxide $\left(\mathrm{Pd} / \mathrm{Co}_{3} \mathrm{O}_{4}\right)$ exhibited low activity and higher methane selectivity; however, the $\mathrm{Pd} / \mathrm{K} / \mathrm{Co}_{3} \mathrm{O}_{4}$ as a catalyst with potassium loading $>0.78 \mathrm{wt} \%$ showed high activity for the WGS reaction. The potassium loading affected the $\mathrm{CO}$ species adsorption state, which caused $\mathrm{Pd} / \mathrm{K} / \mathrm{Co}_{3} \mathrm{O}_{4}$ catalyst to have high activity [48]. Sun et al. synthesized a series of Pd catalysts supported on $\mathrm{FeO}_{\mathrm{x}}$ for WGS reaction and used $\mathrm{Pd} / \mathrm{Al}_{2} \mathrm{O}_{3}$ as a reference for comparison [47]. They found that $\mathrm{Pd} / \mathrm{FeO}_{\mathrm{x}}$ showed a higher $\mathrm{CO}$ conversion compared to $\mathrm{Pd} / \mathrm{Al}_{2} \mathrm{O}_{3}$ (Fig. 3a, b), and with high stability, even in the presence of $\mathrm{CO}_{2}$ and $\mathrm{H}_{2}$. Moreover, Pd single atoms can greatly enhance $\mathrm{FeO}_{\mathrm{x}}$ reducibility and promote oxygen vacancies formation (Fig. 3c, d) [47].

Bulk gold is thought to be chemically inert; nonetheless, gold nanoparticles have revealed a high catalyst activity in the WGS reaction [49]. Bimetals of gold (Au-M, M = metals) on
$\mathrm{CeO}_{2}$ support were evaluated for WGS reaction where $3 \mathrm{wt} \%$ $\mathrm{Au}-\mathrm{Pt} / \mathrm{CeO}_{2}$ showed high activity within a temperature range of $100-300{ }^{\circ} \mathrm{C}[50]$. The WGS activity correlated well with the reducibility of ceria, that in turn was affected by the bimetallic cluster promoted local electronic band causing the stabilization of germinal $\mathrm{OH}$ groups, which were supposed to be responsible for enhanced WGS activity [50]. A comparative study was conducted by Castaño et al. on the performance of gold and platinum catalysts on ceria support [51]. Gold-based catalysts indeed showed a higher reaction rate at $180^{\circ} \mathrm{C}$; however, the activity of the catalysts was sensitive to temperature with Pt showing more activity at the higher temperatures. The gold catalysts had a high dispersion of $32 \%$ with an average crystallite size of $4 \mathrm{~nm}$ (Fig. 4a), that enabled Au to influence the electronic properties of the ceria support, which correlated with the activity for WGS reaction [51]. Later, the same group carried out a comparative study between Pt and structured gold catalysts, both supported on Fe doped ceria mixed oxide inserted onto metallic micro size monolithic structures (Fig. $4 \mathrm{~b}, \mathrm{c})$ in order to find their performance in WGS reaction with $\mathrm{O}_{2}$ assistance [52]. Pt was the most active metal in conventional conditions; nevertheless, in $\mathrm{O}_{2}$ assisted WGS reaction, Au-based catalysts performed superior to Pt-based catalysts [52].

To understand the effect of the preparation method and the amount of $\mathrm{Au}$ on the catalyst activity in low-temperature WGS reaction, Soria et al. synthesized a series of nano-sized $\mathrm{Au} / \mathrm{Fe}_{2} \mathrm{O}_{3}$ catalysts with several $\mathrm{Au}$ loadings and different synthesis methods [53]. The deposition-precipitation (DP) method with the Au content of $5 \mathrm{wt} \%$ (the highest tested loading) (Fig. 4d, e) was found to have the highest conversion of $\mathrm{CO}$. Among the $\mathrm{Au} / \mathrm{Fe}_{2} \mathrm{O}_{3}$ liquid phase reductive deposition (LPRD) samples, the most active catalyst was the one with the lowest quantity of $\mathrm{Au}(1.5 \mathrm{wt} \%)$ (Fig. 4f, g). Based on $\mathrm{H}_{2}$-TPR analysis, the authors concluded that gold could promote $\mathrm{Fe}_{2} \mathrm{O}_{3}$ support reducibility, which seems to be a key factor in enhancing redox WGS reaction activity. In both, the DP and the LPRD methods, high dispersion of gold over the iron support with $2.2-3.1 \mathrm{~nm}$ crystallites was observed, and only an insignificant increase in the average particle size of used catalyst was witnessed after the reaction [53].

In another study, Reina et al. synthesized multicomponent catalysts including $\mathrm{Au} / \mathrm{Ce}_{1-\mathrm{x}} \mathrm{Cu}_{\mathrm{x}} \mathrm{O}_{2} / \mathrm{Al}_{2} \mathrm{O}_{3}$ and tested for WGS reaction to understand the role of each element; $\mathrm{Au}, \mathrm{Ce}$, and $\mathrm{Cu}$; in the reaction [55]. The synergy between $\mathrm{Cu}-\mathrm{Ce}$ and $\mathrm{Au}-$ support interactions greatly influenced the catalytic properties, and oxygen storage capacity. Though copper is an active catalyst for WGS reaction, gold was required to achieve a high conversion of $\mathrm{CO}$. $\mathrm{CeO}_{2}$ also played an important role, as both $\mathrm{Cu}$ and $\mathrm{Au}$ showed remarkable improvement in activity in the presence of $\mathrm{CeO}_{2}$ with reasonable long-term stability [55]. Some studies have discussed that using bimetallic systems could improve both the activity and stability of the catalyst 
Fig. 3 a, b HAADF-STEM images of $1.3 \mathrm{wt} \% \mathrm{Pd} / \mathrm{Al}_{2} \mathrm{O}_{3}$ and $1.1 \mathrm{wt} \% \mathrm{Pd} / \mathrm{FeO}_{\mathrm{x}}$. c, d HAADFSTEM and HRTEM images $0.044 \mathrm{wt} \% \mathrm{Pd} / \mathrm{FeO}_{\mathrm{x}}[47]$

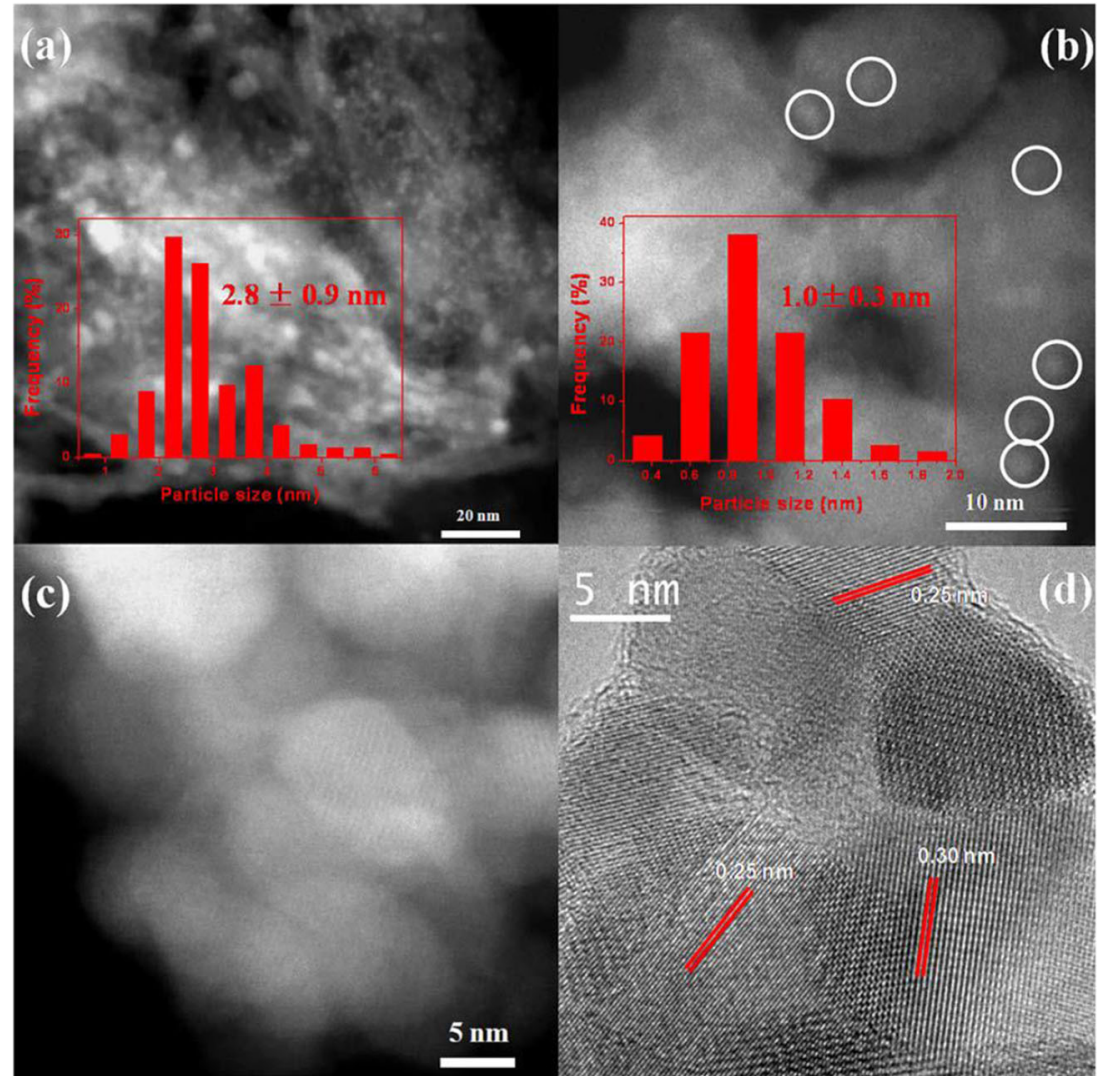

in the WGS reaction. For example, adding rhenium ( $\mathrm{Re}$ ) to $\mathrm{Au}$ catalysts with $\mathrm{CeO}_{2}$ support significantly improved the catalytic activity [56]. Ozyonum et al. conducted an investigation on monolithic $\mathrm{Au}-\mathrm{Re} / \mathrm{CeO}_{2}$ over microchannel cordierite [57]. They realized a relatively lower performance with $\mathrm{Au} / \mathrm{CeO}_{2}$ catalyst in comparison to the considerable improvement with Re addition as a promoter [57]. For achieving a high activity with Au-based catalysts for low-temperature WGS reaction, Yao et al. incorporated atomic layer deposition technique to grow clusters of layered gold on a molybdenum carbide $(\alpha-$ $\mathrm{MoC})$ substrate to create an interfacial catalytic system for ultra-low-temperature WGS (Fig. 4h, i) [44]. This catalytic system was capable of dissociating water efficiently on the MoC surface as well as activating the $\mathrm{CO}$ on neighboring Ag clusters, resulting in high WGS activity at low temperature. Interestingly, even after the reaction, the sample still included both single-atom $\mathrm{Au}$ and layered Au clusters (Fig. $4 \mathrm{j})$. The use of sodium cyanide $(\mathrm{NaCN})$ solution has been effective in selectively leaching the layered Au clusters from in such systems (Fig. 4k) [54, 58].

Santos et al. examined the activity of gold nanoparticles catalyst combined with $\mathrm{Cu} / \mathrm{ZnO} / \mathrm{Al}_{2} \mathrm{O}_{3}$ for hydrogen production through WGS reaction [59]. This system could successfully achieve a full $\mathrm{CO}$ conversion at $180^{\circ} \mathrm{C}$ due to the perfect synergy of gold and copper [59]. Fu et al. synthesized two different kinds of $\mathrm{Au} / \mathrm{Ce}$ WGS reaction catalysts supported on the same nanorods of ceria, one with $<2 \mathrm{~nm}$ disordered clusters, and the other with 3-4-nm particles. The results exhibited that the disordered gold clusters had superior activity than the nanoparticles of gold [60]. Stere et al. utilized nonthermal (cold) plasma activation to facilitate low-temperature WGS reaction over an $\mathrm{Au}$-based/CeZrO $\mathrm{Cr}_{4}$ catalyst, where they concluded that the catalyst activity was comparable to that achieved through heating the catalyst up to $180^{\circ} \mathrm{C}$ [61]. Santos et al. performed an investigation to optimize the performance of the $\mathrm{Au} / \mathrm{Cu}-\mathrm{ZnOAl}_{2} \mathrm{O}_{3}$ catalytic system by applying various ratios of active components as well as the $\mathrm{Au}$ preparation methods [62]. This system not only had a high carbon monoxide conversion but also showed stability during the start/stop operations as well as for long-term TOS, which is a prerequisite in real applications. It was concluded that combining $\mathrm{Au}$ with commercial-like $\mathrm{Cu}-\mathrm{Zn}$-Al compounds by hydrotalcite process can generate a new series of catalysts for WGS reaction with the capability to develop large scale hydrogen production technologies [62]. Au-based catalyst supported on $\mathrm{Ce}-\mathrm{Zr}$ has been considered as one of the most active low-temperature WGS catalysts recorded to date; however, in the reaction conditions, a rapid deactivation occurs $[63,64]$. Carter et al. evaluated a series of Ce-Ti support that were synthesized by the sol-gel method. They supported Au on these mixed metal oxides via a deposition-precipitation method, intending to resolve the deactivation issue. The 


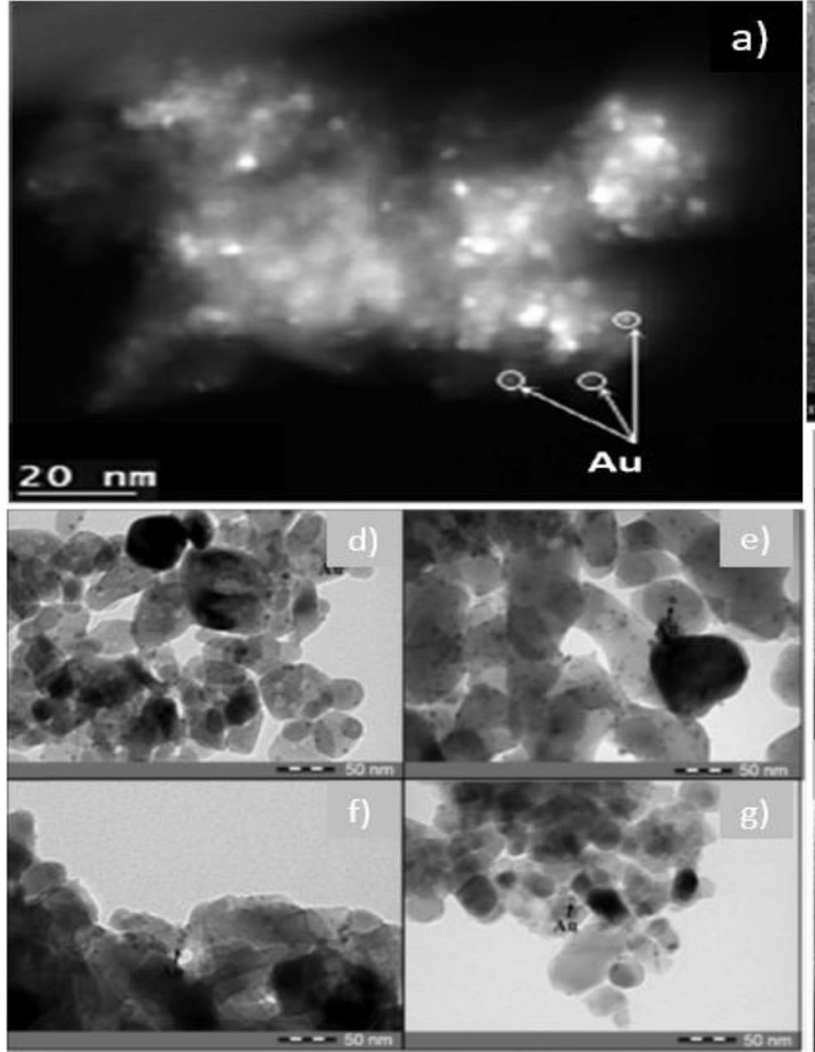

Fig. 4 a HAADF-STEM images of $\mathrm{Au} / \mathrm{CeFeAl}$ [51]. b, c SEM microphotographs of the micro monoliths $\mathrm{Au} / \mathrm{CeFe}$ catalyst: $\mathbf{b}$ front; $\mathbf{c}$ crosssection view [52]. HRTEM images of $\mathbf{d}, \mathbf{e}$ the $5 \mathrm{Au} / \mathrm{Fe}_{2} \mathrm{O}_{3}$ DP fresh and used (f, g) $1.5 \mathrm{Au} / \mathrm{Fe}_{2} \mathrm{O}_{3}$ LPRD fresh and used catalysts, respectively [39]. HAADF-STEM images of $\mathbf{h}, \mathbf{i}$ fresh (2\%) Au/ $\alpha$-MoC, $\mathbf{j}$ used (2\%) Au/ $\alpha$ -

results of low-temperature WGS reaction showed high activity and stability for $\mathrm{Au} / \mathrm{Ce}_{0.2} \mathrm{Ti}_{0.8} \mathrm{O}_{2}$ compared to ceriazirconia due to the highest specific surface area represented by amorphous $\mathrm{Ce}_{0.2} \mathrm{Ti}_{0.8} \mathrm{O}_{2}$ and well-dispersed of $\mathrm{Au}$ species [65].

The use of a suitable Rh single-atom catalyst (SAC) could make the WGS performance very active and selective in terms of adsorption and reaction. SAC is now considered a new dimension in heterogeneous catalysis that presents a very high dispersion of metal species, in atomic form, and reported to display optimum catalytic properties in many cases [67]. Guan et al. reported a $\mathrm{Rh}_{1} / \mathrm{TiO}_{2} \mathrm{SAC}$ with a loading amount of $0.37 \mathrm{wt} \%$, resulting in an overall $95 \% \mathrm{CO}$ conversion with no methanation at $300{ }^{\circ} \mathrm{C}$, which is viable even in a WGS stream rich with $\mathrm{CO}_{2}$ and $\mathrm{H}_{2}$ [66]. The result suggested that $\mathrm{Rh}$ single atoms enhanced the oxygen vacancies formation on $\mathrm{TiO}_{2}$ support in order to generate more $\mathrm{H}_{2}$ than Rh clusters. Besides, the SAC activity was about four times higher than the cluster catalyst with no formation of methane. The single atoms of Rh and nanoclusters were verified by HRTEM, as shown in Fig. 5 [66]. Mandapaka et al. synthesized Rh and aluminum co-doped ceria catalysts by a single-step solution combustion synthesis technique and tested its reactivity for
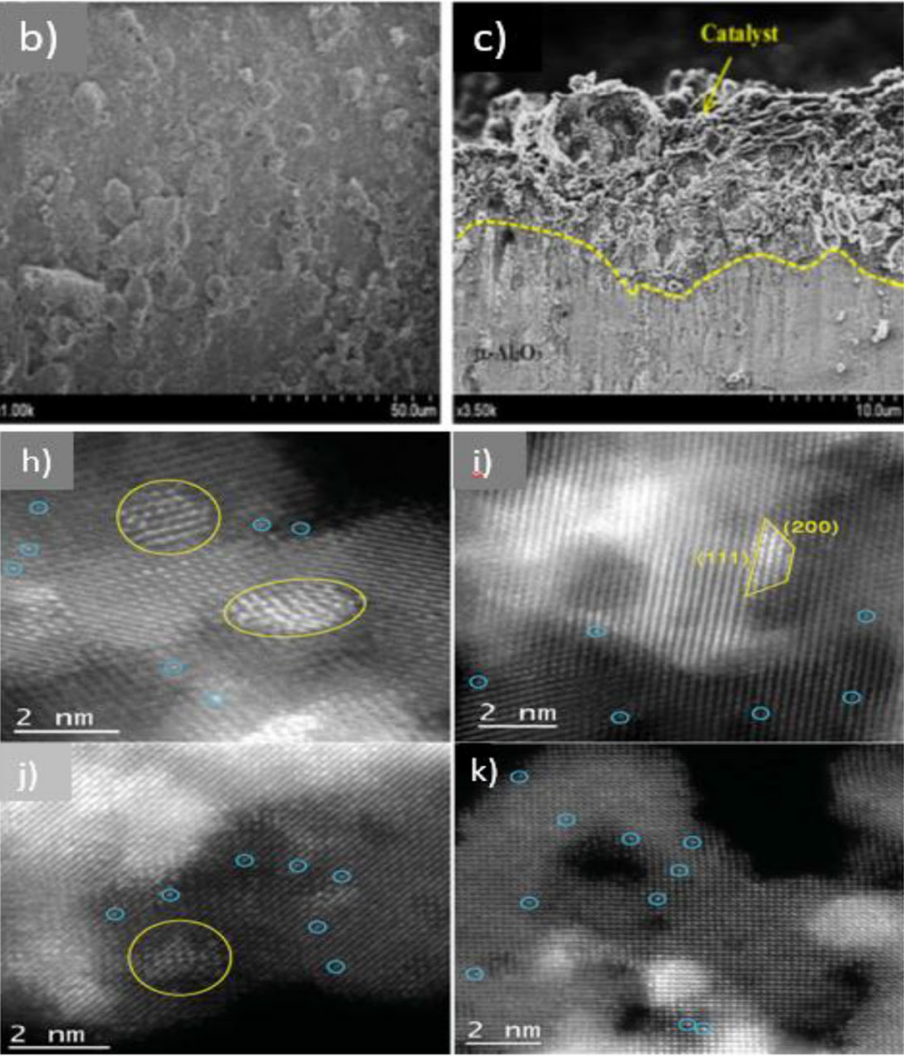

$\mathrm{MoC}$, and $\mathbf{k}$ the $(2 \%) \mathrm{Au} / \alpha-\mathrm{MoC}$ catalyst after $\mathrm{NaCN}$ leaching, representing predominantly $\mathrm{Au}$ single atoms in which most of them overlapped with Mo sites in the support lattice (very bright features were created by overlapping $\mathrm{MoC}$ particles. (Blue circles: $\mathrm{Au}$ single atoms, yellow highlights: layered Au structures) [54]

WGS reaction and $\mathrm{CO}$ oxidation. The results showed that the bimetallic $\mathrm{Rh}$ and $\mathrm{Al}$ doped catalyst yielded a higher activity and surface area than the single metal doping of $\mathrm{Rh} / \mathrm{Ce}$ and $\mathrm{Al} / \mathrm{Ce}$ synthesized by the same method [68].

The catalytic performance in heterogeneous catalysts is affected by the dispersion of the active precious metal, and frequently, the active sites coalesce and grow during the reaction that result in lower activity over a longer time of analysis. Homogeneous catalysts, on the other hand, are known for high turnover frequency due to availability of atomic level sites. Ruthenium-based homogeneous catalysts have been particularly investigated for WGS reaction. Metal carbonyls, e.g., ruthenium-carbonyl, catalysts are low-cost homogeneous catalysts, which have been reported to operate at a lower temperature than the heterogeneous catalyst systems resulting in higher equilibrium conversion [70]. However, these systems require a high $\mathrm{CO}$ pressure, above $10 \mathrm{bar}$, and in this regard, volatile solvents and ionic liquid (IL) have been considered. Huang et al. reported that Ru-iongel catalysts show better activity and stability for low-temperature WGS reaction in comparison to the catalysts with supported ionic liquid (IL) phase, possibly because of a strong interaction between silica support and IL. The iongel catalyst activity increased with 
Fig. 5 a HAADF/STEM images of $0.37 \mathrm{Rh} / \mathrm{TiO}_{2}$-AL. $\mathbf{c}$ Enlarged district in $\mathbf{b}$, showing the loosely $\mathrm{Rh}$ species single-atom dispersion. (White circles: Rh single atoms, red circles: Rh clusters) [66]
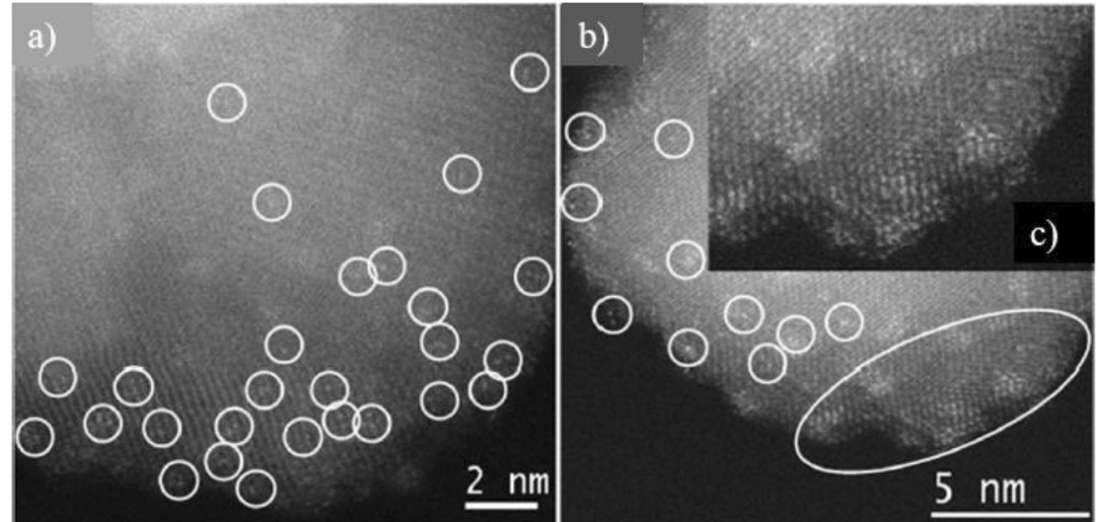

increasing the IL loading, and the larger anions iongel catalysts showed higher activity in the WGS reaction [71]. The effect of adding $\mathrm{K}_{2} \mathrm{CO}_{3}$ on the $\mathrm{Ru} / \mathrm{C}$ catalysts performance (Fig. 6a) was investigated by Liu et al. through the positive reduction method by three different agents, $\mathrm{NaBH}_{4}$, ethylene glycol (EG), and $\mathrm{H}_{2}$, in which the $\mathrm{Ru} / \mathrm{C}$ catalyst reduced by $\mathrm{H}_{2}$ exhibited the highest catalytic activity for WGS reaction (Fig. $6 b)$. The alkali additives showed a strong adsorbed gas bonding that improved the catalytic activity of the $\mathrm{Ru} / \mathrm{C}$. It also

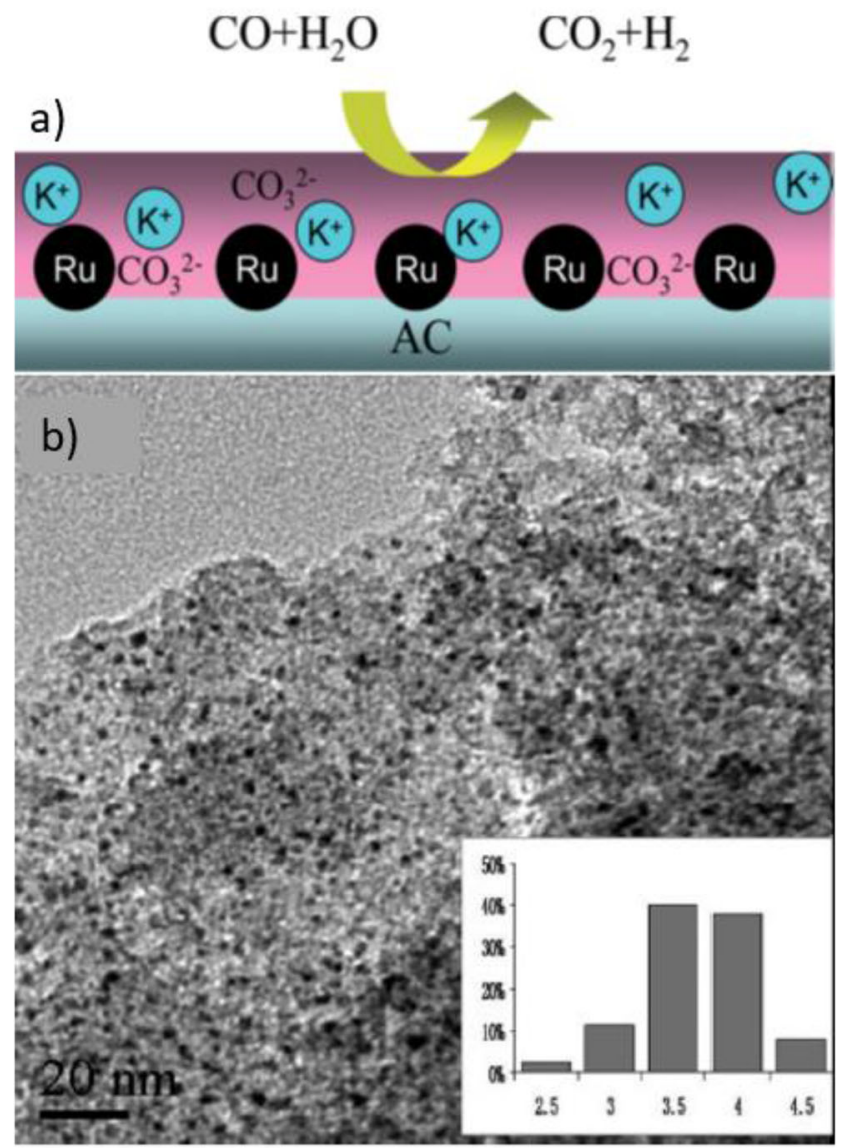

Fig. 6 a The WGS mechanism of the $\mathrm{K}_{2} \mathrm{CO}_{3}$ additive $\mathrm{Ru} / \mathrm{C}$ catalyst, $\mathbf{b}$ TEM images of $\mathrm{Ru} / \mathrm{C}$ catalysts reduced $\mathrm{H}_{2}$ and an estimation of size distributions [69] resulted in a concentration balance of water and $\mathrm{CO}$ on the active sites [69]. Queiroz et al. likewise studied the performance of $2 \% \mathrm{Ru} / \mathrm{C}$ for the low-temperature WGS reaction in a fixed bed reactor that resulted in $80 \% \mathrm{CO}$ conversion under the steady-state condition at $553 \mathrm{~K}$ [72]. Later, they examined the catalytic performance of $\mathrm{Ru}$ during the low-temperature WGS reaction with two different supports, $\mathrm{TiO}_{2}$ and $\mathrm{Al}_{2} \mathrm{O}_{3}$. The result showed that at $573 \mathrm{~K}, \mathrm{CO}$ conversion on both $\mathrm{Ru} /$ $\mathrm{Al}_{2} \mathrm{O}_{3}$ and $\mathrm{Ru} / \mathrm{TiO}_{2}$ catalysts stayed $85 \%$ in a steady-state condition [73]. Queiroz et al. developed a WGS process with a membrane reactor using $2 \mathrm{wt} \% \mathrm{Ru}$ on $\mathrm{TiO}_{2}$ catalyst at $453-$ $573 \mathrm{~K}$ and atmospheric pressure [74]. The result of the experiments at $573 \mathrm{~K}$, both with and without permeation, showed 90 and $75 \%$ CO conversion, respectively. Besides, the results showed a 75-96\% hydrogen recovery in the permeation operation, which was $\sim 5$ times higher than the operation without hydrogen permeation [74]. Supported ionic liquid phase (SILP) materials have been used to perform reactions at a low-temperature range $[75,76]$. Stepic et al. successfully used this approach to enable a highly effective, homogeneously dispersed $\mathrm{Ru}$-based catalyst to perform WGS reaction in the temperature range of $100^{\circ} \mathrm{C}$ and $150{ }^{\circ} \mathrm{C}$ [77].

From this section, it is clear that noble metals have been extensively studied for WGSR. The dispersion of the active metal and the reducibility of the metal oxide support seem to be the key parameters affecting a catalyst's performance. The use of the SCFD method, as well as sonochemical preparation techniques, seems to offer a good control over nanoscale dispersion of the noble metals on the support leading high turnover numbers. In the case of Pt-containing supported catalyst, washing with a base, like $\mathrm{KOH}$, helps in improving the catalyst performance for WGSR. The presence of gold, alone or with other noble metals, is shown to affect the reducibility of $\mathrm{CeO}_{2}$ as well as $\mathrm{FeO}_{\mathrm{x}}$, which in turn positively affects their performance. Single-atom catalysts of Pt and Au supported on $\mathrm{CeO}_{2}$ perform exceptionally well, which can further be improved by promoting the catalyst with single-atom sites of Re.

Next, we review the progress in transition metal catalysts, which offer economic alternatives to the noble metals.

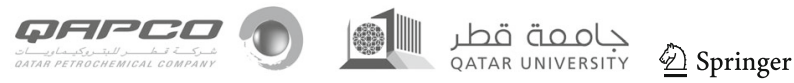


Supported catalysts composed of $\mathrm{Cu}, \mathrm{Zn}, \mathrm{Ni}$, and $\mathrm{Co}$, alone or alloyed, have been investigated broadly for WGSR and offer to have good activity and selectivity for the low-temperature reaction.

\subsubsection{Transition metal catalysts}

Transition metals are elements from groups 3 to 12 in the periodic table, and they are known for their catalytic properties for many reforming reactions. Inclusion of transition metals such as $\mathrm{Fe}, \mathrm{Cu}$, and $\mathrm{Zn}$ as dopants in $\mathrm{CeO}_{2}$ for gold supported ceria catalysts $\left(\mathrm{Au} / \mathrm{CeO}_{2} / \mathrm{Al}_{2} \mathrm{O}_{3}\right)$ is reported to improve the performance for WGSR [78]. Transition metals tend to increase the redox properties and promote structural stability. Herein, we present some of the transition metal-based catalysts for WGSR.

Previous sections indicate that Au nanoparticles act as suitable catalysts for the oxidation of $\mathrm{CO}$; however, some authors argue that water dissociation and adequate WGS reaction rate on pure $\mathrm{Au}$ are challenging to achieve. Copper, on the other hand, is reported to be more active for WGS reaction, although a significant barrier in $\mathrm{Cu}$ activation is required to be overcome for water dissociation [79]. Saqlain et al. studied the behavior of two different catalysts, $\mathrm{Cu}$ (100), and bimetallic $\mathrm{Cu}-\mathrm{Au}$ (100) [80]. Results indicated that the dissociation of water for the $\mathrm{Cu}(100)$ and bimetallic surfaces were spontaneous up to $229 \mathrm{~K}$ and $520 \mathrm{~K}$, respectively. In terms of reactivity, the study suggested that the bimetallic surface was far more reactive compared to the $\mathrm{Cu}(100)$ surface [80]. In another study, Wijayapala et al. used catalyst systems $\mathrm{Mo} / \mathrm{Co} / \mathrm{K} /$ ZSM-5 and Mo/Ni/K/ZSM-5 (ZSM-5 = zeolite), alone and with a copper-based WGS catalyst, for $\mathrm{CO} / \mathrm{H}_{2}$ ratios conversion in a batch reactor into aromatic hydrocarbons. The presence of $\mathrm{Cu}$ in the WGS catalyst system significantly improved $\mathrm{CO}$ conversion from 25 to $90 \%$ at $280{ }^{\circ} \mathrm{C}$ [81]. Jeong et al. reported a strong effect of support on catalytic activity in copper-based WGS catalyst [82]. In this regard, they tested $\mathrm{Cu} / \mathrm{CeO}_{2}$ catalysts prepared by incipient wetness and coprecipitation methods and optimized the copper loading in order to get a highly active $\mathrm{Cu} / \mathrm{CeO}_{2}$ catalyst. Results indicate that the catalysts prepared by co-precipitation (Fig. 7a) had superior performance with highest CO conversion and 100\% $\mathrm{CO}_{2}$ selectivity in addition to easier reducibility [82]. Camara et al. investigated the low-temperature WGSR mechanism on $\mathrm{CeO}_{2} / \mathrm{Cu}$ catalysts using operando SSITKA-DRIFTS-mass spectrometry, where they identified a specific type of carbonate intermediate (bi or tridentate), which was believed to be the rate-limiting intermediate controlling the formation of $\mathrm{CO}_{2}$ [83]. Moreira et al. studied the sorption enhanced WGS reaction at low-temperature $\left(125-295{ }^{\circ} \mathrm{C}\right)$ over $\mathrm{Cu}-\mathrm{CeO}_{2} /$ HTlc catalysts, where they reported a $70 \%$ volume enrichment in hydrogen and improved $\mathrm{CO}$ conversion upon efficient removal of $\mathrm{CO}_{2}$ from the effluent stream [84]. $\mathrm{Cu}$ supported on nanoparticles size polyhedral ceria, with $87.6 \% \mathrm{CO}$ conversion, was found to have the highest activity in comparison to other catalysts reported in this work [84].

Jeong et al. prepared $\mathrm{Cu}-\mathrm{CeO}_{2}, \mathrm{Cu}-\mathrm{ZrO}_{2}$, and $\mathrm{Cu}-\mathrm{CeO}_{2}-$ $\mathrm{ZrO}_{2}$ to obtain feasible catalysts for low-temperature (200 to $400{ }^{\circ} \mathrm{C}$ ) WGS reaction. The cubic $\mathrm{Cu}-\mathrm{Ce}_{0.8} \mathrm{Zr}_{0.2} \mathrm{O}_{2}$ catalyst showed the highest $\mathrm{CO}$ conversion maintaining a stable TOS performance for $100 \mathrm{~h}$ with no significant loss in the activity [85]. Price et al. proposed a design strategy to overcome the limitations of large residence time requirement for $\mathrm{Cu}$-based catalysts in WGS reaction [86]. They synthesized a series of $\mathrm{Cu}-\mathrm{ZnO}$ catalysts with different supports and evaluated their performance. The results indicate that $\mathrm{CeO}_{2}-\mathrm{Al}_{2} \mathrm{O}_{3}$ support can work under medium to high space velocities while maintaining a high activity and long-term stability [86]. Lang et al. introduced copper/ceria/foam catalysts to perform WGS reaction at a temperature range of 150 to $300{ }^{\circ} \mathrm{C}$ and GHSV between 3600 and $9500 \mathrm{~h}^{-1}$ at the outlet of a biomass gasifier with a limited pressure drop. The optimum amount of $\mathrm{Cu}$ and Ce resulting in the highest catalytic activity were 5.5 and $9.0 \mathrm{wt} \%$ respectively on a 30 ppi porosity foam [87]. Dalin $\mathrm{Li}$ et al. developed $\mathrm{Cu} / \mathrm{ZnO} / \mathrm{Al}_{2} \mathrm{O}_{3}$ catalysts with various compositions of $\mathrm{Cu}-\mathrm{Zn}$-Al layered double hydroxides (LDHs) for WGS reaction [88]. The formation of 2-6 nm size $\mathrm{Cu}$ with a dispersion percentage of $18-48 \%$ was observed after the reduction. The results showed that the $30 \% \mathrm{Cu} / \mathrm{Zn}_{1} \mathrm{Al}$ catalyst had the highest activity, thermal stability, and long-time catalytic stability compared to the commercial catalyst of $\mathrm{Cu} / \mathrm{ZnO} /$ $\mathrm{Al}_{2} \mathrm{O}_{3}$ [88]. Zhang et al. used uniform nanocrystals of $\mathrm{Cu}$ to investigate the $\mathrm{Cu}$ actives site for low-temperature WGSR [89]. The results indicated that $\mathrm{Cu}$ cubes with (100) exposed facets, in contrast to $\mathrm{Cu}$ octahedral enclosed with (111) facets, are active up to $548 \mathrm{~K}$. Therefore, it was concluded from this study that $\mathrm{Cu}$ cubes-supported on $\mathrm{ZnO}$ had an extremely high activity for low-temperature WGSR [89]. Yan et al. reported a bulk promoted $\mathrm{Cu}-\mathrm{Fe}_{3} \mathrm{O}_{4}$ catalysts for low-temperature WGS reaction, where the interaction between $\mathrm{Cu}$ and $\mathrm{Fe}$ helped in stabilizing and significantly improving the $\mathrm{Cu}^{0}$ dispersion that resulted in an increased activity for WGS $\mathrm{CO}$ conversion. The $\mathrm{Fe}$ addition promoted both $\mathrm{CO}$ and $\mathrm{H}_{2} \mathrm{O}$ adsorption. Different compositions of $\mathrm{Cu}$ and $\mathrm{Fe}$ were investigated and the $\mathrm{Cu}_{0.3} \mathrm{Fe}_{0.7} \mathrm{O}_{\mathrm{x}}$ catalyst showed a high initial activity that deactivated after $26 \mathrm{~h}$; thereafter, $\mathrm{Cu}_{0.7} \mathrm{Fe}_{0.3} \mathrm{O}_{\mathrm{x}}$ surpassed the $\mathrm{Cu}_{0.3} \mathrm{Fe}_{0.7} \mathrm{O}_{\mathrm{x}}$ activity. Moreover, the inclusion of alumina in the multicomponent $\mathrm{Cu}-\mathrm{Fe}_{3} \mathrm{O}_{4}-\mathrm{Al}_{2} \mathrm{O}_{3}$ catalyst resulted in superior performance, improved activity, and long-term stability compared to the catalysts without alumina in the structure (Fig. 7b) [90].

Coal gasification, which inherently involves WGS, is considered a clean hydrogen production method to convert coal resources into chemical energy; however, the process is still costly. In this regard, Zhao et al. adopted a solar-driven WGS method to significantly decrease the consumption of energy 

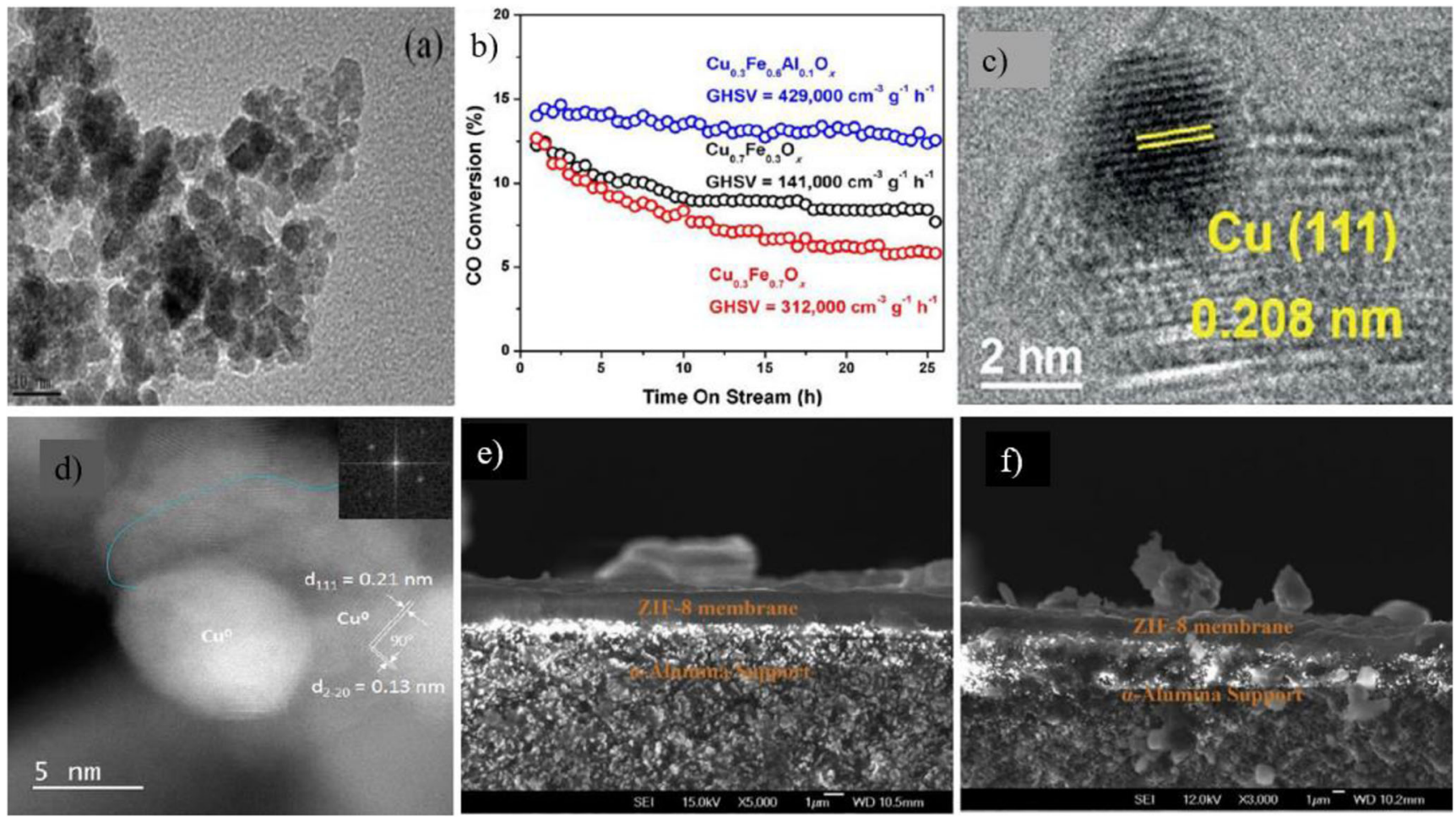

Fig. 7 a TEM image of fresh co-precipitated $\mathrm{CueCeO}_{2}$ [82]. b Time on stream-dependent $\mathrm{CO}$ conversion of $\mathrm{Cu}_{0.3} \mathrm{Fe}_{0.7} \mathrm{O}_{\mathrm{x}}, \mathrm{Cu}_{0.7} \mathrm{Fe}_{0.3} \mathrm{O}_{\mathrm{x}}$, and $\mathrm{Cu}-$ $\mathrm{Fe}_{3} \mathrm{O}_{4}-\mathrm{Al}_{2} \mathrm{O}_{3}$ [90]. c HRTEM of $\mathrm{CuO}_{\mathrm{x}} / \mathrm{Al}_{2} \mathrm{O}_{3}$ catalyst [91]. d High-

resolution STEM image with inset of EDX of the $\mathrm{Cu} / \mathrm{Fe}_{3} \mathrm{O}_{4}$ rods [92]. $\mathbf{e}, \mathbf{f}$ The cross-sectional SEM images of the ZIF- 8 membrane $\mathbf{e}$ before and f after use [94]

[91]. They found that the $\mathrm{CuO}_{\mathrm{x}} / \mathrm{Al}_{2} \mathrm{O}_{3}$ (Fig. 7c) delivered 122 $\mu$ molg ${ }_{\text {cat }}^{-1} \mathrm{~s}^{-1} \mathrm{H}_{2}$ evolution and more than $95 \% \mathrm{CO}$ conversion under light irradiation, that was more efficient than $\mathrm{Au} /$ $\mathrm{Al}_{2} \mathrm{O}_{3}$ and $\mathrm{Pt} / \mathrm{Al}_{2} \mathrm{O}_{3}$. Apart from no cost for electric/thermal power, this solar-driven WGS process was capable of converting $1.1 \%$ light-to-energy [91]. Ma et al. synthesized $\mathrm{Cu} / \mathrm{Fe}_{3} \mathrm{O}_{4}$ catalysts with nanorod structure using aqueous precipitation method (Fig. 7d), which showed good activity for high-temperature WGS reaction but did not show much activity at low temperatures [92]. The authors conducted ambient pressure XPS (AP-XPS) analysis and identified $\mathrm{Cu}^{+}$as the dominant, and possibly active phase, for WGSR.

To investigate the role of preparation method on the structure and catalytic activity in WGSR, Farzanfar et al. synthesized $\mathrm{Cu}-\mathrm{Mn} / \mathrm{SiO}_{2}$ catalysts with three different methods [93]. The results determined that thermal decomposition of the inorganic complex was more suitable compared to impregnation and co-precipitation methods for developing active and stable $\mathrm{Cu}-\mathrm{Mn} / \mathrm{SiO}_{2}$ WGS catalysts for $180-320{ }^{\circ} \mathrm{C}$ temperature range [93].

Kowalik et al. studied the impact of the hydroxycarbonateassisted precipitation media on the physicochemical properties and activity of $\mathrm{Cu} / \mathrm{ZnO} / \mathrm{Al}_{2} \mathrm{O}_{3}$ system in low-temperature WGS reaction [95]. They employed water, glycol, and aqueous ethanol solution as the reactive medium. The results revealed that the alcohol assisted method could lead to a $\mathrm{Cu} /$ $\mathrm{ZnO} / \mathrm{Al}_{2} \mathrm{O}_{3}$ catalysts with higher catalytic activity and

stability than the other conventional techniques [95]. A comprehensive investigation was performed by Yin et al. to illustrate the beneficial characteristics of a zeolitic imidazolate framework-8 (ZIF-8) reactor (Fig. 7e, f) and $\mathrm{Cu} / \mathrm{Zn} / \mathrm{Al}_{2} \mathrm{O}_{3}$ catalysts for a low-temperature WGS reaction [94]. The membrane reactor exhibited $9.2 \times 10^{-7} \mathrm{~mol} / \mathrm{m}^{2} \mathrm{~s} \cdot \mathrm{Pa}$ hydrogen permeance, which was much higher than the conventional metal and zeolite membranes, making it more attractive for practical hydrogen production. In addition, at a low temperature of $120-220^{\circ} \mathrm{C}$, the $\mathrm{CO}$ conversion using the ZIF-8-based membrane reactor was $13.5 \%$ higher than the conventional packed reactor [94]. Despite the high gas permeance of ZIF8 membrane with considerable $\mathrm{H}_{2}$ perm-selectivity, due to the low hydrothermal stability of materials used in this membrane, the system needs further improvements to make it more suitable for WGS reaction conditions [96, 97].

To evaluate the Fe-doping effects on the catalyst performance, Chen et al. synthesized $\mathrm{Fe}-\mathrm{Ce}-\mathrm{O}_{\mathrm{x}}$ composite oxides, consisting of $\mathrm{CeO}_{2}$ nanorods and $\mathrm{Fe}_{2} \mathrm{O}_{3}$ nanoparticles, and applied them in the WGS reaction [98]. The results of the analysis revealed that introducing $\mathrm{Fe}^{3+}$ into $\mathrm{CeO}_{2}$ crystal lattice structure increased the catalytic activity for the WGS reaction. It was also concluded that the reducing gas atmosphere synthesis method was more favorable for enhancing the doping effect. However, the catalyst was more active at high temperature and the $\mathrm{CO}$ conversion increased when the temperature was increased from 300 to $500{ }^{\circ} \mathrm{C}$ [98]. The effect of Fe- 
Ce- $\mathrm{O}_{\mathrm{x}}$ composite oxides had also been studied by other groups showing high catalytic activity towards WGS reaction [99].

With the objective of studying the impact of alkali-I metals promotion, such as $\mathrm{Li}, \mathrm{Na}, \mathrm{K}, \mathrm{Rb}$, and $\mathrm{Cs}$, on both activity and stability of $\mathrm{Co}_{2} \mathrm{C}$ for the low-temperature WGS reaction, Gnanamani et al. performed a study at 453 to $573 \mathrm{~K}$ and atmospheric pressure and compared the results with the unpromoted $\mathrm{Co}_{2} \mathrm{C}$ reference catalyst [99]. The WGS reaction results indicated the unpromoted cobalt carbide to be active, although the catalyst deactivated over longer TOS due to the chemical transition of carbides to metallic form during the WGS reaction. However, the potassium promoted catalyst presented higher activity and better stability compared to the rest of the alkali supported $\mathrm{Co}_{2} \mathrm{C}$ catalysts [100].

Chen et al. studied the intrinsic activities of Co-promoted $\mathrm{MoS}_{2}$ and unpromoted-MoS ${ }_{2}$ on $\mathrm{Co}-\mathrm{MoS}_{2} / \mathrm{Al}_{2} \mathrm{O}_{3}$ for WGSR, and reported a lower activation energy for Co-promoted sites [101]. The Co-promoted $\mathrm{MoS}_{2} / \mathrm{Al}_{2} \mathrm{O}_{3}$ is widely used in hydrogen production industries as a catalyst for WGS reaction in the presence of sulfur [101].

Recently, Alamolhoda et al. worked on understanding the synergetic effect between nickel and cerium as catalysts in WGS reaction, and reported the use of low percentage loading (0-3 wt \%) of cerium and nickel as dispersed phases on MFI framework [102]. According to the results, the cerium only catalysts had shown no sign of reaction, whereas the single metal Ni-MFI series catalysts successfully activated the CO. The prepared Ni-Ce-MFI succession had together speeded up the WGSR even at a low temperature of $503 \mathrm{~K}$, and in some cases, the equilibrium conversion was achieved at temperatures less than $548 \mathrm{~K}$. The presence of ceria is believed to provide the oxygen required for promoting nickel activity, which was clear from the TPR profile requiring lower temperature for nickel reduction in Ni-Ce-MFI catalysts. The lowest reduction temperature was observed when $\mathrm{Ni}$ and $\mathrm{Ce}$ were present in equal weight percentages [102]. Iriarte-Velasco et al. used calcined pork bone, composed mainly of hydroxyapatite (HAp), as support for transition metals for WGSR [103]. Both activity and selectivity were studied and correlated with the catalytic properties. The catalytic activity was observed to follow a trend: $\mathrm{Ni}>\mathrm{Co}>\mathrm{Cu}>\mathrm{Fe}$. Moreover, compared to the synthetic hydroxyapatite, the natural support showed a lower Ni methanation activity and increased longterm stability [103].

From this section, it is clear that transition metals can be a good choice for low-temperature WGS reaction. Bimetals and alloys, particularly of $\mathrm{Cu}$ and $\mathrm{Zn}$, in some cases are reported to offer better performance than single metal catalysts. Transition metals normally enhance the redox properties of the catalyst that helps in improving the activity and longterm stability. Addition of alkali metals is also reported to enhance the activity by facilitating the adsorption and dissociation of the water molecule, which tend to be an energy-consuming step for most of the transition metals. Transition metal carbides (e.g., $\left.\mathrm{Co}_{2} \mathrm{C}\right)$, sulfides $\left(\mathrm{MoS}_{2}\right)$ are also reported to perform well for low-temperature WGS reaction. Throughout the previous section related to catalysts, the function of support is found to be quite instrumental in defining the performance of the catalyst. The next section presents a review on the role and recent development in catalyst supports for WGSR. This part is divided into two categories, metal oxide supports and carbon-based supports, for the ease of reading.

\subsection{Type of metal oxide support}

Ceria has been broadly investigated as a support to disperse the noble metals active sites in WGS reaction. $\mathrm{CeO}_{2}$ supported catalysts have shown effective performance with effluent gas streams resulting in low $\mathrm{CO}$ concentrations. Cerium is known to have dynamic oxidation states which can change easily during reaction conditions. Besides, it also has a high oxygen movement and vacancy [104]. Jain et al. investigated the potential of three distinct Pt/Ceria catalysts at $150-450^{\circ} \mathrm{C}$ with a GHSV of $13,360 \mathrm{~h}^{-1}$ to determine the impact of processing techniques and surface area, as well as porosity and crystallite size of ceria on the rate of WGS reaction [105]. In this work, the mesoporous ceria with a crystallite size of $5.8 \mathrm{~nm}$ and synthesized via sol-gel method was found to be the best catalyst with a complete conversion of $\mathrm{CO}$ at $175^{\circ} \mathrm{C}$ (Fig. 8a-c) [105]. Byun et al. prepared a series of $\mathrm{Cu}-\mathrm{ZnO}-\mathrm{CeO}_{2}$ catalysts to investigate the influence of $\mathrm{CeO}_{2}$ addition on lowtemperature WGS reaction performance [106]. These catalysts included a fixed amount of $\mathrm{Cu}(50 \mathrm{wt} \%)$ and different ceria content (from 0 to $40 \%$ ), which affects the $\mathrm{Cu}$ dispersion and binding energy. The result showed that a $10 \mathrm{wt} \%$ cerium could promote catalyst reduction and $\mathrm{CO}$ conversion at low temperatures of $200-400{ }^{\circ} \mathrm{C}$ [106]. Petallidou et al. also investigated the effect of three synthesis methods (sol-gel, pechini, and urea co-precipitation) on $0.5 \mathrm{wt} \% \mathrm{Pt} / \mathrm{Ce}_{0.5} \mathrm{La}_{0.5} \mathrm{O}_{2-\delta}$ (Ce: $\mathrm{La}=1: 1)$ catalyst and used different characterization techniques, such as in situ Raman, temperature-programmed techniques (TPD- $\mathrm{H}_{2}, \mathrm{TPD}-\mathrm{NH}_{3}$, TPD- $\mathrm{CO}_{2}$ ), powder $\mathrm{XRD}$, and oxygen storage capacity (OSC), to thoroughly analyze the properties of the synthesized catalysts. The results revealed that $\mathrm{Pt} / \mathrm{Ce}_{0.5} \mathrm{La}_{0.5} \mathrm{O}_{2-\delta}$ synthesized by urea co-precipitation had the highest $\mathrm{CO}$ conversion activity compared to the other two methods [107].

Schilling and Hess investigated $\mathrm{CeO}_{2}$ support for Au catalyst using operando Raman spectroscopy to understand the role of bulk and surface oxygen in the WGS reaction [111]. They concluded that the presence of $0.5 \mathrm{wt} \% \mathrm{Au} / \mathrm{CeO}_{2}$ catalyst could successfully reduce the Ce support under WGS conditions. Results also revealed the dominant mechanism of the reaction to be the redox-type [111]. The use of 

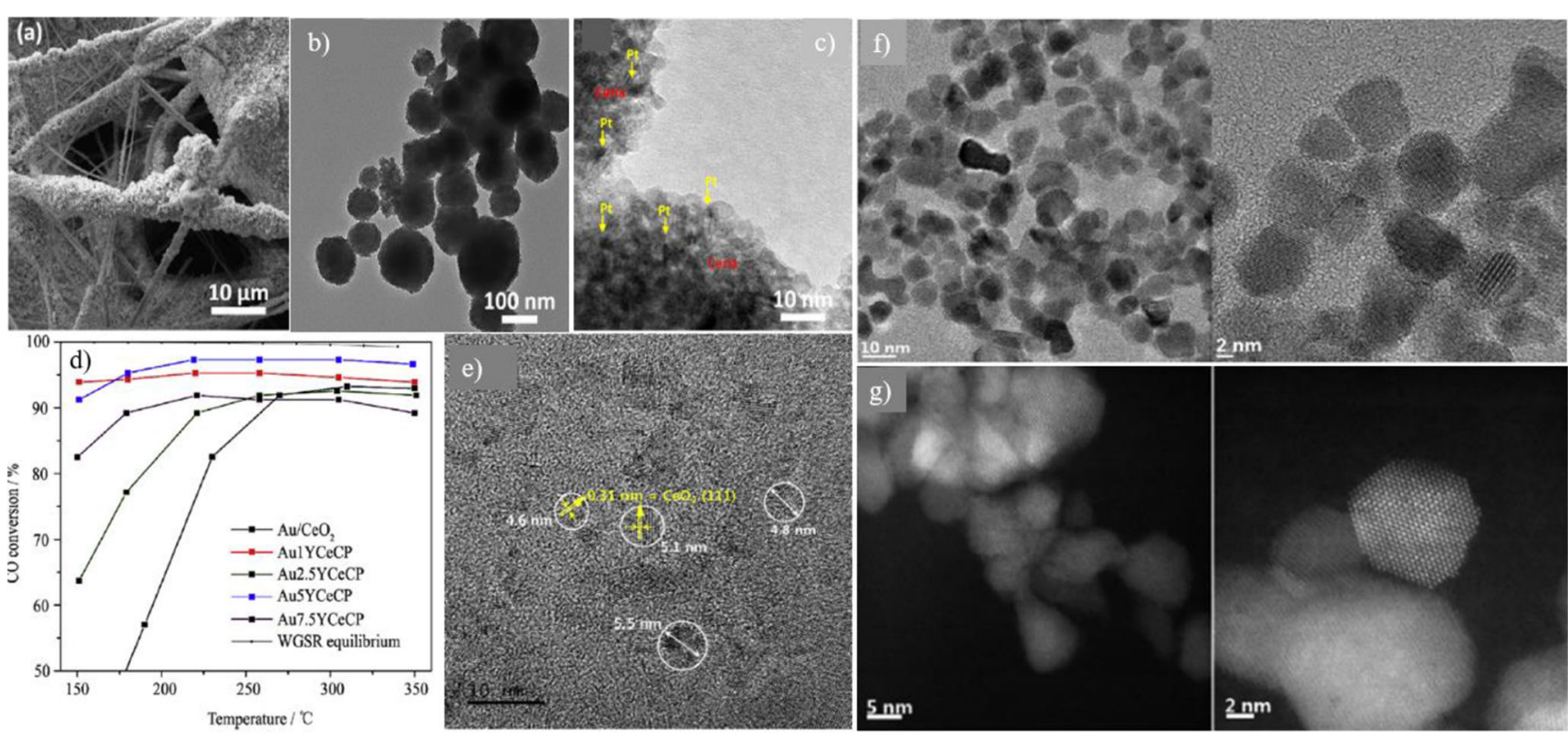

TEM images of the $\mathrm{Cu} / \mathrm{CeO}_{2}$ catalysts prepared by reverse precipitation method [108]. f TEM and HRTEM images of $\mathrm{CuO} / \mathrm{CeO}_{2}$ (ns), $\mathbf{g}$ STEM and HRSTEM images of $\mathrm{CuO} / \mathrm{CeO}_{2}$ (ns) [109] sol-gel after WGS testing [104]. d Temperature dependence of the CO conversion over Au catalysts on Y-doped Ce synthesized by CP [107]. e

mesoporous ceria, both as a catalyst and as a support, is widely seen for different reactions due to a large amount of specific surface area, well-developed nanocrystalline framework, and excellent surface oxygen vacancy compared to the bulk form of ceria [112]. In a study conducted by Li et al., an ordered mesoporous series of ternary metal oxide $\mathrm{Cu}-\mathrm{Mn}-\mathrm{Ce}$ were synthesized using a nano-casting method [113]. It was found that among the tested catalysts, the $\mathrm{Cu}_{0.18} \mathrm{Mn}_{0.02} \mathrm{Ce}_{0.8} \mathrm{O}_{2}$ mesoporous catalyst had the highest activity with almost 100\% CO conversion for low-temperature WGS reaction without any methane production. Moreover, the catalyst was tested for $16 \mathrm{~h}$ TOS with no significant activity loss [113]. In order to understand the effect of modifying ceria by $\mathrm{Y}_{2} \mathrm{O}_{3}$ rare earth on the WGS reaction activity of Au/ceria, a study was conducted by Tabakova et al., in which all the designed catalysts, except for $\mathrm{Au}_{2.5} \mathrm{YCe}$ synthesized by co-precipitation method, showed $>90 \% \mathrm{CO}$ conversion at $180-220{ }^{\circ} \mathrm{C}$ (Fig. 8d) [108].

Ceria with less than $10 \mathrm{~nm}$ particle size with exposure to WGS environment containing $\mathrm{H}_{2} \mathrm{O}$ show high densities of adsorbed -OH group resulting in hydroxylated ceria nanoparticles [114]. Huang et al. showed that hydroxylated ceria nanoparticles are active for WGS reaction without requiring any metal cocatalyst and have a small activation energy of $0.5 \mathrm{eV}$ [115]. Na et al. proposed a single-step reverse precipitation preparation technique to control the physicochemical properties of nano-sized $\mathrm{CeO}_{2}$ as support for low-temperature WGS reaction (Fig. 8e), which resulted in a high surface area support of $162.8 \mathrm{~m}^{2} / \mathrm{g}$ [109]. They compared the catalytic activity with a normal precipitation method synthesized $\mathrm{CeO}_{2}$ by supporting $5 \mathrm{wt} \% \mathrm{Cu}$ on both the supports. The results indicated that the one with the support prepared by reverse precipitation exhibited higher $\mathrm{CO}$ conversion than the $\mathrm{CeO}_{2}$ prepared by normal precipitation method [109].

The ceria support morphology has a significant impact on the properties of the catalysts and can affect the catalytic dispersion, water dissociation, the metallic-base stability, and the metal particle size upon reduction during WGS reaction. In this regard, Yao et al. synthesized three different shapecontrolled $\mathrm{CeO}_{2}$ nanostructured supports with $\mathrm{CuO}$ to catalyze WGSR [110]. The result showed that the nanospheres (NS) ceria support (Fig. 8f, g) had the highest activity and long-term stability in comparison to the nanorods (NR) and nanocubes (NC) [110].

Cámara et al. studied the effect of a novel manganesedoped inverse $\mathrm{CeO}_{2} / \mathrm{CuO}$ catalyst under WGS reaction conditions [116]. The presence of $\mathrm{Mn}$ along with $\mathrm{Cu}$ strongly influenced the physical and chemical properties of the ceria nanoparticles leading to high catalytic activity towards WGS reaction [116]. They also examined $\mathrm{CeO}_{2} / \mathrm{CuO}, \mathrm{Mn}$-doped $\mathrm{CuO}$, and $\mathrm{Zn}$-doped $\mathrm{CuO}$ for WGS catalytic performance, and the effect of $\mathrm{O}_{2}$ and/or $\mathrm{H}_{2}$ present in the reaction mixture. The result of this work demonstrated a positive impact of $\mathrm{Mn}$ and $\mathrm{Zn}$ doping on WGS performance; whereas for the undoped catalyst, $\mathrm{CO}$ conversion enhancement was seen in the presence of some oxygen at low temperature and high $\mathrm{CO} /$ $\mathrm{O}_{2}$ ratio [117].

Tabakova et al. conducted a study aiming to introduce an efficient, cost-effective catalyst of alumina-supported $\mathrm{Cu}-\mathrm{Mn}$ mixed oxides (Fig. 9a, b) synthesized by wet impregnation, where $\mathrm{Au}$ nanoparticles promoters were prepared by the deposition-precipitation approach [118]. According to the 
Fig. 9 a, b HRTEM micrograph of a fresh $\mathrm{Au} / \mathrm{CuMn}(2: 1)$ catalyst [117]. SEM images of $\mathbf{c} \mathrm{CuAl}$ ceramometal and $\mathbf{d}$ CZA oxide catalyst [124]

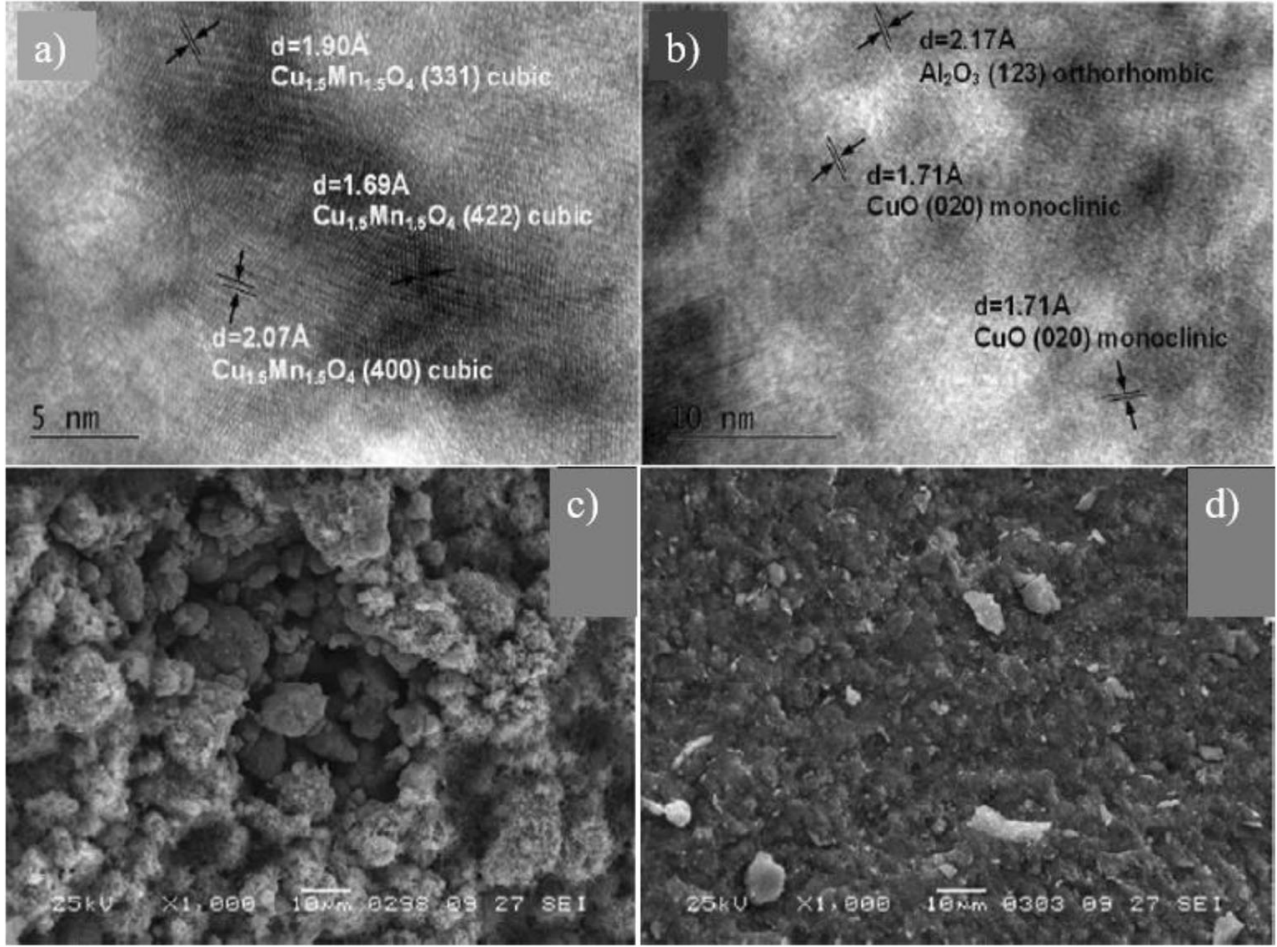

result, the $\mathrm{Au}$ promotional effect was more demonstrated in a sample with a higher amount of $\mathrm{Cu}(\mathrm{Cu}: \mathrm{Mn}$ molar ratio of 2:1) due to the active presence of the two dispersed metallic phases. The high surface area of alumina modified by $\mathrm{Cu}-$ Mn mixed oxides surface fraction also favored the stabilization of dispersed gold nanoparticles. The high activity of this catalyst system makes it capable of practical usages, primarily due to economic viability as it consists of $80 \%$ alumina [118]. Sagata et al. investigated the effect of aluminum oxide and the pore size of the support on the catalytic activity during the low-temperature WGS reaction over $\mathrm{Cu}$ catalyst [119]. They concluded that by decreasing the mesopore size of $\mathrm{Cu} / \mathrm{Al}_{2} \mathrm{O}_{3}$, the catalytic activity increased only when the steam/carbon $(\mathrm{S} / \mathrm{C})$ ratio was 2.2 , whereas the catalytic activity increased in the $\mathrm{S} / \mathrm{C}$ ratio of 4.6 by increasing the mesopore size [119]. One of the important considerations in an industrial sulfur tolerant WGS process is that the reaction conditions, not only catalysts, dictate many of the outcomes such as improvements in production capacity, decreasing production costs, and change in the catalytic activity $[120,121]$. For example, Liu et al. developed Mo-Co/alkali/ $/ \mathrm{Al}_{2} \mathrm{O}_{3}$ for sulfur tolerant WGS reaction that resulted in a steady operation even at $0.2-0.3$ steam to gas ratio. Plant efficiency improvement, enhanced safety, and reduction in steam consumption during $\mathrm{H}_{2}$ production were some of the key achievements [122].

Nano-structural composites of ceramometals (or cermets) can be attractive owing to reported catalytic property improvements compared to the common solid oxide supports. The ceramometals have excellent thermal conductivity and high strength as well as regulated mesoporous structure suitable for catalytic reactions to take place without much transport limitations [123]. Tikhov et al. synthesized porous $\mathrm{CuAlO} /$ $\mathrm{CuAl}$ ceramometals and tested for WGS reaction, where they reported the granulated ceramometals catalytic activity to be comparable with granulated $\mathrm{CuZnAl}$ oxide, owing to a high diffusion permeability (Fig. 9d) [124]. In another study based on low-temperature WGS, they compared catalysts prepared by co-precipitation method and ceramometal $\mathrm{CuAlO} / \mathrm{CuAl}$ catalysts that were made from $\mathrm{CuAl}$ alloy powder (Fig. 9c). The catalysts activity was tested at one bar, using a mixture of CO: $\mathrm{H}_{2} \mathrm{O}: \mathrm{H}_{2}=8: 42: 50$ and at a steam/gas proportion of 0.6 0.7 in both small $(0.14-0.25 \mathrm{~mm})$ and large $(3.2 \times 3.2 \times$ $5 \mathrm{~mm}$ ) portions. The result accordingly showed that the large fraction ceramometal catalyst had doubled the efficiency owing to a greater inner dissemination [125].

Longlong et al. studied the aluminum doping effect in $\mathrm{Cu} /$ $\mathrm{ZnO} / \mathrm{Al}_{2} \mathrm{O}_{3}$ complex synthesized via modified coprecipitation method. The catalyst produced with this method containing $2.5 \%$ co-precipitated $\mathrm{Al}^{3+}$ of total $\mathrm{Cu}$ and $\mathrm{Zn}$ atoms exhibited higher activity and stability in the WGS reaction compared to the commercial sample [126].

Silva et al. studied the impact of $\mathrm{H}_{2} \mathrm{~S}$ on the platinum catalysts performance in WGS reaction. In this regard, they tested Pt-based catalysts with various oxides supports under real conditions, both with and without the presence of $\mathrm{H}_{2} \mathrm{~S}$, thereafter extended the experiment further in the absence of $\mathrm{H}_{2} \mathrm{~S}$ to see if the catalyst performance can be recovered [127]. They found that zirconia incorporation to $\mathrm{CeO}_{2}$ showed increased 
sulfur tolerance as well as preserved high activity. They concluded that in the presence of $\mathrm{H}_{2} \mathrm{~S}$, the $\mathrm{Pt} / \mathrm{Ce}_{0.25} \mathrm{Zr}_{0.75} \mathrm{O}_{2}$ showed the best performance in terms of lower deactivation, higher activity, and complete recovery, whereas under contaminated conditions, $\mathrm{Pt} / \mathrm{CeO}_{2}$ was not suitable anymore because of a higher deactivation rate [127].

Some reports indicate that the reducible oxides and solids providing oxygen vacancies can enhance the employed metal activity for the WGS reaction [128]. For example, GarcíaMoncada et al. presented a multicomponent catalyst designed using different active phases $(\mathrm{Cu}, \mathrm{Pt}$, or $\mathrm{Au})$ and different ionic conductors for WGS reaction [129]. The results of the study demonstrated that the ionic conductor, along with an appropriate catalyst, is necessary to the water supply as it potentiates activation of water as well as overall performance. The influence trend of $\mathrm{ZrEu}>\mathrm{MoEu}>\mathrm{NbEu}$ was observed for the ionic conductors, no matter the nature of the catalyst (Fig. 10a-c). The $\mathrm{ZrEu}$ ion was the most suitable conductor for the WGS reaction owing to the more oxygen vacancies provided by having a sub-stoichiometric structure [129]. A similar result was also presented by González-Castaño et al. in 2017 by using a bi-doped of $\mathrm{Zr}$ and $\mathrm{Fe}$ [130]. Yun and Guliants synthesized $\mathrm{ZrO}_{2}$-supported Mo sulfide (Mo-S/ $\mathrm{ZrO}_{2}$ ) WGS catalysts using incipient wetness impregnation approach with different $\mathrm{MoO}_{3}$ surface coverage (Fig. 10d-f). The CO conversion in WGS reaction over these catalysts increased with the presence of Mo content up to the monolayer coverage that showed a good correlation with the Mo sulfidation extent [131].

Molybdenum (Mo) and Molybdenum oxide $\left(\mathrm{MoO}_{\mathrm{x}}\right)$ as promoters are reported to improve the performance of Ptbased WGS reaction catalysts (Fig. 11a) [132]. Pt-Mo/ $/ \mathrm{SiO}_{2}$ prepared with the impregnation-reduction technique have been used as effective catalysts in low-temperature (below $300{ }^{\circ} \mathrm{C}$ ) WGS reaction. Pt nanoparticles with Mo promotion showed higher activity than $\mathrm{Pt} / \mathrm{SiO}_{2}$ due to an improvement in Pt dispersion as well as a synergistic effect in Pt-Mo system that were found to correlate with the atomic ratio of $\mathrm{Mo} / \mathrm{Pt}$ (Fig. 11b) [132]. Marras et al. used two different types of porous silica, namely aerogel and cubic mesostructured, as supports for $\mathrm{Cu}$-based nanoparticles that were tested for WGS reaction at $200-350{ }^{\circ} \mathrm{C}$ [133]. The catalytic performance was found to be influenced by the ability of the support matrices to disperse the copper nanoparticles. The results showed that the silica aerogel was a highly stable matrix throughout the catalytic cycles with a constant $\mathrm{CO}$ conversion [133].

$\mathrm{TiO}_{2}$ is considered a good choice for catalyst support on the basis of as low-cost, non-toxic, and chemically stable nature. Some supports such as $\mathrm{CeO}_{2}$ with variable oxidation states tend to be more effective only under specific conditions [134]. During the low-temperature WGSR, some metals,
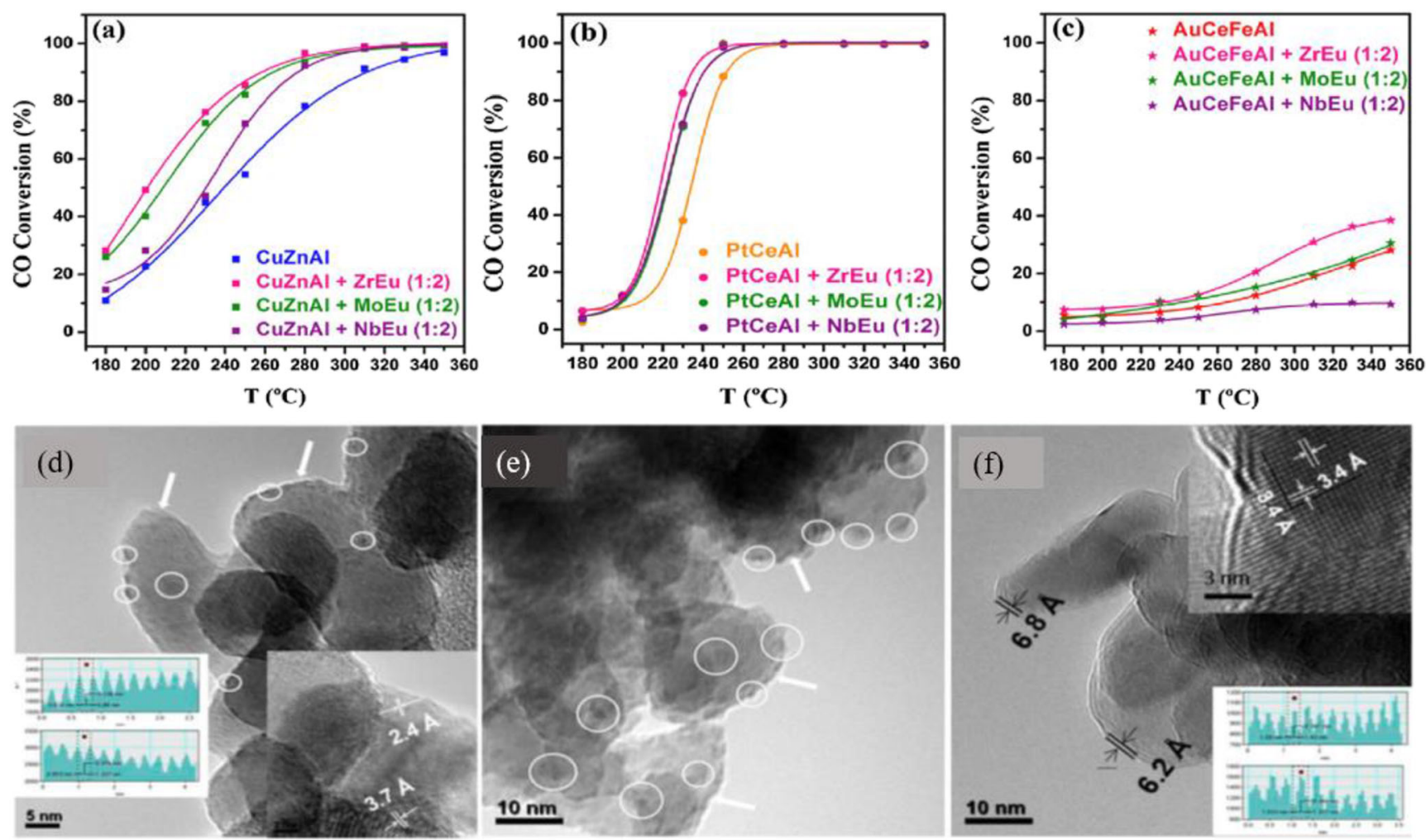

Fig. 10 a-c Temperature dependence of the CO conversion over a CuZnAl, b PtCeAl, and $\mathbf{c} \mathrm{AuCeAl}$; bare catalyst' activity and their mixtures with different ionic conductors. d-f TEM images of ZrO2 supported d Mo2-S, e Mo5-S, and f Mo15-S [130]

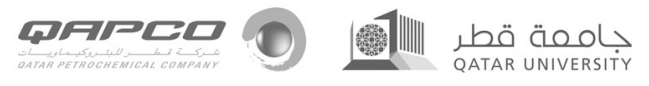


Fig. 11 a Schematic of $\mathrm{Pt}$ nanoparticles along with $\mathrm{MoO}_{\mathrm{x}}$ nano-patches. b Temperature dependence of the $\mathrm{CO}$ conversion over different catalysts and $\mathrm{Mo} / \mathrm{Pt}$ atomic ratios [131]

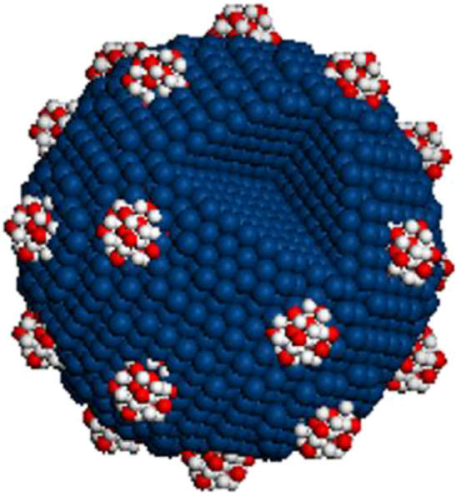

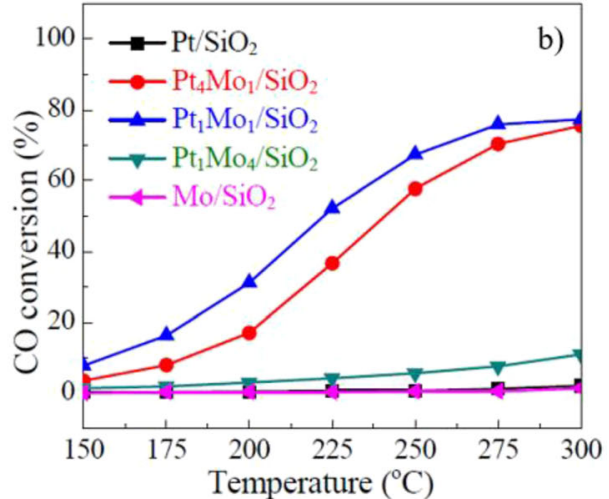

e.g., gold nanoparticles, tend to agglomerate even on rigid support like $\mathrm{TiO}_{2}$ which has a higher ability to disperse them; nonetheless, this effect is reported to depend on the catalyst synthesis method as well [135]. For example, in a study conducted by Pérez et al., $\mathrm{Au} / \mathrm{TiO}_{2}$ was synthesized by different methods and Au loading was also controlled by three methods (double impregnation method (DIM), deposition-precipitation (DP), and liquid phase reductive deposition (LPRD)). The catalysts were evaluated for low-temperature WGSR and compared with the commercial sample provided by the World Gold Council (WGC) (Fig. 12a). The results revealed that the $\mathrm{Au} / \mathrm{TiO}_{2}$ synthesized by the DP (Fig. 12b) method with $2.36 \%$ Au showed $85 \% \mathrm{CO}$ conversion at $300{ }^{\circ} \mathrm{C}$, while the WGC sample had just about $52 \%$ CO conversion under the same conditions [135]. Li et al. synthesized mesoporous, nanocrystalline composite catalysts of $\mathrm{K} / \mathrm{Pd} / \mathrm{TiO}_{2}$ with a)

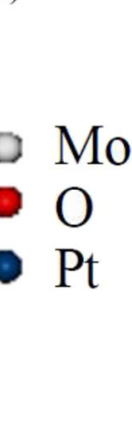

different $\mathrm{Pd}$ molar ratio and tested their catalytic activity towards the low-temperature WGS reaction [136]. All the samples showed almost zero methane formation, whereas the inclusion of $\mathrm{K}$ in $\mathrm{Pd}$ caused a reduction in sintering, and supporting the $\mathrm{Pd}$ on smaller $\mathrm{TiO}_{2}$ particle size resulted in better catalytic performance [136].

Apart from the well-known oxides, such as $\mathrm{Al}_{2} \mathrm{O}_{3}, \mathrm{SiO}_{2}$, $\mathrm{ZrO}_{2}, \mathrm{CeO}_{2}$, and $\mathrm{TiO}_{2}$, manganese oxides have also been reported as supports for low-temperature WGS reaction. The role of oxygen vacancies in manganese oxides has been critical, effective, economically favorable, and in some cases competitive to $\mathrm{CeO}_{2}$ [137]. In this regard, Shan et al. reported a relatively good catalytic activity of $\mathrm{Pd}$ and $\mathrm{Pt}$ nanoparticles supported on $\alpha-\mathrm{MnO}_{2}$ nanorods (termed as $\mathrm{Pd} / \alpha-\mathrm{MnO}_{2}$ and $\mathrm{Pt} / \alpha-\mathrm{MnO}_{2}$ ) prepared by precipitation deposition method at $300{ }^{\circ} \mathrm{C}$ for WGSR with low-temperature $\left(140-350{ }^{\circ} \mathrm{C}\right)$, which
Fig. 12 HRTEM images for both fresh and spent $\mathrm{Au} / \mathrm{TiO}_{2}$ catalysts: a WGC, b DP-2.36\% [135]

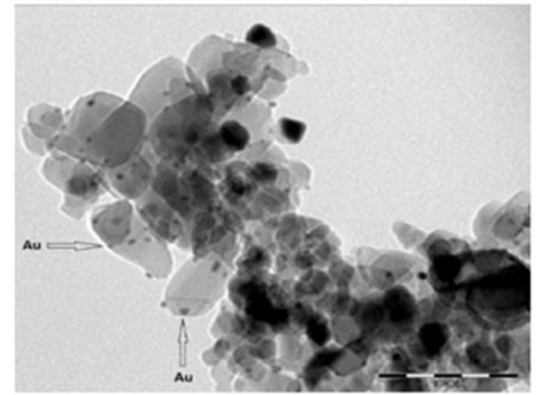

(fresh sample)

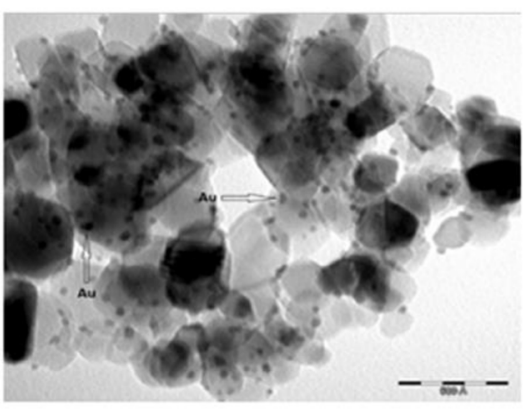

(fresh sample) (a)

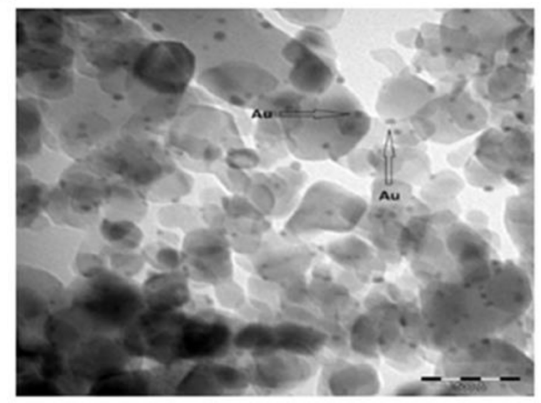

(spent sample)

(b)

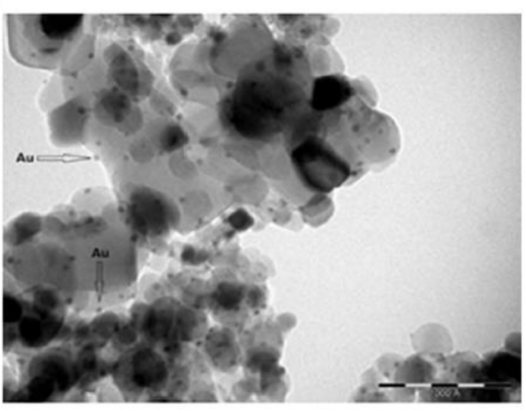

(spent sample) 
were comparable to $\mathrm{Pd} / \mathrm{CeO}_{2}$ and $\mathrm{Pt} / \mathrm{CeO}_{2}$. The surface oxygen vacancies density of the catalysts generally remained at $10-15 \%$ during the WGS reaction [137]. Poggio-Fraccari et al. evaluated copper and nickel separately as monometallic catalysts supported on cerium-manganese mixed oxides through a WGS reaction, where they found that both $\mathrm{Cu}$ and Ni performed best on $\mathrm{MnO}_{\mathrm{x}}-\mathrm{CeO}_{2}$ oxides support with $30 \%$ Mn:Ce molar ratio [138]. $\mathrm{Pd} / \mathrm{CeO}_{2}$ catalysts are believed to show irreversible deactivation in the WGS reaction owing to losses in the metal surface area. Some reports suggest the use of transition metals as additives in $\mathrm{Pd} / \mathrm{CeO}_{2}$ to counter the irreversible deactivation [139]. Xiao et al. tested $\mathrm{PdO} / \mathrm{MnO}_{\mathrm{x}} /$ $\mathrm{CeO}_{2}-\mathrm{ZrO}_{2}$ catalyst along with a series of other catalysts as references (e.g., $\mathrm{PdO} / \mathrm{CeO}_{2}-\mathrm{ZrO}_{2}, \mathrm{PdO} / \mathrm{Al}_{2} \mathrm{O}_{3}, \mathrm{PdO} / \mathrm{MnO}_{x} /$ $\mathrm{Al}_{2} \mathrm{O}_{3}, \mathrm{CeO}_{2}-\mathrm{ZrO}_{2}$, and $\mathrm{MnO}_{x} / \mathrm{CeO}_{2}-\mathrm{ZrO}_{2}$ ) [140]. They reported an enhancement in the WGS activity by using manganese oxide, which possibly could be due to an improvement in the redox property in presence of Pd-Mn and particularly MnCe interactions. The other reason for catalytic performance enhancement was attributed to the formation of metallic Pd species because of the electron-donating effect of $\mathrm{MnO}_{\mathrm{x}}$ neighbor, which facilitates water dissociation [140]. Lanthanum is also reported to have a unique electronic structure and oxygen storage capability to act as co-catalysts, where it can store as well as release oxygen during oxidation-reduction reactions. In a study conducted by Runxia et al., the effects of La loading on $\mathrm{Cu}-\mathrm{Mn}$ catalysts towards low-temperature WGS reaction were investigated, and the results showed significant improvement in the catalyst activity by using $0.5 \mathrm{~mol} \% \mathrm{La}$ [141]. The introduction of La resulted in an increase in the dispersion of $\mathrm{Cu}$ on the catalyst surface, as well as a more uniform distribution of $\mathrm{Cu}$ and $\mathrm{Mn}$ in the catalyst [141].

\subsection{Carbon-based supports}

Carbon, in different forms, has gained significant research interest as a support for active sites in catalysis [142]. An investigation, by Zugic et al., on Pt supported on oxygenated multi-walled carbon nanotubes (MWNTs) indicates that platinum can be activated by controlled addition of alkali promotor (Na) on MWCNTs (Fig. 13a) [143]. Pt on MWCNs without $\mathrm{Na}$ was however reported to be not active for the WGS reaction. The sample prepared by suspending MWNTs $\left(\mathrm{C}_{\mathrm{N}}\right)$ in the $\mathrm{HNO}_{3}$ solution for $2 \mathrm{~h}$ and then dissolving in $1 \mathrm{M}$ sodium acetate with a heat-treatment at $800^{\circ} \mathrm{C}(\mathrm{Pt} /$ $800-\mathrm{Na}-2 \mathrm{hr}-\mathrm{C}_{\mathrm{N}}$; Fig. 13b, c) was found to have the highest WGS activity (Fig. 13d) [143]. In another study, they also reported a direct promotional impact of sodium on the WGS platinum activity and stability when supported on oxygen-free $\mathrm{C}_{\mathrm{N}}$. The co-impregnation of $1 \mathrm{wt} \% \mathrm{Pt}$ and $\mathrm{Na}$ on the annealed nanotubes ( $1 \mathrm{wt} \% \mathrm{Pt}_{1} \mathrm{Na}_{6} / 1000-2 \mathrm{~h}-\mathrm{C}_{\mathrm{N}}$; Fig. $13 \mathrm{e}$, f) resulted in an exceptionally high catalytic activity in WGSR [144].
Dongil et al. examined two commercial $\mathrm{Ni} / \mathrm{CeO}_{2} / \mathrm{CNT}$ catalysts for low-temperature WGSR; moreover, they also used activated carbon for comparison [145]. They demonstrated that CNTs improved the dispersion of ceria, leading to a better $\mathrm{CO}$ activity than the ceria used with activated carbon. Furthermore, in conditions where $\mathrm{CO}_{2}$ and $\mathrm{H}_{2}$ exist in the feed, the activity decreased slightly, and methanation was discovered at temperatures only above $573 \mathrm{~K}$ [145].

Carbon nanofibers (CNF) is another promising alternative to metal oxide-based supports due to the unique structural characteristics that enhance the metal and support interactions. They also have high mechanical strength, high electrical conductivity, and specific surface area, which is suitable for formation and anchoring of smaller metal nanoparticle [146]. Oliveira, Valençaa, and Vieira studied both $\mathrm{Cu} / \mathrm{CNF}$ and $\mathrm{Cu} / \mathrm{Al}_{2} \mathrm{O}_{3}$ catalysts for the WGS reaction at a temperature range of 398-573 K [147]. In the case of the lowest evaluated water partial pressure and $\mathrm{H}_{2} \mathrm{O}: \mathrm{CO}$ ratio of $3.1, \mathrm{Cu} / \mathrm{CNF}$ exhibited the highest activity. In the WGS reaction, however, $5 \% \mathrm{Cu} / \mathrm{Al}_{2} \mathrm{O}_{3}$ exhibited better results owing to the support hydrophobicity of $\mathrm{Cu} / \mathrm{CNF}$ that prevents water adsorption [147].

Graphitic oxides are also reported to enhance the catalytic performance due to their surface chemical functions and confinement effects [149]. Dongil et al. successfully investigated the low-temperature WGS reaction using both binary $\mathrm{Ni} /$ Graphene and ternary $\mathrm{Ni}-\mathrm{CeO}_{2} /$ graphene systems with $5 \mathrm{wt} \% \mathrm{Ni}$ and $20 \mathrm{wt} \% \mathrm{CeO}_{2}$ and compared them with $\mathrm{NiCeO}_{2}$ catalyst [148]. The catalytic activity improved with sodium addition in the presence of $\mathrm{Ce}\left(\mathrm{Ni}-\mathrm{CeO}_{2} / \mathrm{G}-\mathrm{Na}\right)$, possibly due to the promotional effect of $\mathrm{Na}$ in facilitating ceria reduction (Fig. 14) [148]. Pastor-Perez, Buitrago-Sierra, and Sepulveda-Escribano dispersed different loadings of cerium oxide over activated carbon and investigated their catalytic behavior [150]. The synthesis resulted in small ceria particles, high surface area, and an easier reduction of ceria in the presence of Ni. The catalysts, Ni supported on different loading of $\mathrm{CeO}_{2} / \mathrm{C}$ as well as $\mathrm{Ni} / \mathrm{CeO}_{2}$ (Fig. $15 \mathrm{a}$ ) were examined for the low-temperature WGSR. The optimum amount of $\mathrm{CeO}_{2}$ loading was determined to be $20 \mathrm{wt} \%$ (Fig. 15b); however, in the realistic conditions, in the presence of $\mathrm{CO}_{2}$, the catalyst with

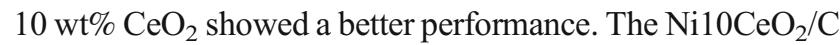
catalyst was found to have a $40 \% \mathrm{CO}$ conversion after a $150-\mathrm{h}$ stability test at $493 \mathrm{~K}$ (Fig. 15c, d) [150]. In a comparative study conducted by Pastor-Pérez et al. on the WGS performance using $\mathrm{Ni} / \mathrm{CeO}_{2}$ bulk and $\mathrm{Ni} 20 \mathrm{CeO}_{2} / \mathrm{C}$, the carbonsupported catalyst showed far more activity than the one without the carbon support which can be due to its capacity to store oxygen. Moreover, the $\mathrm{Ni}-\mathrm{CeO}_{2} / \mathrm{C}$ stability (Fig. $15 \mathrm{e}$, f) was evaluated under practical conditions, revealing a considerable catalyst activity loss, owing to the Ni particles sintering [151].

A summary table is provided below to enlist the different catalysts used in the review. The synthesis methods and 
a)

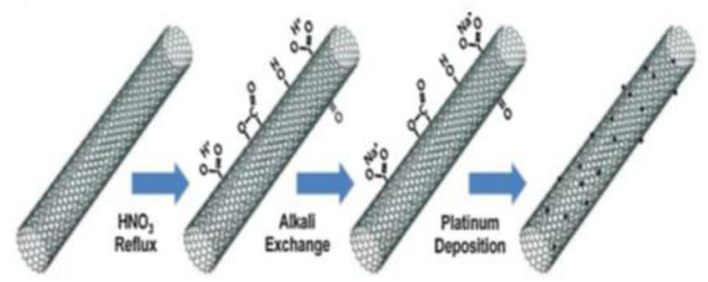

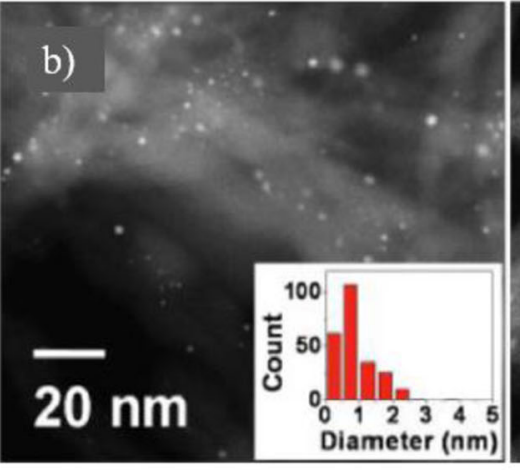
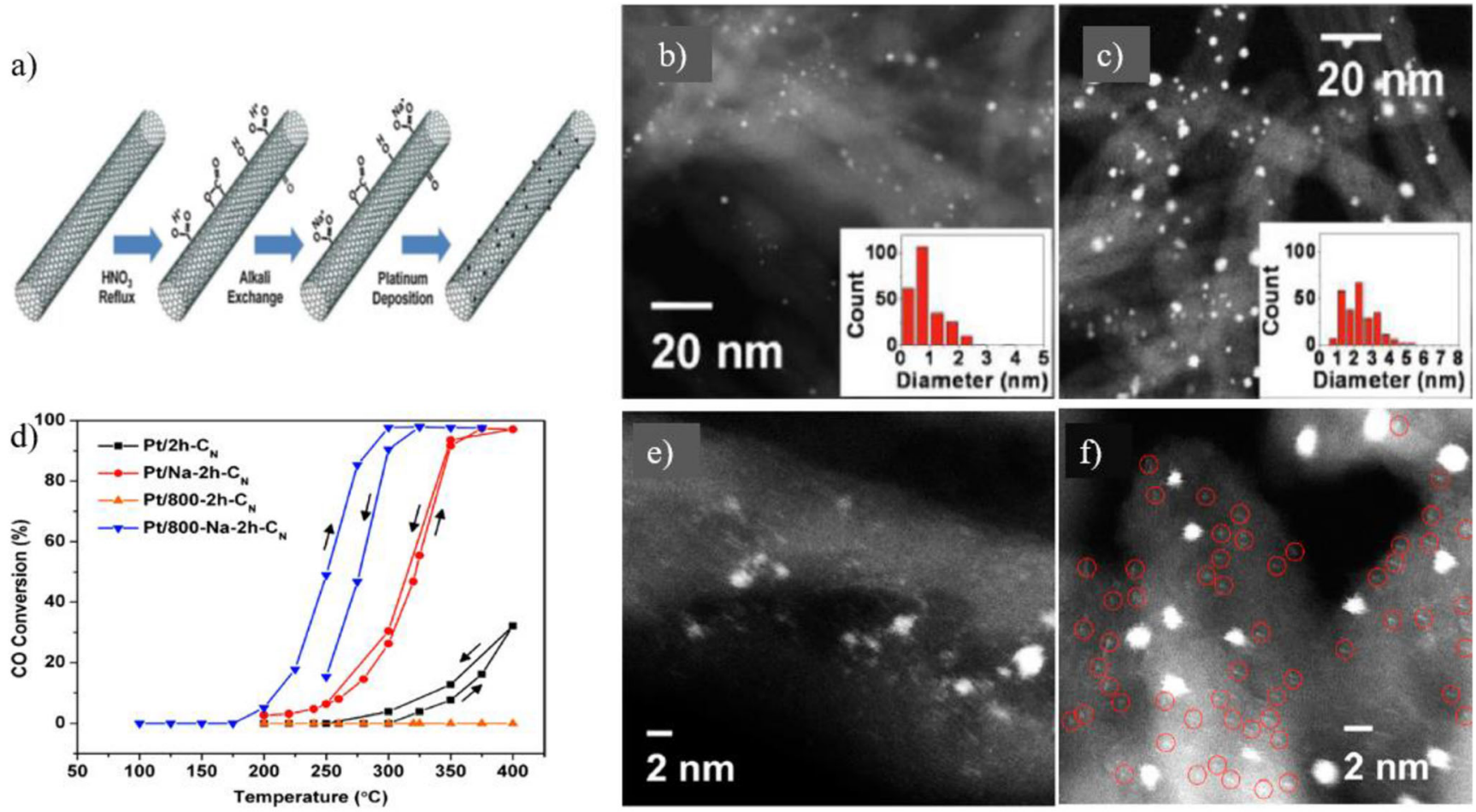

Fig. 13 a Preparation schematic of alkali-promoted Pt/MWNT catalysts. b, $\mathbf{c}$ HAADF-STEM images of $\mathbf{b}$ fresh $\mathrm{Pt} / 800-2 \mathrm{~h}-\mathrm{C}_{\mathrm{N}}$ and $\mathbf{c}$ used $\mathrm{Pt} / 800-$ $2 \mathrm{~h}-\mathrm{C}_{\mathrm{N}}$. $\mathbf{d}$ Temperature dependence of the $\mathrm{CO}$ conversion over Pt catalysts

on different supports [143]. e, f HAADF-STEM images of e fresh $\mathrm{Pt}_{1} \mathrm{Na}_{6}$ $1000-2 \mathrm{~h}-\mathrm{C}_{\mathrm{N}}$ and $\mathbf{f}$ used $\mathrm{Pt}_{1} \mathrm{Na}_{6} / 1000-2 \mathrm{~h}-\mathrm{C}_{\mathrm{N}}$ (red circles are atomically scattered species) [144]
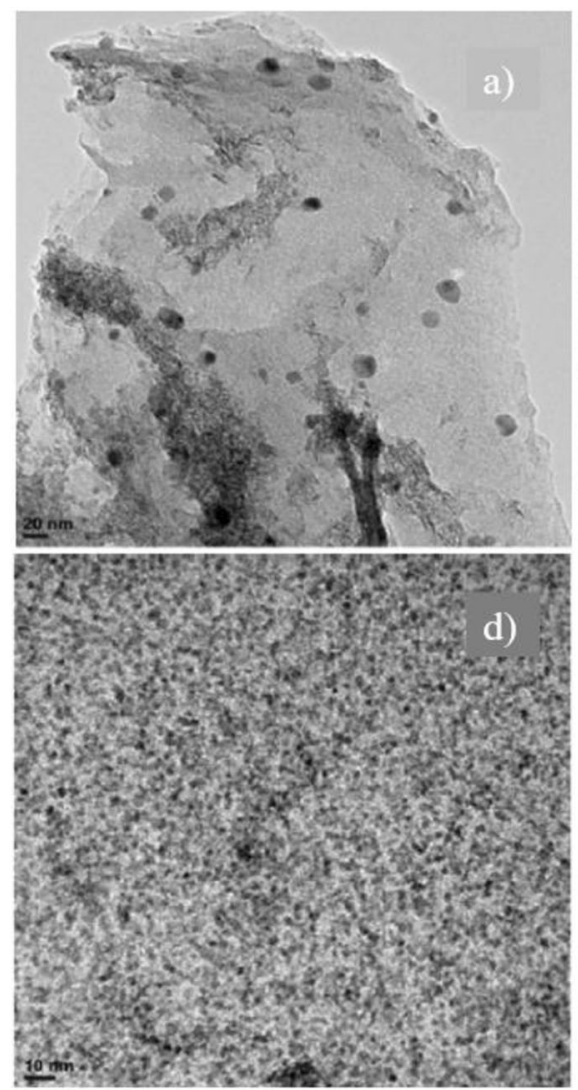
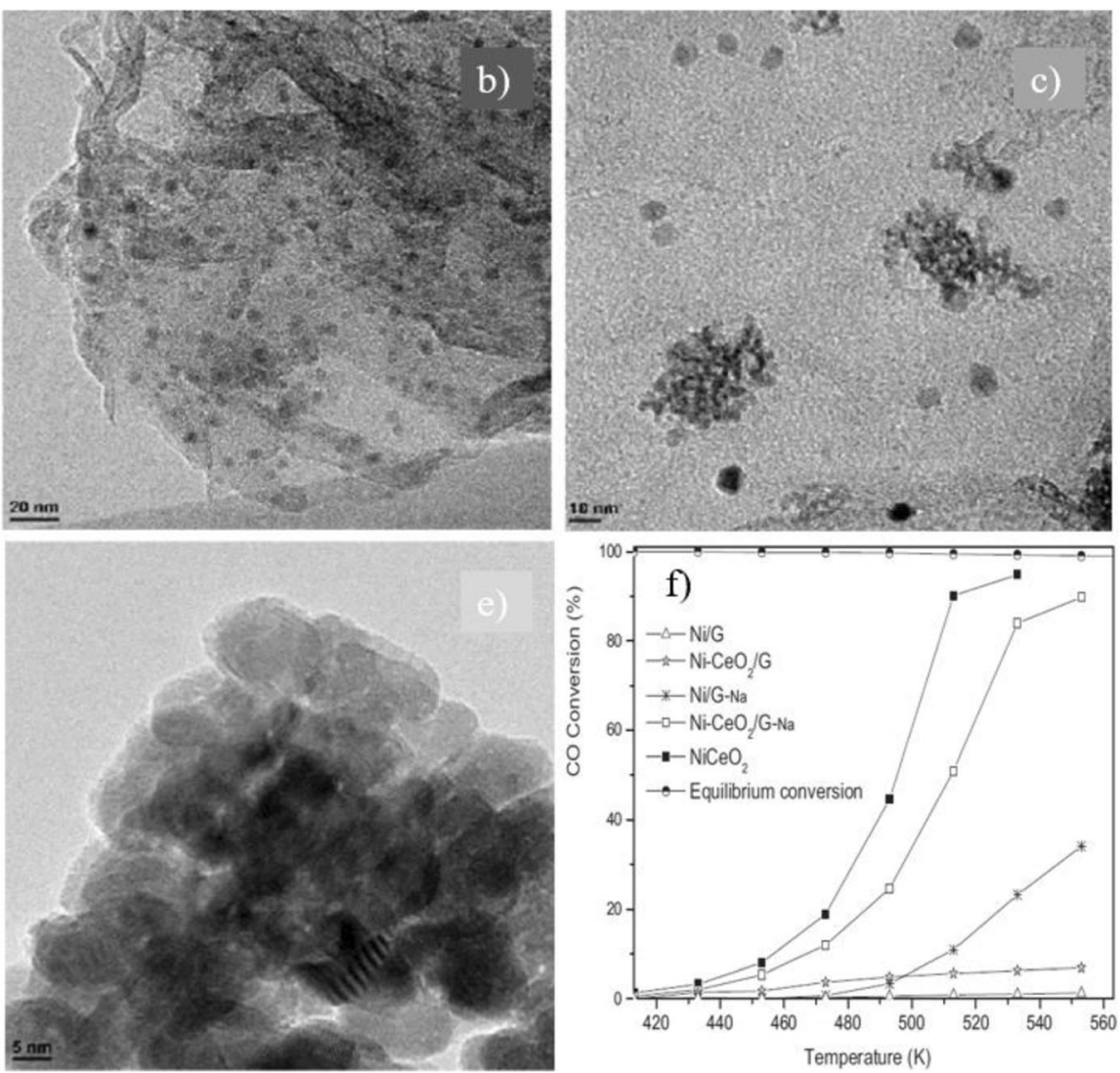

Fig. 14 a-e TEM micrographs of a Ni/G-Na, b Ni/G, $\mathbf{c} \mathrm{Ni}-\mathrm{CeO}_{2} / \mathrm{G}, \mathbf{d} \mathrm{Ni}-\mathrm{CeO}_{2} / \mathrm{G}-\mathrm{Na}, \mathbf{e} \mathrm{NiCeO}_{2}$, and $\mathbf{f}$ temperature dependence of the $\mathrm{CO}$ conversion over different catalysts [147]

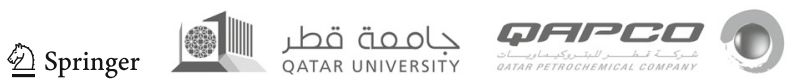



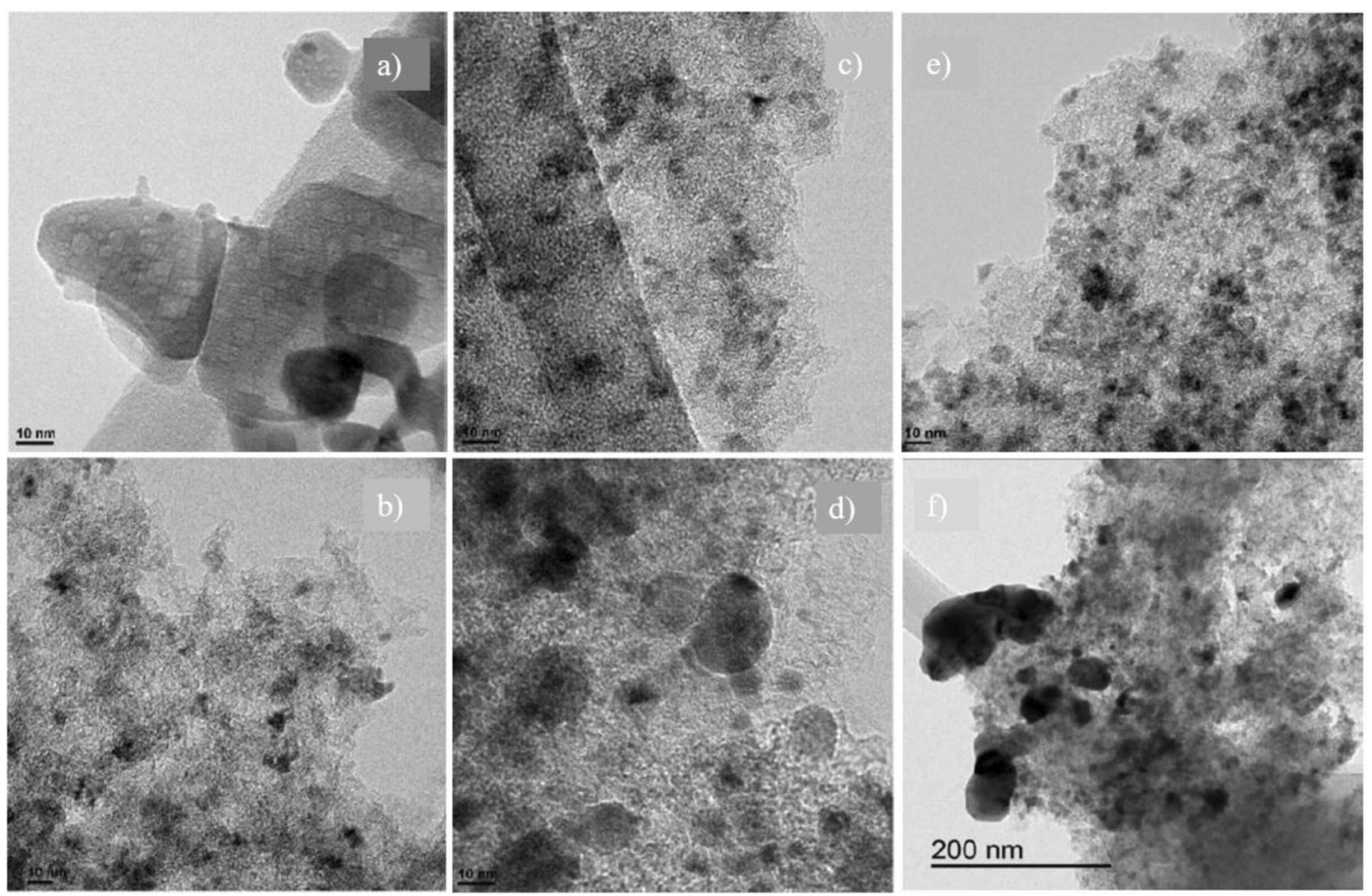

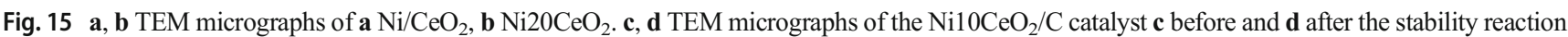
test at $220{ }^{\circ} \mathrm{C}$ [149]. e, $\mathbf{f}$ TEM micrographs of the $\mathrm{Ni}-\mathrm{CeO} 2 / \mathrm{C}$ catalyst $\mathbf{e}$ before and $\mathbf{f}$ after the stability reaction test at $250{ }^{\circ} \mathrm{C}[150]$

experimental conditions under which the catalysts were evaluated for WGS reaction are also provided along with the key results in a convenient way to compare their performance (Table 1).

To understand the effect of nanostructure and shape of active metals at nanoscale, following table is constructed by coming the literature reports on similar materials with different nanostructures and morphology (Table 2).

\subsection{Summary and future outlook}

WGSR is one of the commonly used industrial reactions for hydrogen production, and by some estimates, approximately $10 \%$ of the annual world energy consumption by 2030 will be linked to the WGS reaction [153]. The WGSR is a wellestablished procedure in conventional chemical/hydrocarbon industries for the production of ammonia, methanol, hydrogen, saturated hydrocarbons, and many other chemicals and petrochemicals. Thermodynamically, WGSR should be conducted at low temperatures for higher hydrogen selectivity; however, low temperature reduces the kinetics rate and thereby increases the required amount of catalysts to achieve high CO conversions [154]. The recent few years have seen considerable growth in nanomaterials and chemical characterization techniques, leading to unique details that were unheard of before. The catalysis community has benefitted significantly with these developments in understanding the dynamic changes in the structure of the catalysts in situ during the reaction conditions, in a more realistic environment than under ultra-high vacuum. Herein, we provided a review of the recent development in the catalysts used for low-temperature WGSR focusing on the nanostructure of the catalysts along with other key factors influencing catalytic performance, such as synthesis technique, nature of active site/phase and support, and reaction environment.

Introducing support materials, especially those with controlled and uniform nanostructured morphology, onto various metal, non-metal, and carbon-based catalysts can be beneficial in achieving catalytic systems with larger surface area and abundant active sites resulting in higher $\mathrm{CO}$ conversion activity, and long-term stability. Supports with oxygen storage capacity, such as $\mathrm{CeO}_{2}$, are particularly favorable for lowtemperature WGSR. Synergistic effects of combining different catalysts or adding various alkali promoters not only improve the performance of the existing catalysts but also help in reducing the overall cost by introducing earth-abundant elements in developing new types of highly active and stable catalysts. Notably, the introduction of promoters leads to a high chemical and thermal stability for these catalysts by limiting the sintering of smaller particles under severe reaction conditions. Many of the recent work focused on single-atom catalysis to achieve a very high dispersion of the active sites encapsulated on the support structure, which seems to achieve higher turnover rates compared to bigger nanoparticles. 


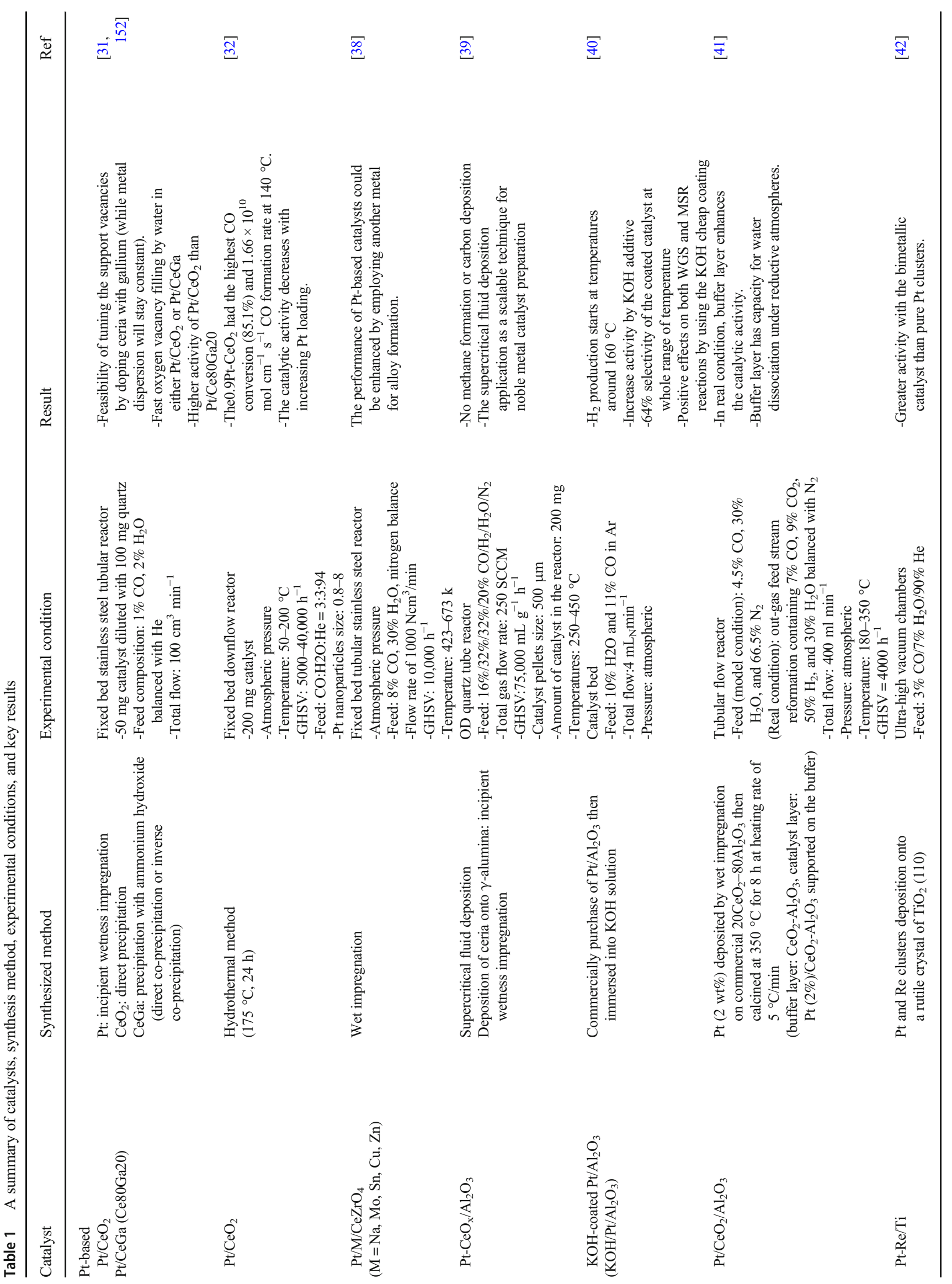




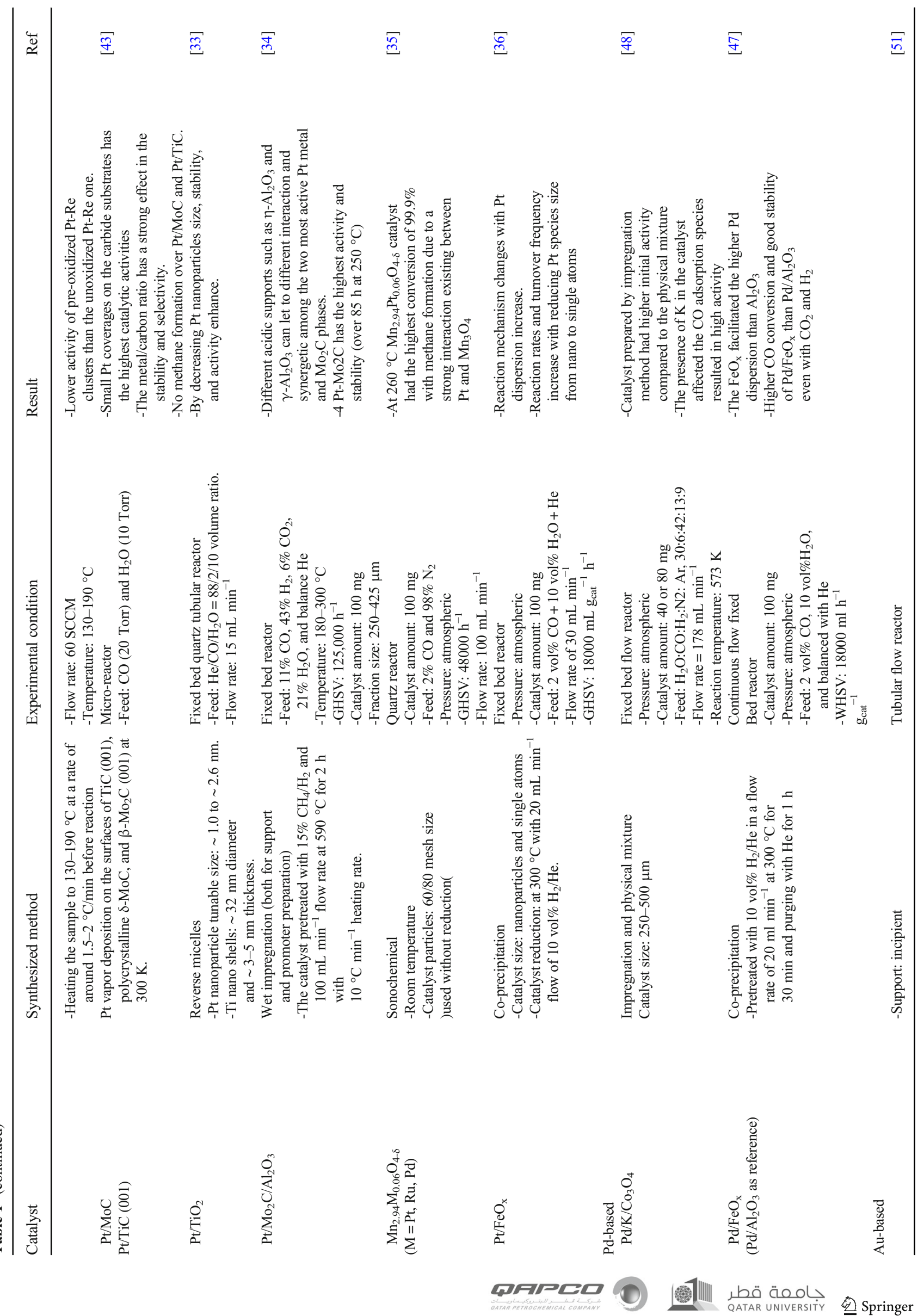




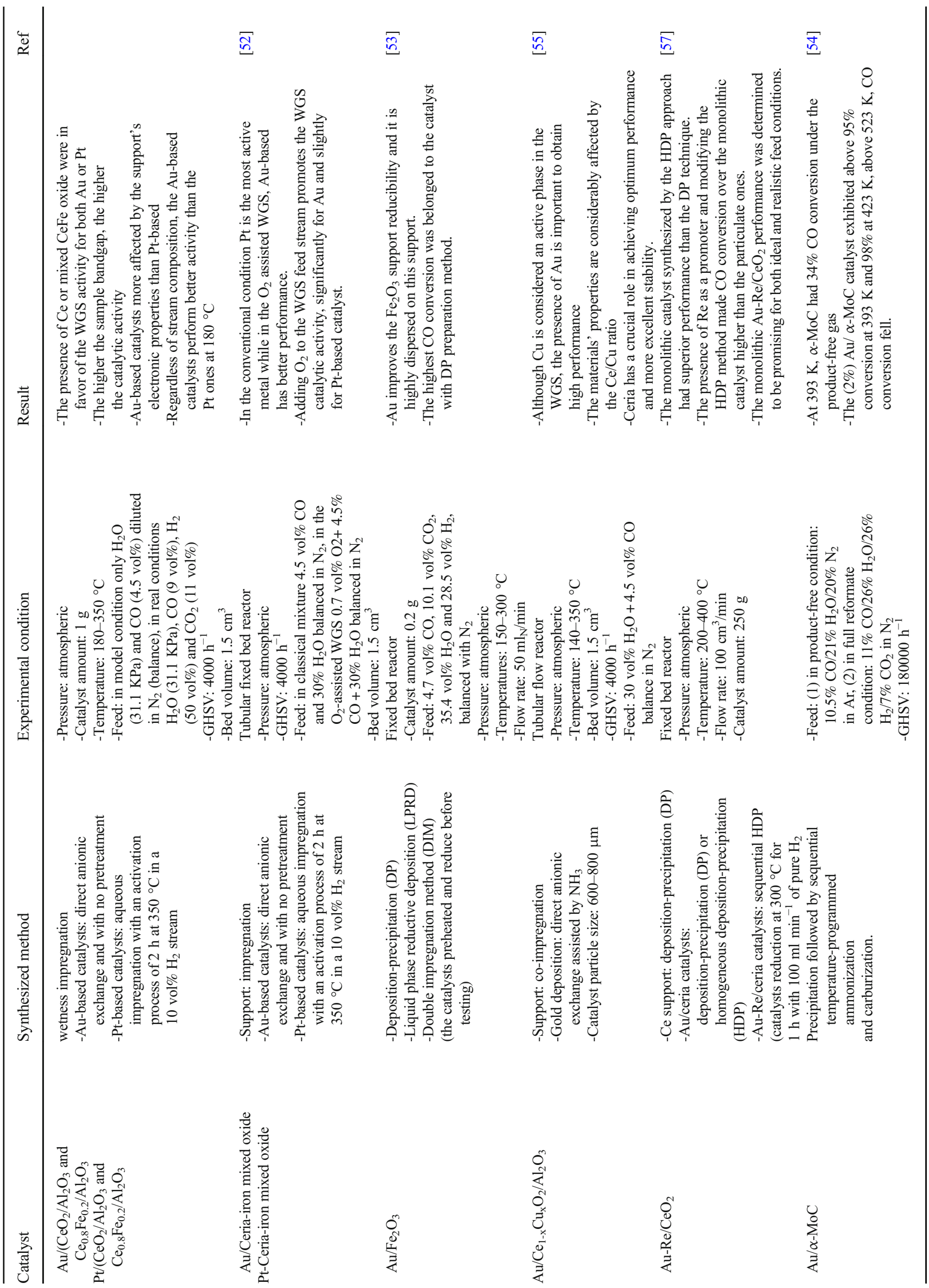




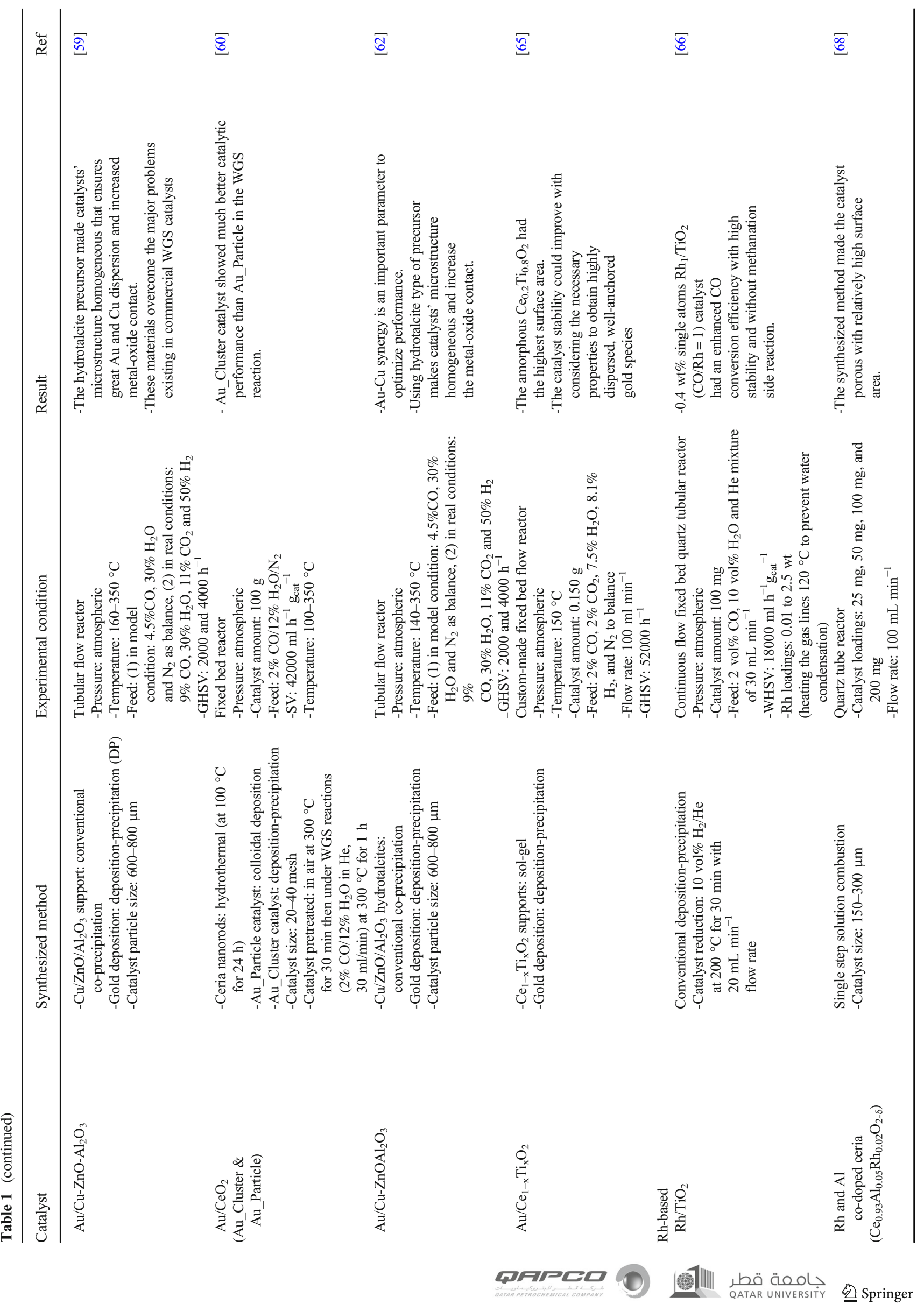



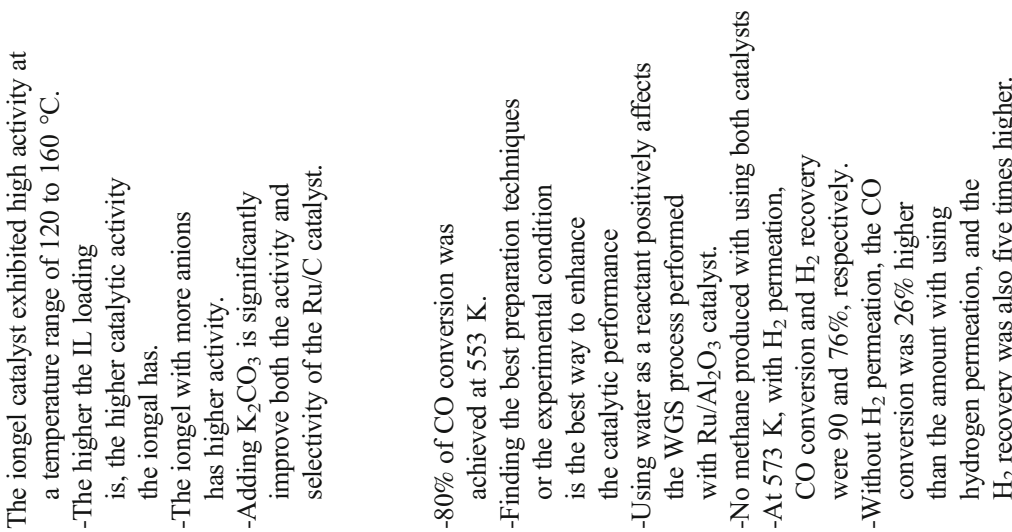

$\overline{\bar{\infty}} \quad \underline{\widetilde{\infty}}$

$\Xi$

ब。․․

$\bar{\Xi}$

$\stackrel{E}{\Xi}$

离 要

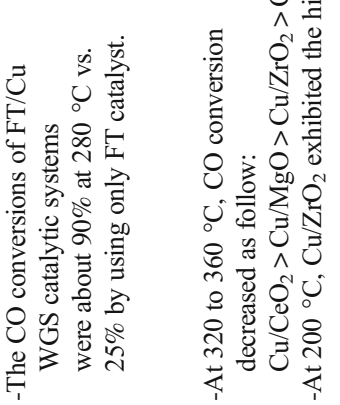

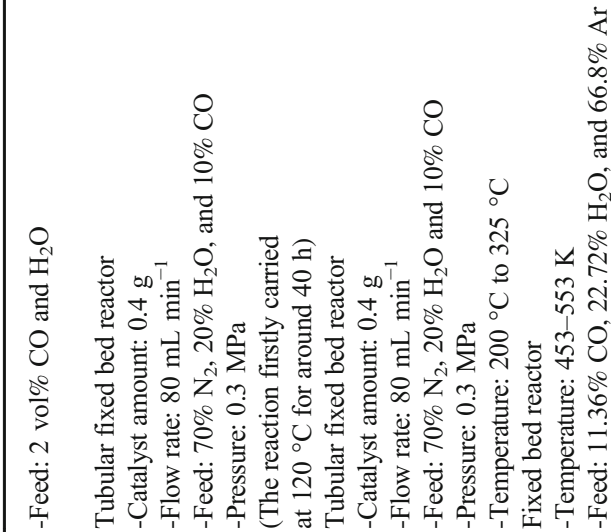

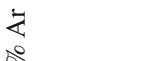

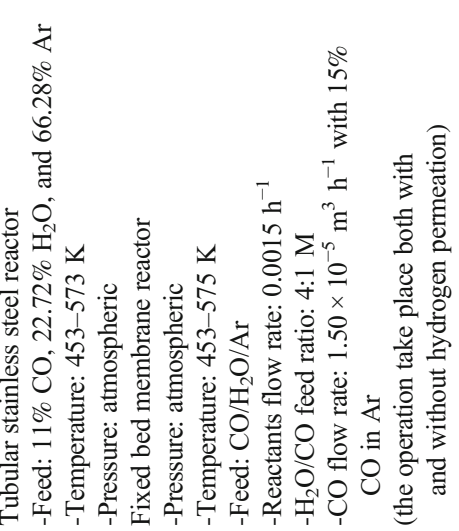

ำ ํํำ 年

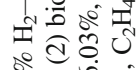

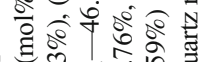

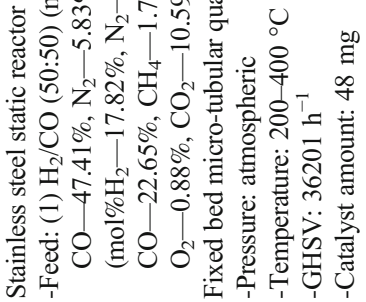
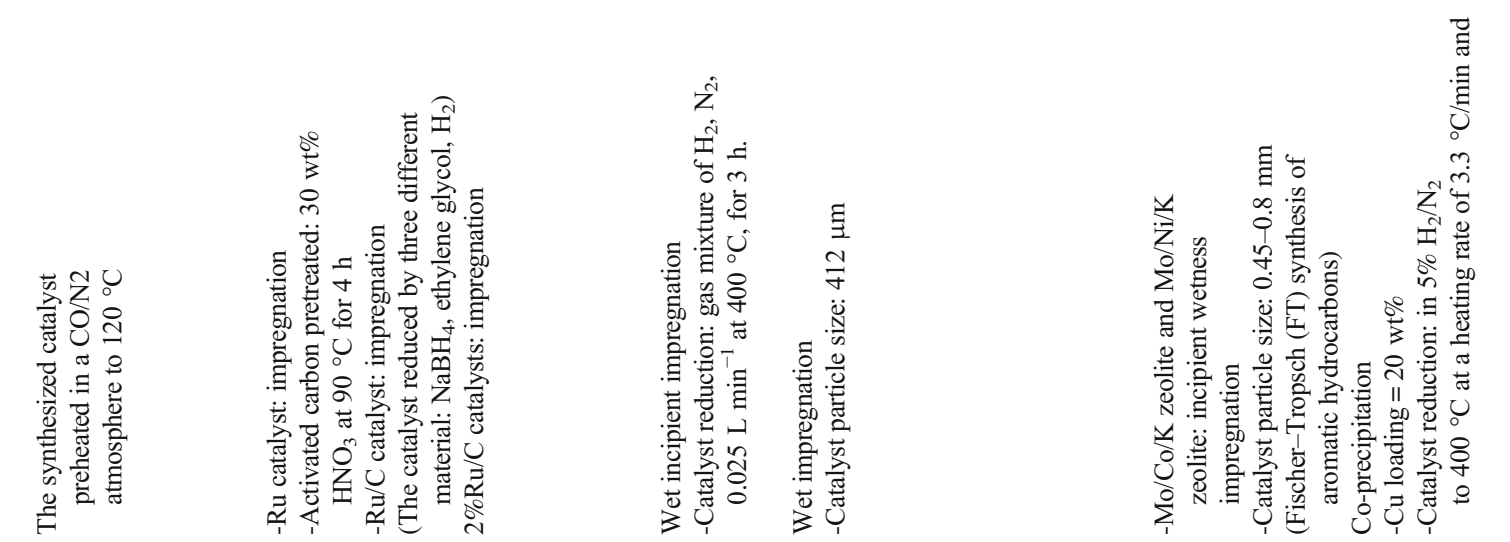

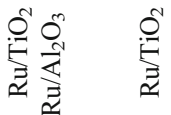

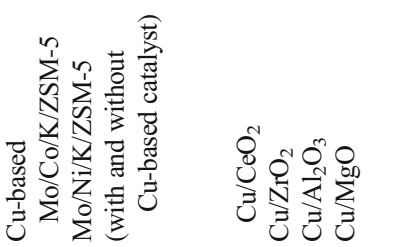




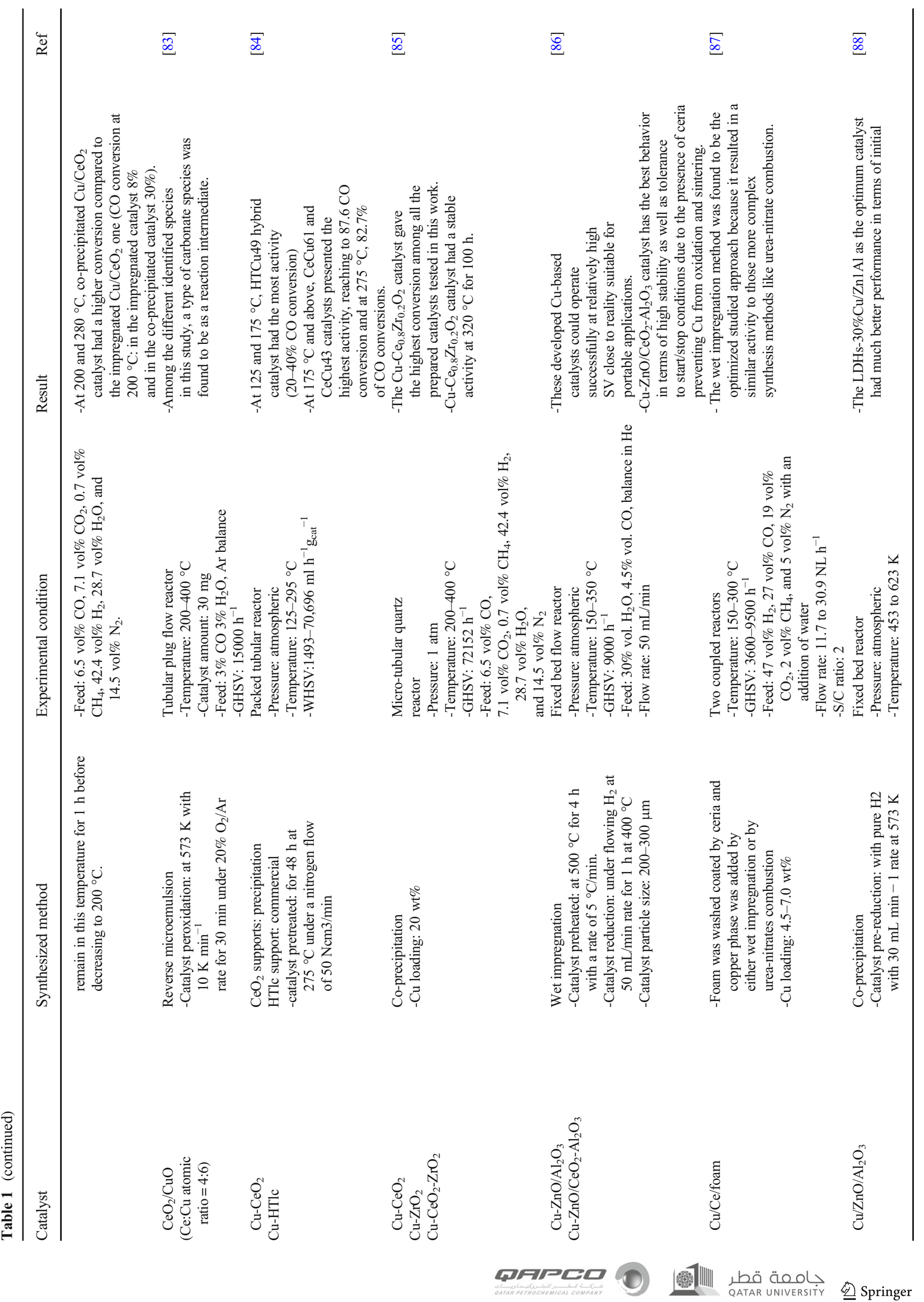




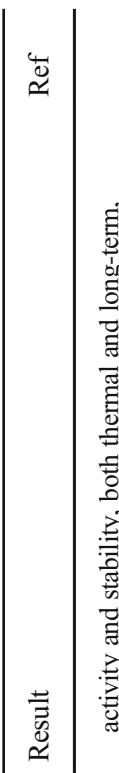

$\stackrel{2}{2}$

$\bar{\sigma} \quad \bar{\Omega}$

$\bar{\Xi} \quad \bar{\Xi}$

$\overline{\widetilde{S}}$

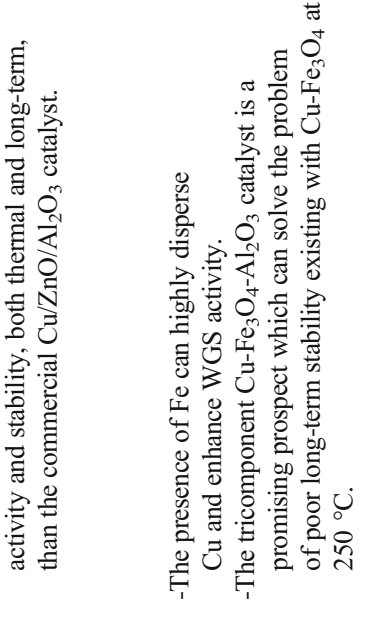

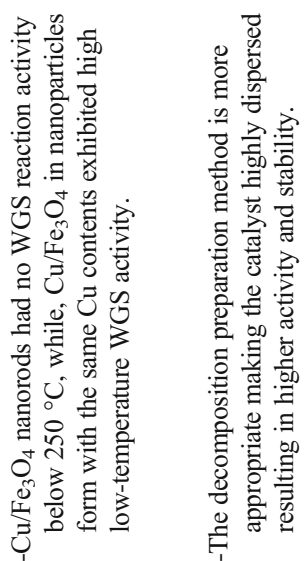

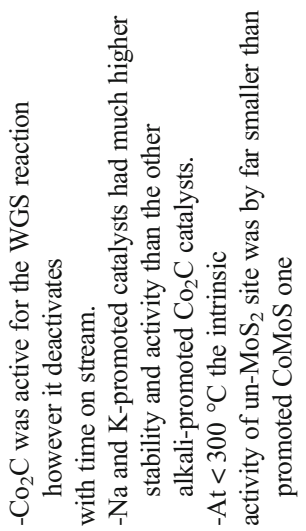

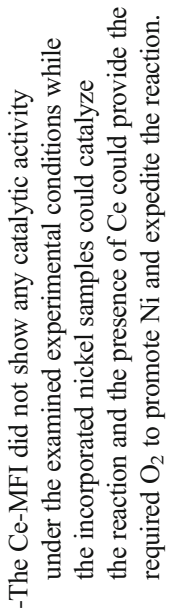

高

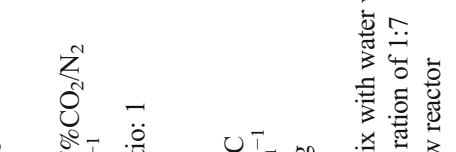

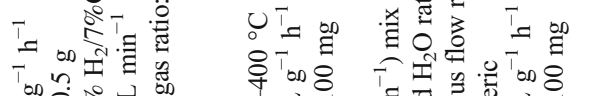

บ

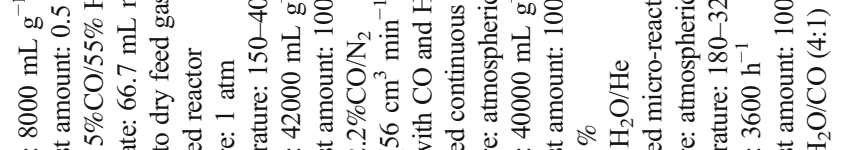

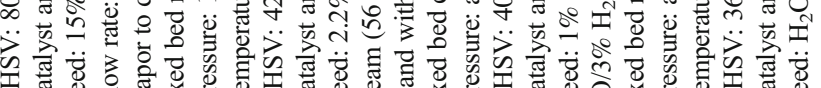

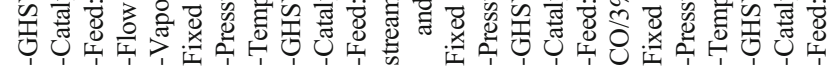

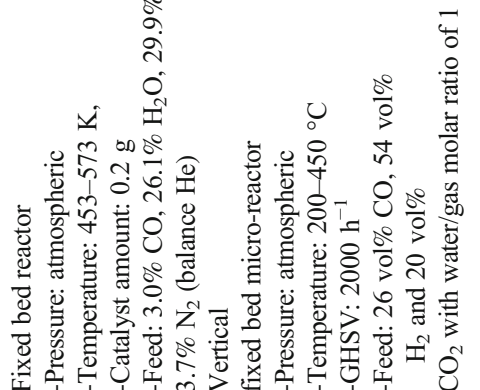

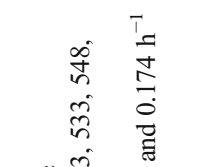

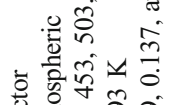

ซ

चै

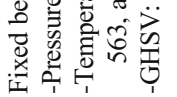

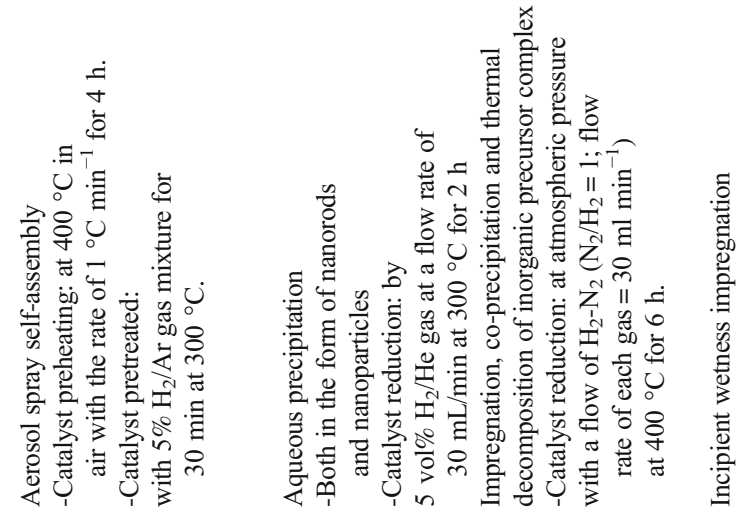

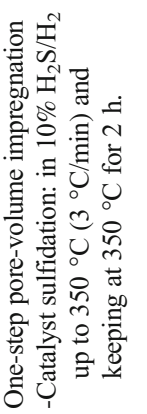

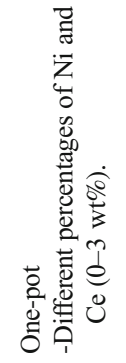

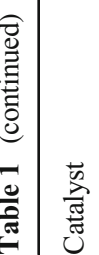

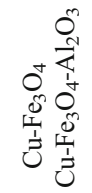

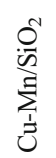

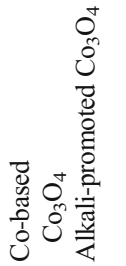

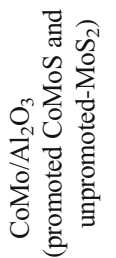

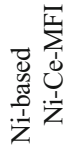




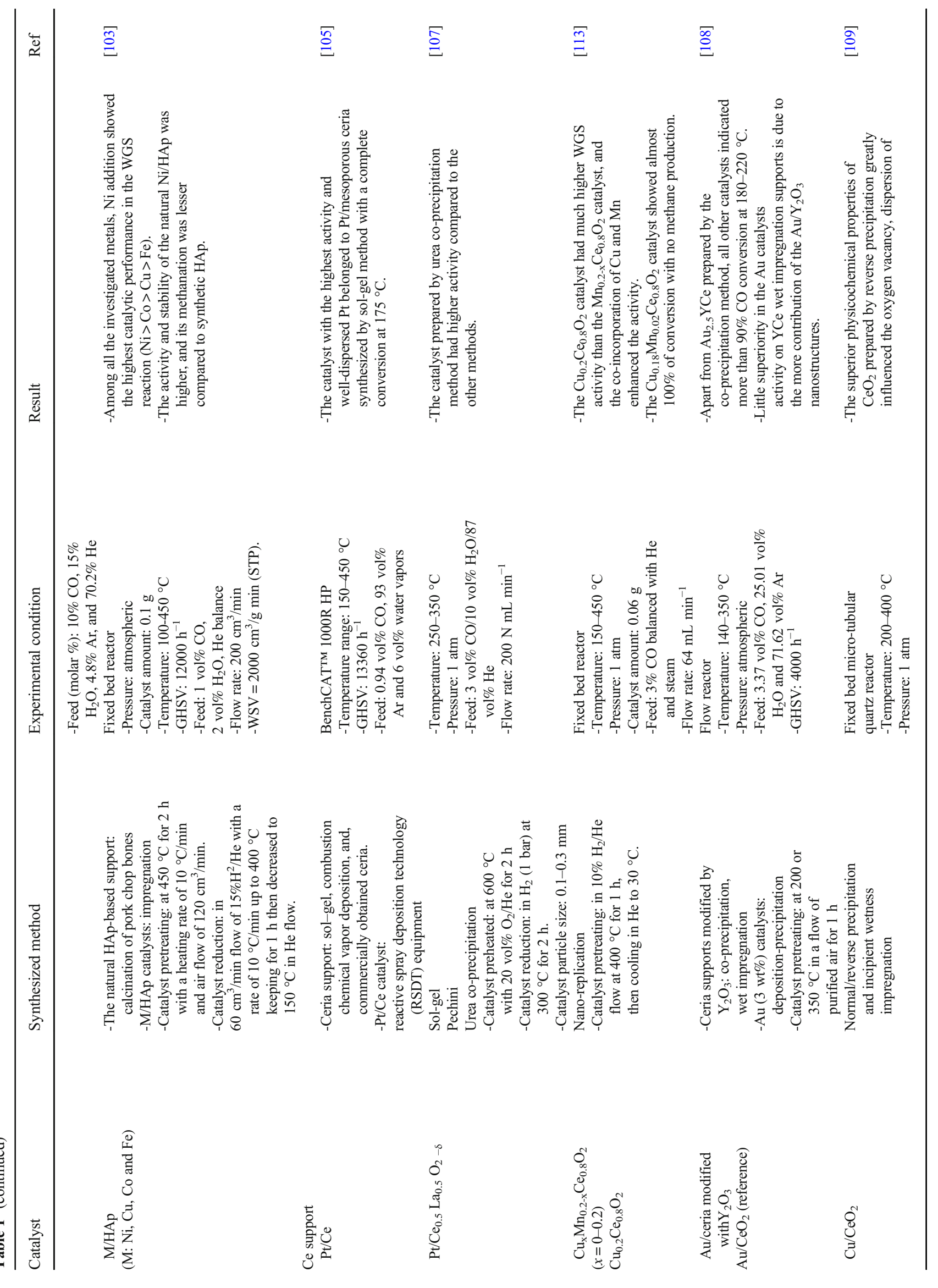




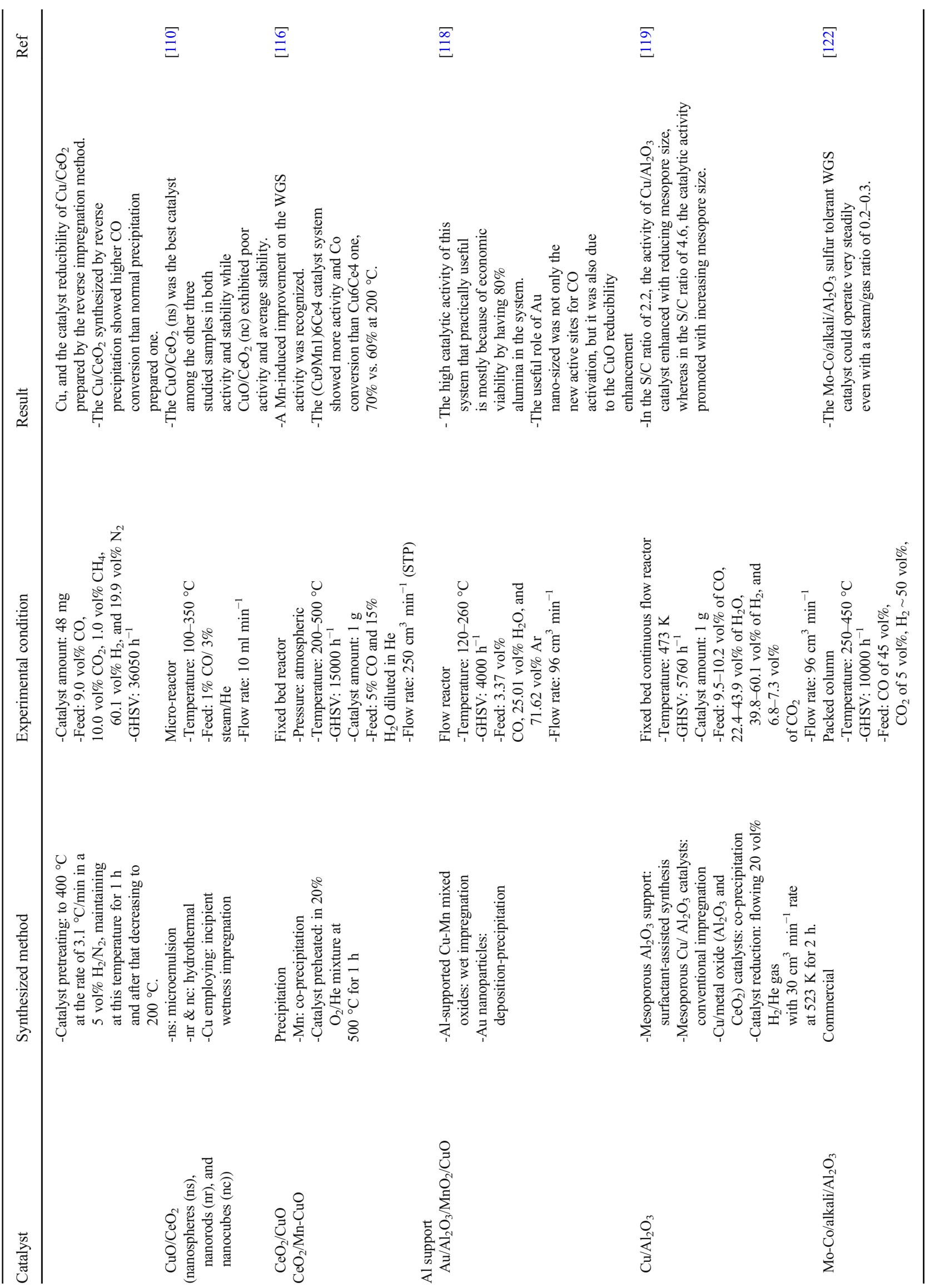




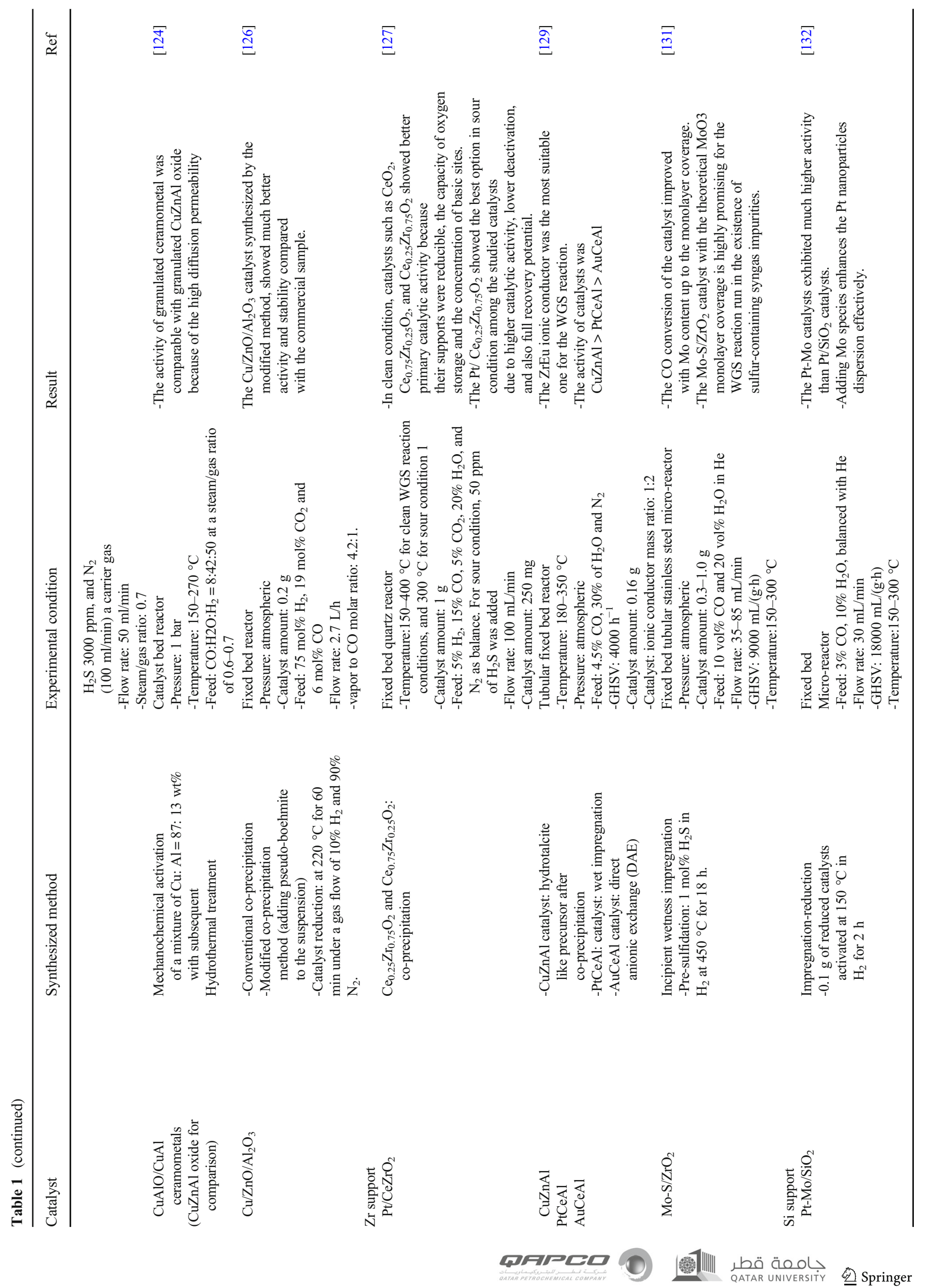



$\stackrel{\sqrt[m]{2}}{\stackrel{\varpi}{\Xi}}$

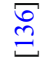
$\underset{\stackrel{2}{\Xi}}{\overparen{2}}$

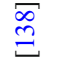
$\stackrel{?}{g}$

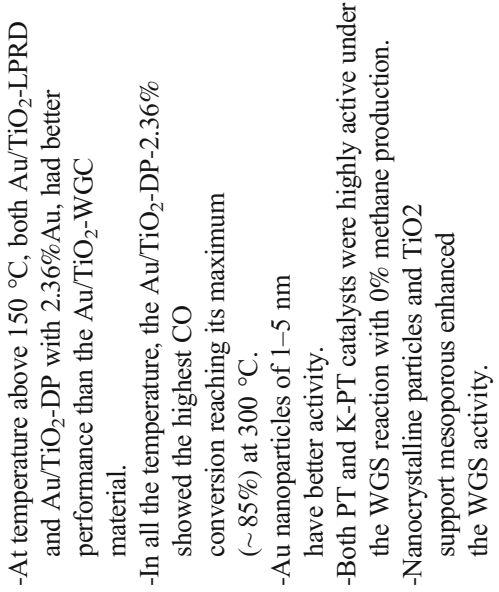

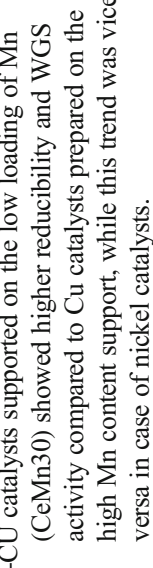

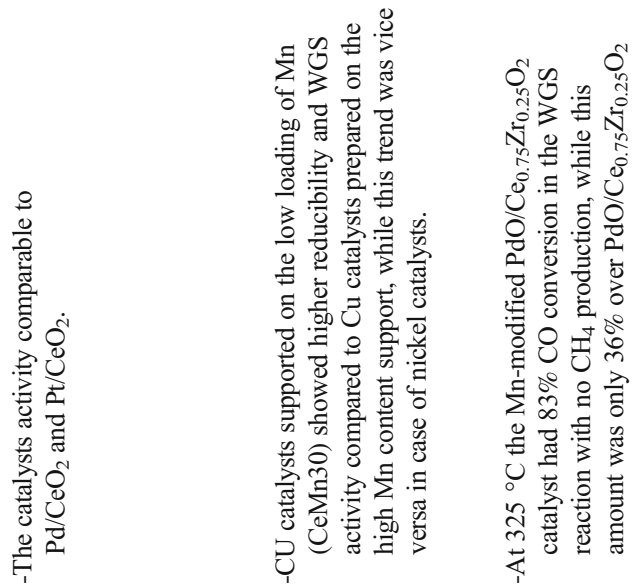

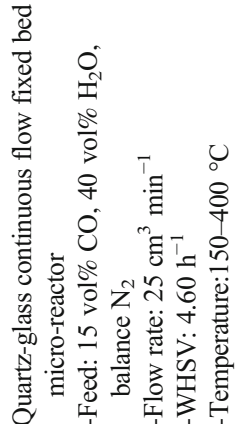

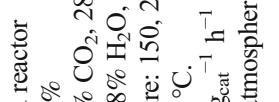

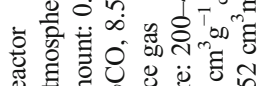

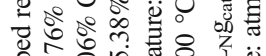

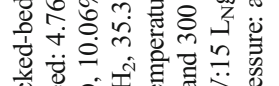

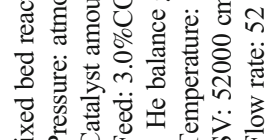

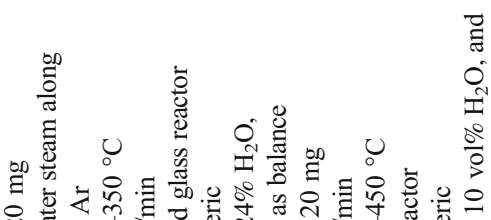

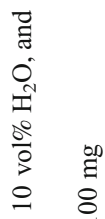

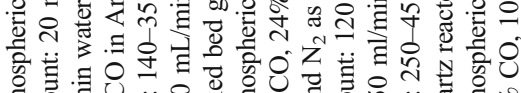

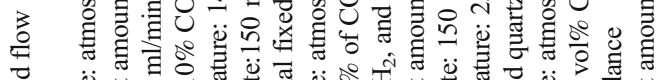

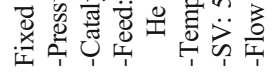

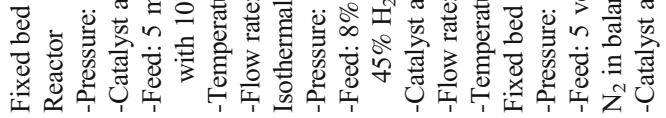<smiles>CC1CCCC1</smiles>

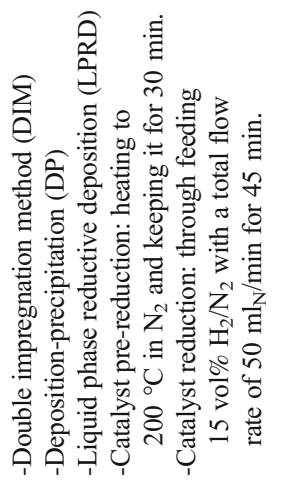
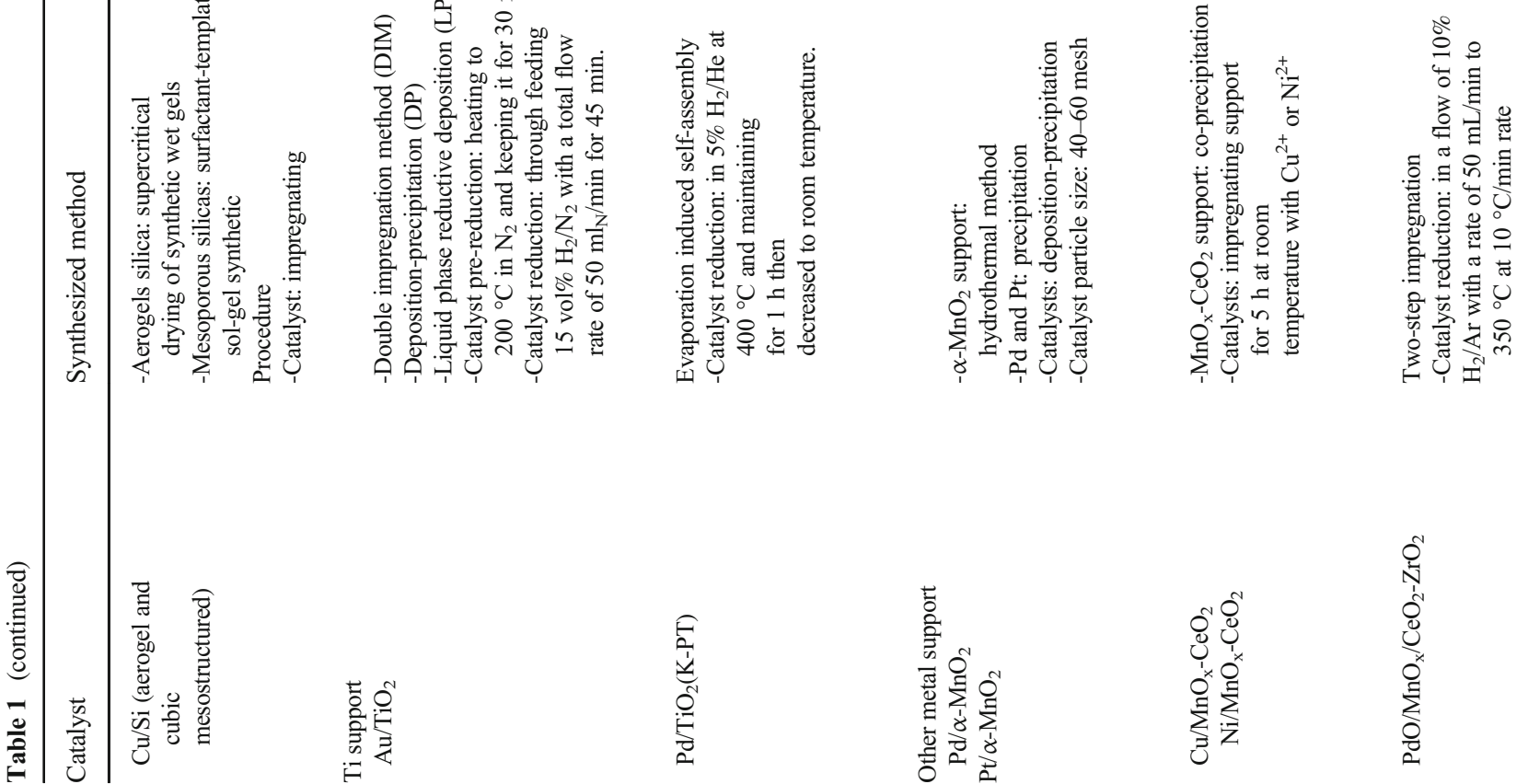

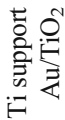

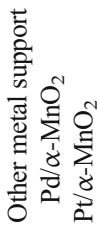

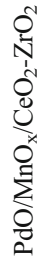




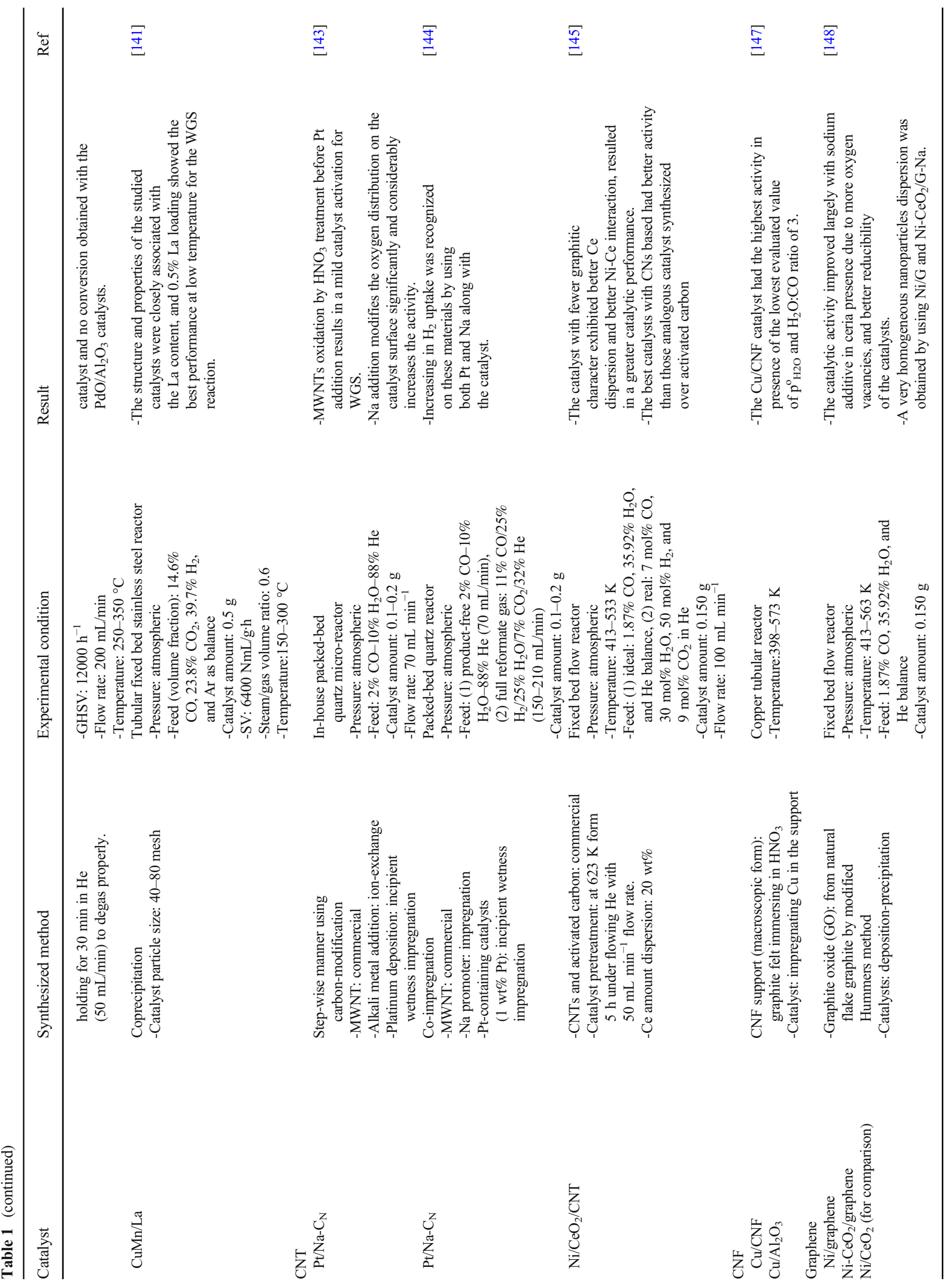


Table 2 Effect of different nanostructure and morphology of the catalysts towards WGSR

\begin{tabular}{llc}
\hline Nanostructure & Activity $\left(\mathrm{T}_{50}\right)$ & Ref \\
\hline Pt-SAC & $\begin{array}{l}285^{\circ} \mathrm{C} \\
\text { Poes not reach } 50 \% \text { WGSR } \\
\text { activity before } 300{ }^{\circ} \mathrm{C}\end{array}$ & {$[36]$} \\
& $200{ }^{\circ} \mathrm{C}$ & \\
Au-cluster & $375^{\circ} \mathrm{C}$ & {$[60]$} \\
Au-particle & High WGS activity & \\
Cu-nanoparticles & No WGSR activity below $25^{\circ} \mathrm{C}$ & \\
Cu-nanorods & 320 & {$[110]$} \\
Ceria-nanosphere & 337 & \\
Ceria-nanorod & Does not reach $50 \%$ WGSR \\
Ceria-nanocube & activity before $375{ }^{\circ} \mathrm{C}$ & \\
&
\end{tabular}

Application of ionic conductors in the support also provided encouraging results by enhancing the mobility of oxygen and vacant sites. The search for a low-cost catalyst with high activity, good hydrogen selectivity, and long-term stability will remain the focus from an economic point of view. Though many reports are available on the WGSR mechanism, the reaction pathway is still not very clear on many catalytic surfaces, particularly on catalysts with a low number of active sites. Efficient reactor design, along with catalyst development, will also play a critical role in this thermodynamically limited reaction. An optimal design will ensure quick removal of the products to push the reaction further by avoiding the reaching of thermodynamic equilibrium conditions.

Acknowledgements The author(s) would like to acknowledge support from Qatar University internal grant QUCG-CENG-19/20-7 for conducting this study. Authors would also like to acknowledge the open access funding provided by the Qatar National Library.

Funding Information Open Access funding provided by the Qatar National Library.

\section{Compliance with ethical standards}

Conflict of interest The authors declare that there are no conflicts of interest.

Abbreviations AC, activated carbon; ACP, aromatic conductive polymer; ASSA, aerosol spray self-assembly; CNF, carbon nano fibers; CNT, carbon nanotube; DFT, density functional theory; DI, double impregnation; EDX, energy dispersive X-ray; EG, ethylene glycol; GHSV, gas hourly space velocity; GO, graphene oxide; HAADF- STEM, high-angle annular dark-field scanning transmission electron microscopy; HAp, hydroxyapatite; HDP, homogeneous deposition precipitation; HRSTEM, high-resolution scanning transmission electron microscopy; HRTEM, high-resolution transmission electron microscopy; HTlc, hydrotalcite; IL, ionic liquid; I-R, impregnation-reduction; IWI, incipient wetness impregnation; LDHs, layered double hydroxides; LPRD, liquid phase reductive deposition; MFI, mordenite framework inverted; MWNTs, multiwalled carbon nanotubes; NC, nanocube; NR, nanorod; NS, nanospheres; OSC, oxygen storage capacity; $\mathrm{PD}$, precipitation deposition; RM, reverse microemulsion; SAC, single-atom catalyst; SCFD, supercritical fluid 
deposition; SEM, scanning electron microscopy; SFD, supercritical fluid deposition; SILP, supported ionic liquid phase; SV, space velocity; TEM, transmission electron microscopy; TOS, time on stream; TPD, temperature-programmed desorption; WGC, world gold council; WGS, watergas shift; WGSR, water-gas shift reaction; WHSV, weight hourly space velocity; XRD, X-ray diffraction; ZIF-8, zeolitic imidazolate framework8; ZSM-5, zeolite socony mobil-5

Open Access This article is licensed under a Creative Commons Attribution 4.0 International License, which permits use, sharing, adaptation, distribution and reproduction in any medium or format, as long as you give appropriate credit to the original author(s) and the source, provide a link to the Creative Commons licence, and indicate if changes were made. The images or other third party material in this article are included in the article's Creative Commons licence, unless indicated otherwise in a credit line to the material. If material is not included in the article's Creative Commons licence and your intended use is not permitted by statutory regulation or exceeds the permitted use, you will need to obtain permission directly from the copyright holder. To view a copy of this licence, visit http://creativecommons.org/licenses/by/4.0/.

\section{References}

1. D. Pal et al., Performance of water gas shift reaction catalysts: a review. Renew. Sust. Energ. Rev. 93, 549-565 (2018)

2. X. Chen, S. Shen, L. Guo, S.S. Mao, Semiconductor-based photocatalytic hydrogen generation. Chem. Rev. 110(11), 6503-6570 (2010)

3. C. Rhodes, G. Hutchings, A. Ward, Water-gas shift reaction: finding the mechanistic boundary. Catal. Today 23(1), 43-58 (1995)

4. M.D. Bhatt, J.S. Lee, Nanomaterials for photocatalytic hydrogen production: from theoretical perspectives. RSC Adv. 7(55), 34875-34885 (2017)

5. S. Kahng, H. Yoo, J.H. Kim, Recent advances in earth-abundant photocatalyst materials for solar $\mathrm{H} 2$ production. Adv. Powder Technol. 31(1), 11-28 (2020)

6. Y. Peng, P. Kan, Q. Zhang, Y. Zhou, Oxygen vacancy enhanced photoreduction $\mathrm{Cr}$ (VI) on few-layers $\mathrm{BiOBr}$ nanosheets. Catalysts 9(6), 558 (2019)

7. H. Li, J. Shang, Z. Ai, L. Zhang, Efficient visible light nitrogen fixation with $\mathrm{BiOBr}$ nanosheets of oxygen vacancies on the exposed $\{001\}$ facets. J. Am. Chem. Soc. 137(19), 6393-6399 (2015)

8. Liu, S., et al., Promoting hydrogen evolution reaction through oxygen vacancies and phase transformation engineering on layered double hydroxide nanosheets. Journal of Materials Chemistry A, 2020

9. L. Gradisher, B. Dutcher, M. Fan, Catalytic hydrogen production from fossil fuels via the water gas shift reaction. Appl. Energy 139, 335-349 (2015)

10. R.J. Byron Smith, M. Loganathan, M.S. Shantha, A review of the water gas shift reaction kinetics. Int. J. Chem. React. Eng., 8(1) (2010)

11. Amos, W.A., Biological water-gas shift conversion of carbon monoxide to hydrogen. Milestone Completion Report, National Renewable Energy Laboratory (NREL) MP-560-35592, 2004

12. M. Dolan, S. Hla, L. Morpeth, Design and operational considerations for a catalytic membrane reactor incorporating a vanadiumbased membrane. Sep. Purif. Technol. 147, 398-405 (2015)

13. S.-E. Park, J.-S. Chang, K.-W. Lee, Carbon Dioxide Utilization for Global Sustainability: Proceedings of the 7th International
Conference on Carbon Dioxide Utilization (Elsevier, Seoul, Korea, October 12-16, 2003, 2004)

14. C.Á. Galván et al., Reverse water-gas shift reaction at the $\mathrm{Cu} / \mathrm{ZnO}$ interface: influence of the $\mathrm{Cu} / \mathrm{Zn}$ ratio on structure-activity correlations. Appl. Catal. B Environ. 195, 104-111 (2016)

15. H. Chu, Q. Li, A. Meng, Y. Zhang, Investigation of hydrogen production from model bio-syngas with high $\mathrm{CO} 2$ content by water-gas shift reaction. Int. J. Hydrog. Energy 40(11), 4092$4100(2015)$

16. A. Alijani, A. Irankhah, Effect of nickel addition on ceriasupported platinum catalysts for medium-temperature shift reaction in fuel processors. Chem. Eng. Technol. 36(4), 552-558 (2013)

17. K.-J. Kim, Y.L. Lee, H.S. Na, S.Y. Ahn, J.O. Shim, B.H. Jeon, H.S. Roh, Efficient waste to energy conversion based on co-ceo2 catalyzed water-gas shift reaction. Catalysts 10(4), 420 (2020)

18. Brenna, G., New catalysts for the H2 production by water-gas shift reaction processes. 2011, alma

19. K. Sun, M. Kohyama, S. Tanaka, S. Takeda, Reaction mechanism of the low-temperature water-gas shift reaction on $\mathrm{Au} / \mathrm{TiO} 2$ catalysts. J. Phys. Chem. C 121(22), 12178-12187 (2017)

20. S.C. Ammal, A. Heyden, Water-gas shift activity of atomically dispersed cationic platinum versus metallic platinum clusters on titania supports. ACS Catal. 7(1), 301-309 (2017)

21. A.A. Gokhale, J.A. Dumesic, M. Mavrikakis, On the mechanism of low-temperature water gas shift reaction on copper. J. Am. Chem. Soc. 130(4), 1402-1414 (2008)

22. R. Bouarab, S. Bennici, C. Mirodatos, A. Auroux, Hydrogen production from the water-gas shift reaction on iron oxide catalysts. J. Catal. 2014, 1-6 (2014)

23. N. Schumacher, A. Boisen, S. Dahl, A.A. Gokhale, S. Kandoi, L.C. Grabow, J.A. Dumesic, M. Mavrikakis, I. Chorkendorff, Trends in low-temperature water-gas shift reactivity on transition metals. J. Catal. 229(2) 267-275 (2005)

24. S.C. Ammal, A. Heyden, Origin of the unique activity of Pt/TiO2 catalysts for the water-gas shift reaction. J. Catal. 306, 78-90 (2013)

25. D. Trimm, Minimisation of carbon monoxide in a hydrogen stream for fuel cell application. Appl. Catal. A Gen. 296(1), 1$11(2005)$

26. Z.I. Oensan, Catalytic processes for clean hydrogen production from hydrocarbons. Turk. J. Chem. 31(5), 531-550 (2007)

27. C. Ratnasamy, J.P. Wagner, Water gas shift catalysis. Catal. Rev. 51(3), 325-440 (2009)

28. Ç. Odabașı, M.E. Günay, R. Yıldırım, Knowledge extraction for water gas shift reaction over noble metal catalysts from publications in the literature between 2002 and 2012. Int. J. Hydrog. Energy 39(11), 5733-5746 (2014)

29. D. Andreeva, I. Ivanov, L. Ilieva, M.V. Abrashev, R. Zanella, J.W. Sobczak, W. Lisowski, M. Kantcheva, G. Avdeev, K. Petrov, Gold catalysts supported on ceria doped by rare earth metals for water gas shift reaction: influence of the preparation method. Appl. Catal. A Gen. 357(2), 159-169 (2009)

30. P. Panagiotopoulou, D.I. Kondarides, Effect of the nature of the support on the catalytic performance of noble metal catalysts for the water-gas shift reaction. Catal. Today 112(1-4), 49-52 (2006)

31. J. Vecchietti, A. Bonivardi, W. Xu, D. Stacchiola, J.J. Delgado, M. Calatayud, S.E. Collins, Understanding the role of oxygen vacancies in the water gas shift reaction on ceria-supported platinum catalysts. ACS Catal. 4(6), 2088-2096 (2014)

32. R. Tiwari, B. Sarkar, R. Tiwari, C. Pendem, T. Sasaki, S. Saran, R. $\mathrm{Bal}, \mathrm{Pt}$ nanoparticles with tuneable size supported on nanocrystalline ceria for the low temperature water-gas-shift (WGS) reaction. J. Mol. Catal. A Chem. 395, 117-123 (2014)

33. H. Zhao, S. Yao, M. Zhang, F. Huang, Q. Fan, S. Zhang, H. Liu, D. Ma, C. Gao, Ultra-small platinum nanoparticles encapsulated 
in Sub-50 nm hollow titania nanospheres for low-temperature water-gas shift reaction. ACS Appl. Mater. Interfaces 10(43), 36954-36960 (2018)

34. A.I. Osman, J.K. Abu-Dahrieh, N. Cherkasov, J. FernandezGarcia, D. Walker, R.I. Walton, D.W. Rooney, E. Rebrov, A highly active and synergistic $\mathrm{Pt} / \mathrm{Mo} 2 \mathrm{C} / \mathrm{A} 12 \mathrm{O} 3$ catalyst for watergas shift reaction. Mol. Catal. 455, 38-47 (2018)

35. Anil, C. and G. Madras, Catalytic behaviour of Mn2. 94M0. 06O4- $\delta(M=P t, R u$ and $P d)$ catalysts for low temperature water gas shift (WGS) and CO oxidation. International Journal of Hydrogen Energy, 2019

36. Y. Chen, J. Lin, L. Li, B. Qiao, J. Liu, Y. Su, X. Wang, Identifying size effects of $\mathrm{Pt}$ as single atoms and nanoparticles supported on $\mathrm{FeO} x$ for the water-gas shift reaction. ACS Catal. 8(2), 859-868 (2018)

37. T.-D. Nguyen-Phan, A.E. Baber, J.A. Rodriguez, S.D. Senanayake, Au and Pt nanoparticle supported catalysts tailored for $\mathrm{H} 2$ production: from models to powder catalysts. Appl. Catal. A Gen. 518, 18-47 (2016)

38. V. Palma et al., Catalytic activities of bimetallic catalysts for low temperature water gas shift reaction. Chem. Eng. Trans. 52, 481486 (2016)

39. J.W. Deal, P. le, C.B. Corey, K. More, C.W. West, Water-gas shift reaction on alumina-supported $\mathrm{Pt}-\mathrm{CeOx}$ catalysts prepared by supercritical fluid deposition. J. Supercrit. Fluids 119, 113-121 (2017)

40. A. Kaftan, M. Kusche, M. Laurin, P. Wasserscheid, J. Libuda, $\mathrm{KOH}$-promoted Pt/A12O3 catalysts for water gas shift and methanol steam reforming: an operando DRIFTS-MS study. Appl. Catal. B Environ. 201, 169-181 (2017)

41. M. González-Castaño, S. Ivanova, O.H. Laguna, L.M. Martínez T., M.A. Centeno, J.A. Odriozola, Structuring Pt/CeO2/A12O3 WGS catalyst: introduction of buffer layer. Appl. Catal. B Environ. 200, 420-427 (2017)

42. A.S. Duke, K. Xie, A.J. Brandt, T.D. Maddumapatabandi, S.C. Ammal, A. Heyden, J.R. Monnier, D.A. Chen, Understanding active sites in the water-gas shift reaction for Pt-re catalysts on titania. ACS Catal. 7(4), 2597-2606 (2017)

43. J.A. Rodriguez, P.J. Ramírez, R.A. Gutierrez, Highly active Pt/ $\mathrm{MoC}$ and $\mathrm{Pt} / \mathrm{TiC}$ catalysts for the low-temperature water-gas shift reaction: effects of the carbide metal/carbon ratio on the catalyst performance. Catal. Today 289, 47-52 (2017)

44. M.A. Rivero-Crespo, M. Mon, J. Ferrando-Soria, C.W. Lopes, M. Boronat, A. Leyva-Pérez, A. Corma, J.C. Hernández-Garrido, M. López-Haro, J.J. Calvino, E.V. Ramos-Fernandez, D. Armentano, E. Pardo, Confined Pt11+ water clusters in a MOF catalyze the low-temperature water-gas shift reaction with both $\mathrm{CO} 2$ oxygen atoms coming from water. Angew. Chem. Int. Ed. 57(52), 17094 17099 (2018)

45. R.V. Kumar, Y. Diamant, A. Gedanken, Sonochemical synthesis and characterization of nanometer-size transition metal oxides from metal acetates. Chem. Mater. 12(8), 2301-2305 (2000)

46. J.L. Fajín, M.N.D. Cordeiro, Probing the efficiency of platinum nanotubes for the $\mathrm{H} 2$ production by water gas shift reaction: a DFT study. Appl. Catal. B Environ. 263, 118301 (2020)

47. X. Sun, J. Lin, Y. Zhou, L. Li, Y. Su, X. Wang, T. Zhang, FeOx supported single-atom Pd bifunctional catalyst for water gas shift reaction. AICHE J. 63(9), 4022-4031 (2017)

48. E. Kono, S. Tamura, K. Yamamuro, S. Ogo, Y. Sekine, Pd/K/Cooxide catalyst for water gas shift. Appl. Catal. A Gen. 489, 247254 (2015)

49. M. Shekhar, J. Wang, W.S. Lee, M. Cem Akatay, E.A. Stach, W. Nicholas Delgass, F.H. Ribeiro, Counting Au catalytic sites for the water-gas shift reaction. J. Catal. 293, 94-102 (2012)
50. C.M. Yeung, S.C. Tsang, A study of co-precipitated bimetallic gold catalysts for water-gas shift reaction. Catal. Commun. 9(7), 1551-1557 (2008)

51. M.G. Castaño et al., Pt vs. Au in water-gas shift reaction. J. Catal. 314, 1-9 (2014)

52. M. González-Castaño, T. R. Reina, S. Ivanova, L.M. Martínez Tejada, M.A. Centeno, J.A. Odriozola, O2-assisted water gas shift reaction over structured $\mathrm{Au}$ and Pt catalysts. Appl. Catal. B Environ. 185, 337-343 (2016)

53. M. Soria et al., Effect of the preparation method on the catalytic activity and stability of $\mathrm{Au} / \mathrm{Fe} 2 \mathrm{O} 3$ catalysts in the low-temperature water-gas shift reaction. Appl. Catal. A Gen. 470, 45-55 (2014)

54. S. Yao, X. Zhang, W. Zhou, R. Gao, W. Xu, Y. Ye, L. Lin, X. Wen, P. Liu, B. Chen, E. Crumlin, J. Guo, Z. Zuo, W. Li, J. Xie, L. Lu, C.J. Kiely, L. Gu, C. Shi, J.A. Rodriguez, D. Ma, Atomiclayered $\mathrm{Au}$ clusters on $\alpha$-MoC as catalysts for the low-temperature water-gas shift reaction. Science 357(6349), 389-393 (2017)

55. T. Reina et al., The role of $\mathrm{Au}, \mathrm{Cu} \& \mathrm{CeO}_{2}$ and their interactions for an enhanced WGS performance. Appl. Catal. B Environ. 187, 98-107 (2016)

56. B.S. Çağlayan, A.E. Aksoylu, Water-gas shift activity of ceria supported Au-Re catalysts. Catal. Commun. 12(13), 1206-1211 (2011)

57. G.N. Özyönüm, R. Yildirim, Water gas shift activity of Au-Re catalyst over microstructured cordierite monolith wash-coated by ceria. Int. J. Hydrog. Energy 41(12), 5513-5521 (2016)

58. Q. Fu, H. Saltsburg, M. Flytzani-Stephanopoulos, Active nonmetallic $\mathrm{Au}$ and $\mathrm{Pt}$ species on ceria-based water-gas shift catalysts. Science 301(5635), 935-938 (2003)

59. J. Santos et al., Gold promoted $\mathrm{Cu} / \mathrm{ZnO} / \mathrm{Al} 2 \mathrm{O} 3$ catalysts prepared from hydrotalcite precursors: advanced materials for the WGS reaction. Appl. Catal. B Environ. 201, 310-317 (2017)

60. X.-P. Fu, L.W. Guo, W.W. Wang, C. Ma, C.J. Jia, K. Wu, R. Si, L.D. Sun, C.H. Yan, Direct identification of active surface species for the water-gas shift reaction on a gold-ceria catalyst. J. Am. Chem. Soc. 141(11), 4613-4623 (2019)

61. C.E. Stere, J.A. Anderson, S. Chansai, J.J. Delgado, A. Goguet, W.G. Graham, C. Hardacre, S.F.R. Taylor, X. Tu, Z. Wang, H. Yang, Non-thermal plasma activation of gold-based catalysts for low-temperature water-gas shift catalysis. Angew. Chem. Int. Ed. 56(20), 5579-5583 (2017)

62. J. Santos et al., Multicomponent au/cu-ZnO-Al2O3 catalysts: robust materials for clean hydrogen production. Appl. Catal. A Gen. 558, 91-98 (2018)

63. A. Goguet, R. Burch, Y. Chen, C. Hardacre, P. Hu, R.W. Joyner, F.C. Meunier, B.S. Mun, D. Thompsett, D. Tibiletti, Deactivation mechanism of a $\mathrm{Au} / \mathrm{CeZrO} 4$ catalyst during a low-temperature water gas shift reaction. J. Phys. Chem. C 111(45), 16927 16933 (2007)

64. D. Tibiletti, A. Amieiro-Fonseca, R. Burch, Y. Chen, J.M. Fisher, A. Goguet, C. Hardacre, P. Hu, D. Thompsett, DFT and in situ EXAFS investigation of gold/ceria- zirconia low-temperature water gas shift catalysts: identification of the nature of the active form of gold. J. Phys. Chem. B 109(47), 22553-22559 (2005)

65. J.H. Carter, P.M. Shah, E. Nowicka, S.J. Freakley, D.J. Morgan, S. Golunski, G.J. Hutchings, Enhanced activity and stability of gold/ceria-titania for the low-temperature water-gas shift reaction. Frontiers in chemistry 7 (2019)

66. H. Guan, J. Lin, B. Qiao, S. Miao, A.Q. Wang, X. Wang, T. Zhang, Enhanced performance of Rh1/TiO2 catalyst without methanation in water-gas shift reaction. AICHE J. 63(6), 20812088 (2017)

67. X.-F. Yang, A. Wang, B. Qiao, J. Li, J. Liu, T. Zhang, Single-atom catalysts: a new frontier in heterogeneous catalysis. Acc. Chem. Res. 46(8), 1740-1748 (2013) 
68. R. Mandapaka, G. Madras, Aluminium and rhodium co-doped ceria for water gas shift reaction and $\mathrm{CO}$ oxidation. Molecular Catalysis 451, 4-12 (2018)

69. B. Liu, T. Huang, Z. Zhang, Z. Wang, Y. Zhang, J. Li, The effect of the alkali additive on the highly active $\mathrm{Ru} / \mathrm{C}$ catalyst for water gas shift reaction. Catal. Sci. Technol. 4(5), 1286-1292 (2014)

70. P.C. Ford, The water gas shift reaction: homogeneous catalysis by ruthenium and other metal carbonyls. Acc. Chem. Res. 14(2), 3137 (1981)

71. T. Huang, B. Liu, Z. Zhang, Y. Zhang, J. Li, Preparation of confined Ru-iongel catalysts and their application for a low temperature water-gas shift reaction. RSC Adv. 4(54), 28529-28536 (2014)

72. Queiroz, G., C. Barbosa, and C. Abreu, Production of hydrogen by water-gas shift reaction on Ru/C catalyst. Brazilian Journal of Petroleum and Gas, 2018. 12(2)

73. Queiroz, G., C. Barbosa, and C. Abreu, Low-temperature watergas shift reaction with Ru/TiO2 and Ru/Al2O3 catalysts. Brazilian Journal of Petroleum and Gas, 2016. 10(3)

74. G.A. de Queiroz, C.M.B. de Menezes Barbosa, C. A. Pimentel, C.A.M. de Abreu, Performance of the water gas shift process with a ruthenium catalyst for hydrogen production in a membrane reactor. React. Kinet. Mech. Catal. 123(2), 679-687 (2018)

75. S. Werner, N. Szesni, A. Bittermann, M.J. Schneider, P. Härter, M. Haumann, P. Wasserscheid, Screening of supported ionic liquid phase (SILP) catalysts for the very low temperature water-gasshift reaction. Appl. Catal. A Gen. 377(1-2), 70-75 (2010)

76. S. Werner, N. Szesni, R.W. Fischer, M. Haumann, P. Wasserscheid, Homogeneous ruthenium-based water-gas shift catalysts via supported ionic liquid phase (SILP) technology at low temperature and ambient pressure. Phys. Chem. Chem. Phys. 11(46), 10817-10819 (2009)

77. R. Stepić, C.R. Wick, V. Strobel, D. Berger, N. VučemilovićAlagić, M. Haumann, P. Wasserscheid, A.S. Smith, D.M. Smith, Mechanism of the water-gas shift reaction catalyzed by efficient ruthenium-based catalysts: a computational and experimental study. Angew. Chem. Int. Ed. 58(3), 741-745 (2019)

78. M.Á. Centeno Gallego et al., Boosting the activity of a $\mathrm{Au} / \mathrm{CeO} 2 /$ $\mathrm{Al} 2 \mathrm{O} 3$ catalyst for the WGS reaction. Catal. Today 253, 149-154 (2015)

79. P. Liu, J.A. Rodriguez, Water-gas-shift reaction on metal nanoparticles and surfaces. J. Chem. Phys. 126(16), 164705 (2007)

80. M.A. Saqlain, A. Hussain, D.M. Siddiq, O. Leenaerts, A.A. Leitão, DFT study of synergistic catalysis of the water-gas-shift reaction on $\mathrm{Cu}-\mathrm{Au}$ bimetallic surfaces. ChemCatChem $\mathbf{8}(6)$, 1208-1217 (2016)

81. R. Wijayapala, F. Yu, C.U. Pittman Jr., T.E. Mlsna, K-promoted $\mathrm{Mo} / \mathrm{Co}$-and $\mathrm{Mo} / \mathrm{Ni}$-catalyzed Fischer-Tropsch synthesis of aromatic hydrocarbons with and without a $\mathrm{Cu}$ water gas shift catalyst. Appl. Catal. A Gen. 480, 93-99 (2014)

82. D.-W. Jeong, W.J. Jang, J.O. Shim, W.B. Han, H.S. Roh, U.H. Jung, W.L. Yoon, Low-temperature water-gas shift reaction over supported Cu catalysts. Renew. Energy 65, 102-107 (2014)

83. A.L. Cámara, S. Chansai, C. Hardacre, A. Martínez-Arias, The water-gas shift reaction over $\mathrm{CeO} / \mathrm{CuO}$ : operando SSITKADRIFTS-mass spectrometry study of low temperature mechanism. Int. J. Hydrog. Energy 39(8), 4095-4101 (2014)

84. M.N. Moreira, A.M. Ribeiro, A.F. Cunha, A.E. Rodrigues, M. Zabilskiy, P. Djinović, A. Pintar, Copper based materials for water-gas shift equilibrium displacement. Appl. Catal. B Environ. 189, 199-209 (2016)

85. D.-W. Jeong, H.S. Na, J.O. Shim, W.J. Jang, H.S. Roh, A crucial role for the $\mathrm{CeO} 2-\mathrm{ZrO} 2$ support for the low temperature water gas shift reaction over $\mathrm{Cu}-\mathrm{CeO} 2-\mathrm{ZrO} 2$ catalysts. Catal Sci. Technol. 5(7), 3706-3713 (2015)
86. C. Price, L. Pastor-Pérez, E. le Saché, A. Sepúlveda-Escribano, T.R. Reina, Highly active $\mathrm{Cu}-\mathrm{ZnO}$ catalysts for the WGS reaction at medium-high space velocities: effect of the support composition. Int. J. Hydrog. Energy 42(16), 10747-10751 (2017)

87. C. Lang, X. Sécordel, C. Courson, Copper-based water gas shift catalysts for hydrogen rich syngas production from biomass steam gasification. Energy Fuel 31(11), 12932-12941 (2017)

88. D. Li, S. Xu, Y. Cai, C. Chen, Y. Zhan, L. Jiang, Characterization and catalytic performance of $\mathrm{Cu} / \mathrm{ZnO} / \mathrm{Al} 2 \mathrm{O} 3$ water-gas shift catalysts derived from $\mathrm{Cu}-\mathrm{Zn}-\mathrm{Al}$ layered double hydroxides. Ind. Eng. Chem. Res. 56(12), 3175-3183 (2017)

89. Z. Zhang, S.S. Wang, R. Song, T. Cao, L. Luo, X. Chen, Y. Gao, J. Lu, W.X. Li, W. Huang, The most active $\mathrm{Cu}$ facet for lowtemperature water gas shift reaction. Nat. Commun. 8(1), 488 (2017)

90. Han Yan, X.-T.Q., Yue Yin, Yun-Fei Teng, Zhao Jin, Chun-Jiang Jia, Promoted $\mathrm{Cu}-\mathrm{Fe} 3 \mathrm{O} 4$ catalysts for low-temperature water gas shift reaction: optimization of $\mathrm{Cu}$ content. Applied Catalysis B: Environmental, 2018: p. 182-193

92. L. Zhao, Y. Qi, L. Song, S. Ning, S. Ouyang, H. Xu, J. Ye, Solardriven water-gas shift reaction over $\mathrm{CuOx} / \mathrm{Al} 2 \mathrm{O} 3$ with $1.1 \%$ of light-to-energy storage. Angew. Chem. Int. Ed. 58(23), 77087712 (2019)

93. L. Ma, H. Ma, D. Han, M. Qiu, Y. Guan, Y. Hu, Evolution of copper supported on $\mathrm{Fe} 3 \mathrm{O} 4$ nanorods for WGS reaction. Catalysts 8(10), 415 (2018)

94. J. Farzanfar, R. Rezvani, Inorganic complex precursor: preparation of $\mathrm{Cu}-\mathrm{Mn} / \mathrm{SiO} 2$ mixed oxide nanocatalyst for lowtemperature water-gas shift reaction. J. Sci. Islamic Repub Iran 29(4), 321-333 (2018)

95. H. Yin, J. Shang, J. Choi, A.C.K. Yip, Generation and extraction of hydrogen from low-temperature water-gas-shift reaction by a ZIF-8-based membrane reactor. Microporous Mesoporous Mater. 280, 347-356 (2019)

96. P. Kowalik, K. Antoniak-Jurak, R. Bicki, W. Próchniak, P. Wiercioch, K. Michalska, The alcohol-modified CuZnAl hydroxycarbonate synthesis as a convenient preparation route of high activity $\mathrm{Cu} / \mathrm{ZnO} / \mathrm{Al} 2 \mathrm{O} 3$ catalysts for WGS. Int. J. Hydrog. Energy 44(2), 913-922 (2019)

97. E. Jang, E. Kim, H. Kim, T. Lee, H.J. Yeom, Y.W. Kim, J. Choi, Formation of ZIF-8 membranes inside porous supports for improving both their $\mathrm{H} 2 / \mathrm{CO} 2$ separation performance and thermal/ mechanical stability. J. Membr. Sci. 540, 430-439 (2017)

98. H. Yin, H. Kim, J. Choi, A.C.K. Yip, Thermal stability of ZIF-8 under oxidative and inert environments: a practical perspective on using ZIF-8 as a catalyst support. Chem. Eng. J. 278, 293-300 (2015)

99. Chen, L., J. Zhang, and X. Liang, Reducing gas atmosphere (H2, $\mathrm{CO}$ ) assisted formation of $\mathrm{Fe}-\mathrm{Ce}-\mathrm{Ox}$ composite oxides with enhanced catalytic activity for water-gas shift reaction. Catal. Commun., 2019: p. 105849

100. T.R. Reina, S. Ivanova, V. Idakiev, J.J. Delgado, I. Ivanov, T. Tabakova, M.A. Centeno, J.A. Odriozola, Impact of Ce-Fe synergism on the catalytic behaviour of $\mathrm{Au} / \mathrm{CeO} 2-\mathrm{FeO}$ x/A12O3 for pure H2 production. Catal. Sci. Technol. 3(3), 779-787 (2013)

101. M.K. Gnanamani, G. Jacobs, W.D. Shafer, D.E. Sparks, S. Hopps, G.A. Thomas, B.H. Davis, Low temperature water-gas shift reaction over alkali metal promoted cobalt carbide catalysts. Top. Catal. 57(6-9), 612-618 (2014)

102. J. Chen, J. Zhang, J. Mi, E.D. Garcia, Y. Cao, L. Jiang, L. Oliviero, F. Maugé, Hydrogen production by water-gas shift reaction over Co-promoted MoS2/Al2O3 catalyst: the intrinsic activities of Co-promoted and unprompted sites. Int. J. Hydrog. Energy 43(15), 7405-7410 (2018) 
103. S. Alamolhoda, G. Vitale, A. Hassan, N.N. Nassar, P.P. Almao, Synergetic effects of cerium and nickel in Ce-Ni-MFI catalysts on low-temperature water-gas shift reaction. Fuel 237, 361-372 (2019)

104. U. Iriarte-Velasco, J.L. Ayastuy, Z. Boukha, R. Bravo, M.Á. Gutierrez-Ortiz, Transition metals supported on bone-derived hydroxyapatite as potential catalysts for the water-gas shift reaction. Renew. Energy 115, 641-648 (2018)

105. A. Luengnaruemitchai, S. Osuwan, E. Gulari, Comparative studies of low-temperature water-gas shift reaction over $\mathrm{Pt} / \mathrm{CeO} 2, \mathrm{Au} /$ $\mathrm{CeO} 2$, and $\mathrm{Au} / \mathrm{Fe} 2 \mathrm{O} 3$ catalysts. Catal. Commun. 4(5), 215-221 (2003)

106. R. Jain, A.S. Poyraz, D.P. Gamliel, J. Valla, S.L. Suib, R. Maric, Comparative study for low temperature water-gas shift reaction on $\mathrm{Pt} /$ ceria catalysts: role of different ceria supports. Appl. Catal. A Gen. 507, 1-13 (2015)

107. C.K. Byun, H.B. Im, J. Park, J. Baek, J. Jeong, W.R. Yoon, K.B. $\mathrm{Yi}$, Enhanced catalytic activity of $\mathrm{Cu} / \mathrm{Zn}$ catalyst by $\mathrm{Ce}$ addition for low temperature water gas shift reaction. Clean Technology 21(3), 200-206 (2015)

108. K.C. Petallidou, S. Boghosian, A.M. Efstathiou, Low-temperature water-gas shift on Pt/Ce0. 5La0. 5O2- $\delta$ : effect of support synthesis method. Catal. Today 242, 153-167 (2015)

109. T. Tabakova, L. Ilieva, I. Ivanov, M. Manzoli, R. Zanella, P. Petrova, Z. Kaszkur, Structure-activity relationship in water-gas shift reaction over gold catalysts supported on Y-doped ceria. J. Rare Earths 37(4), 383-392 (2019)

110. H.-S. Na, J.O. Shim, S.Y. Ahn, W.J. Jang, K.W. Jeon, H.M. Kim, Y.L. Lee, K.J. Kim, H.S. Roh, Effect of precipitation sequence on physicochemical properties of $\mathrm{CeO} 2$ support for hydrogen production from low-temperature water-gas shift reaction. Int. J. Hydrog. Energy 43(37), 17718-17725 (2018)

111. S. Yao et al., Morphological effects of the nanostructured ceria support on the activity and stability of $\mathrm{CuO} / \mathrm{CeO} 2$ catalysts for the water-gas shift reaction. Phys. Chem. Chem. Phys. 16(32), 17183-17195 (2014)

112. C. Schilling, C. Hess, Elucidating the role of support oxygen in the water-gas shift reaction over ceria-supported gold catalysts using operando spectroscopy. ACS Catal. 9(2), 1159-1171 (2018)

113. D. Gu et al., Ordered mesoporous cu-Ce-O catalysts for $\mathrm{CO}$ preferential oxidation in H2-rich gases: influence of copper content and pretreatment conditions. Appl. Catal. B Environ. 152, 11-18 (2014)

114. C. Li, Z. Li, H.Y. Oh, G.H. Hong, J.S. Park, J.M. Kim, Ordered mesoporous $\mathrm{Cu}-\mathrm{Mn}$-Ce ternary metal oxide catalysts for low temperature water-gas shift reaction. Catal. Today 307, 237-242 (2018)

115. X. Huang, M.J. Beck, Determining the oxidation state of small, hydroxylated metal-oxide nanoparticles with infrared absorption spectroscopy. Chem. Mater. 27(8), 2965-2972 (2015)

116. X. Huang, M.J. Beck, Metal-free low-temperature water-gas shift catalysis over small, hydroxylated ceria nanoparticles. ACS Catal. 5(11), 6362-6369 (2015)

117. A.L. Cámara et al., Novel manganese-promoted inverse $\mathrm{CeO} 2 /$ $\mathrm{CuO}$ catalyst: in situ characterization and activity for the watergas shift reaction. Catal. Today 339, 24-31 (2020)

118. Cámara, A.L., V.C. Corberán, and A. Martínez-Arias, Inverse $\mathrm{CeO} / \mathrm{CuO}$ WGS catalysts: influence of the presence of oxygen in the reactant mixture. Catal. Today, 2019

119. T. Tabakova, I. Ivanov, Y. Karakirova, D. Karashanova, A. Venezia, P. Petrova, G. Avdeev, E. Kolentsova, K. Ivanov, Promotional effect of gold on the WGS activity of aluminasupported copper-manganese mixed oxides. Catalysts 8(11), 563 (2018)

120. K. Sagata, Y. Kaneda, H. Yamaura, S. Kobayashi, H. Yahiro, Influence of coexisting $\mathrm{Al} 2 \mathrm{O} 3$ on the activity of copper catalyst for water-gas-shift reaction. Int. J. Hydrog. Energy 39(35), 20639-20645 (2014)

121. D.S. Newsome, The water-gas shift reaction. Catal. Rev. Sci. Eng. 21(2), 275-318 (1980)

122. D. Nikolova et al., The state of $(\mathrm{K})(\mathrm{Ni}) \mathrm{Mo} / \gamma-\mathrm{Al} 2 \mathrm{O} 3$ catalysts after water-gas shift reaction in the presence of sulfur in the feed: XPS and EPR study. Appl. Catal. A Gen. 297(2), 135-144 (2006)

123. B. Liu et al., Recent advances in industrial sulfur tolerant water gas shift catalysts for syngas hydrogen enrichment: application of lean (low) steam/gas ratio. Catalysts 9(9), 772 (2019)

124. S.F. Tikhov, V.A. Sadykov, K.R. Valeev, A.N. Salanov, S.V. Cherepanova, Y.N. Bespalko, V.E. Ramanenkau, Y.Y. Piatsiushyk, S.V. Dimov, Preparation of porous ceramometal composites through the stages of mechanical activation and hydrothermal partial oxidation of Me-Al powders. Catal. Today 246, 232-238 (2015)

125. S. Tikhov, T. Minyukova, K. Valeev, S. Cherepanova, A. Salanov, V. Kaichev, A. Saraev, A. Andreev, O. Lapina, V. Sadykov, Design of micro-shell $\mathrm{Cu}-\mathrm{Al}$ porous ceramometals as catalysts for the water-gas shift reaction. RSC Adv. 7(67), 42443-42454 (2017)

126. S. Tikhov et al., Particularities of low-temperature WGSR over ceramometal and oxide catalysts: effect of catalyst particle size. Chem. Eng. J. 374, 405-411 (2019)

127. L. Xu, D. Peng, W. Liu, Y. Feng, Y. Hou, X. Li, C. Huang, A modified co-precipitation method to prepare $\mathrm{Cu} / \mathrm{ZnO} / \mathrm{Al} 2 \mathrm{O} 3$ catalyst and its application in low temperature water-gas shift (LT-WGS) reaction. J Wuhan Univ Technol.-Mater. Sci. Ed. 33(4), 876-883 (2018)

128. L.P. Silva et al., Sour water-gas shift reaction over $\mathrm{Pt} / \mathrm{CeZrO} 2$ catalysts. J. Catal. 341, 1-12 (2016)

129. Wang, X., et al., In situ time-resolved characterization of Au-Ce $O 2$ and $A u O x-C e O 2$ catalysts during the water-gas shift reaction: presence of $A u$ and $O$ vacancies in the active phase. 2005, American Institute of Physics

130. N. García-Moncada, M. González-Castaño, S. Ivanova, M.Á. Centeno, F. Romero-Sarria, J.A. Odriozola, New concept for old reaction: novel WGS catalyst design. Appl. Catal. B Environ. 238, $1-5(2018)$

131. M. González-Castaño, S. Ivanova, T. Ioannides, M.A. Centeno, J.A. Odriozola, Deep insight into $\mathrm{Zr} / \mathrm{Fe}$ combination for successful $\mathrm{Pt} / \mathrm{CeO} 2 / \mathrm{Al} 2 \mathrm{O} 3$ WGS catalyst doping. Catal. Sci. Technol. 7(7), 1556-1564 (2017)

132. Yun, S. and V. Guliants, Surface coverage effects on water gas shift activity of $\mathrm{ZrO} 2$ supported Mo sulfide catalysts. Catal. Commun., 2019: p. 105810

133. X. Xu, Q. Fu, X. Bao, MoOx-promoted Pt catalysts for the water gas shift reaction at low temperatures. Chin. J. Catal. 36(5), 750 756 (2015)

134. C. Marras, D. Loche, D. Carta, M.F. Casula, M. Schirru, M.G. Cutrufello, A. Corrias, Copper-based catalysts supported on highly porous silica for the water gas shift reaction. ChemPlusChem 81(4), 421-432 (2016)

135. S. Carrettin, M.C. Blanco, A. Corma, A.S.K. Hashmi, Heterogeneous gold-catalysed synthesis of phenols. Adv. Synth. Catal. 348(10-11), 1283-1288 (2006)

136. P. Pérez et al., Application of Au/TiO2 catalysts in the lowtemperature water-gas shift reaction. Int. J. Hydrog. Energy 41(8), 4670-4681 (2016)

137. C. Li, K. Sivaranjani, J.M. Kim, Synthesis of alkali promoted mesoporous, nanocrystalline $\mathrm{Pd} / \mathrm{TiO} 2$ catalyst for water gas shift reaction. Catal. Today 265, 45-51 (2016)

138. J.-J. Shan et al., Water-gas shift on $\mathrm{Pd} / \alpha-\mathrm{MnO} 2$ and $\mathrm{Pt} / \alpha-\mathrm{MnO} 2$. Catal. Lett. 145(8), 1571-1580 (2015)

139. E. Poggio-Fraccari, J. Sambeth, G. Baronetti, F. Mariño, Cu/ $\mathrm{MnOx}-\mathrm{CeO} 2$ and $\mathrm{Ni} / \mathrm{MnOx}-\mathrm{CeO} 2$ catalysts for the water-gas 
shift reaction: metal-support interaction. Int. J. Hydrog. Energy 39(16), 8675-8681 (2014)

140. X. Wang, R.J. Gorte, J. Wagner, Deactivation mechanisms for Pd/ ceria during the water-gas-shift reaction. J. Catal. 212(2), 225$230(2002)$

141. Y. Xiao, X. Wu, S. Liu, J. Wan, M. Li, D. Weng, C. Tong, Modification of $\mathrm{PdO} / \mathrm{CeO} 2-\mathrm{ZrO} 2$ catalyst by $\mathrm{MnO} \times$ for water-gas shift reaction: redox property and valence state of $\mathrm{Pd}$. J. Mater. Sci. 51(11), 5377-5387 (2016)

142. H. Runxia et al., $\mathrm{Cu}-\mathrm{Mn}$ catalysts modified by rare earth lantnaum for low temperature water-gas shift reaction. J. Rare Earths 34(10), 994-1003 (2016)

143. Serp, P. and B. Machado, Nanostructured carbon materials for catalysis. 2015: Royal Society of Chemistry

144. B. Zugic, D.C. Bell, M. Flytzani-Stephanopoulos, Activation of carbon-supported platinum catalysts by sodium for the lowtemperature water-gas shift reaction. Appl. Catal. B Environ. 144, 243-251 (2014)

145. B. Zugic, S. Zhang, D.C. Bell, F.(.F.). Tao, M. FlytzaniStephanopoulos, Probing the low-temperature water-gas shift activity of alkali-promoted platinum catalysts stabilized on carbon supports. J. Am. Chem. Soc. 136(8), 3238-3245 (2014)

146. A.B. Dongil et al., Carbon nanotube-supported $\mathrm{Ni}-\mathrm{CeO} 2$ catalysts. Effect of the support on the catalytic performance in the low-temperature WGS reaction. Carbon 101, 296-304 (2016)

147. F. Huber, Z. Yu, J.C. Walmsley, D. Chen, H.J. Venvik, A. Holmen, Nanocrystalline $\mathrm{Cu}-\mathrm{Ce}-\mathrm{Zr}$ mixed oxide catalysts for water-gas shift: carbon nanofibers as dispersing agent for the mixed oxide particles. Appl. Catal. B Environ. 71(1-2), 7-15 (2007)

148. N. Oliveira, G.P. Valençaa, R. Vieirab, Water gas shift reaction on copper catalysts supported on alumina and carbon nanofibers. Chem. Eng. 43, 931-936 (2015)

149. A.B. Dongil, L. Pastor-Pérez, A. Sepúlveda-Escribano, P. Reyes, Promoter effect of sodium in graphene-supported $\mathrm{Ni}$ and $\mathrm{Ni}-$ $\mathrm{CeO} 2$ catalyst for the low-temperature WGS reaction. Appl. Catal. A Gen. 505, 98-104 (2015)

150. A. Dongil et al., Chemoselective hydrogenation of cinnamaldehyde: a comparison of the immobilization of $\mathrm{Ru}-$ phosphine complex on graphite oxide and on graphitic surfaces. J. Catal. 282(2), 299-309 (2011)

151. L. Pastor-Pérez, R. Buitrago-Sierra, A. Sepúlveda-Escribano, CeO2-promoted Ni/activated carbon catalysts for the water-gas shift (WGS) reaction. Int. J. Hydrog. Energy 39(31), 1758917599 (2014)

152. L. Pastor-Pérez, T. Reina, S. Ivanova, M. Centeno, J. Odriozola, A. Sepúlveda-Escribano, Ni-CeO2/C catalysts with enhanced OSC for the WGS reaction. Catalysts 5(1), 298-309 (2015)

153. S. Collins, G. Finos, R. Alcántara, E. del Rio, S. Bernal, A. Bonivardi, Effect of gallia doping on the acid-base and redox properties of ceria. Appl. Catal. A Gen. 388(1-2), 202-210 (2010)

154. T. Chapman, The hydrogen economy blasts off. Physics world 15(7), 29 (2002)

155. Pistikopoulos, E.N., M.C. Georgiadis, and A. Kokossis, 21st European Symposium on Computer Aided Process Engineering. 2011: Elsevier 